\title{
Agglomeration: A Long-Run Panel Data Approach
}

\author{
W. Walker Hanlon* \\ UCLA and NBER
}

\author{
Antonio Miscio ${ }^{\dagger}$ \\ Columbia University
}

December 9, 2016

\begin{abstract}
This paper studies the sources of agglomeration economies in cities. We begin by incorporating within and cross-industry spillovers into a dynamic spatial equilibrium model in order to obtain a panel data estimating equation. This gives us a framework for measuring a rich set of agglomeration forces while controlling for a variety of potentially confounding effects. We apply this estimation strategy to detailed new data describing the industry composition of 31 English cities from 1851-1911. Our results show that industries grew more rapidly in cities where they had more local suppliers or other occupationallysimilar industries. We find no evidence of dynamic within-industry effects, i.e., industries generally did not grow more rapidly in cities in which they were already large. Once we control for these agglomeration forces, we find evidence of strong dynamic congestion forces related to city size. We also show how to construct estimates of the combined strength of the many agglomeration forces in our model. These results suggest a lower bound estimate of the strength of agglomeration forces equivalent to a city-size divergence rate of $1.6-2.3 \%$ per decade. JEL Codes: R1, N93, O3 Keywords: Agglomeration, City Growth
\end{abstract}

${ }^{*}$ Corresponding author. Contact information: whanlon@econ.ucla.edu, 8283 Bunche Hall, UCLA, Los Angeles, CA 90095.

${ }^{\dagger}$ Contact information: am3559@columbia.edu.

C 2017. This manuscript version is made available under the Elsevier user license http://www.elsevier.com/open-access/userlicense/1.0/ 


\section{Introduction}

What are the key factors driving city growth over the long term? One of the leading answers to this question, dating back to Marshall (1890), is that firms may benefit from proximity to one another through agglomeration economies. While compelling, this explanation raises further questions about the nature of these agglomeration economies. Do firms primarily benefit from proximity to other firms in the same industry, or, as suggested by Jacobs (1969), is proximity to other related industries more important? How do these forces vary across industries? What role does city size play in industry growth? How can we separate all of these features from the fixed locational advantages of cities? These are important questions for our understanding of cities. Their answers also have implications for the design of place-based policies, which can top $\$ 80$ billion per year in the U.S. and are also widely used in other countries. $^{1}$

Not surprisingly, there is a large body of existing research exploring the nature of agglomeration economies. This study builds on two important strands of this literature. $^{2}$ One approach uses long-differences in the growth of city-industries over time and relates them to rough measures of initial conditions in a city, such as an industry's share of city employment or the Herfindahl index over major city-industries (Glaeser et al. (1992), Henderson et al. (1995)). The main concern with this line of research is that it ignores much of the richness and heterogeneity that are likely to characterize agglomeration economies. A more recent approach allows for a richer set of inter-industry relationships using connection matrices based on input-output flows, labor force similarity, or technology spillovers. These connections are then compared to a cross-section of industry locations (Rosenthal \& Strange (2001), Ellison et al. (2010), Faggio et al. (Forthcoming)). ${ }^{3}$ A limitation of this type of static exercise

\footnotetext{
${ }^{1}$ The New York Times has constructed a database of incentives awarded by cities, counties and states to attract companies to locate in their area. The database is available at http://www.nytimes.com/interactive/2012/12/01/us/government-incentives.html.

${ }^{2}$ There are several other strands of the agglomeration literature which are less directly related to this paper. Other alternative approaches use individual-level wage data (Glaeser \& Mare (2001), Combes et al. (2008), Combes et al. (2011)) or firm-level data (Dumais et al. (2002), Rosenthal \& Strange (2003), Combes et al. (2012)) to investigate the effects of city size. See Rosenthal \& Strange (2004) and Combes \& Gobillon (2015) for reviews of this literature.

${ }^{3}$ These studies are part of a broader literature looking at the impact of inter-industry connections, particularly through input-output linkages, that includes work by Amiti \& Cameron (2007) and Lopez \& Sudekum (2009).
} 
is that it is more difficult to control for locational fundamentals in cross-sectional regressions.

Our approach builds on these previous studies, but also seeks to address some of the remaining issues facing the literature. Specifically, this study contributes to the existing literature in five ways. First, while this is primarily an empirical paper, we begin by introducing a new dynamic spatial equilibrium model of cityindustry growth. This model incorporates a rich set of within- and cross-industry spillover effects, which allows us to ground our study of these agglomeration forces in a theoretically-consistent framework. Recent work has highlighted the need for theoretical foundations in this literature. ${ }^{4}$

Second, motivated by the theory, we introduce a panel-data econometric approach for estimating the magnitude of agglomeration forces. ${ }^{5}$ The key feature of our approach is that we are able to estimate the importance of dynamic agglomeration forces related to industry scale, cross-industry connections, and city-size in a unified framework, while dealing with fixed locational fundamentals and time-varying industry-specific shocks. Previous research has examined these elements separately, but we are not aware of existing work that studies all of these effects in a unified way. In addition, the use of panel data offers some well-known advantages relative to the cross-sectional or long-difference methods used in most existing work. However, applying this approach to study agglomeration economies requires overcoming challenges related to identification and correlated errors. Our study makes progress in this direction, allowing us to address some of the identification concerns present in previous work. The approach that we develop can potentially be applied in a wide range of settings in which consistent panels of city-industry employment data can be constructed.

Third, to implement our approach, we construct a rich dataset describing the evolution of city-industry employment over six decades. The availability of detailed long-run city-industry data has been a major impediment to previous work on agglomeration economies. The database constructed in this study helps address this

\footnotetext{
${ }^{4}$ See the handbook chapter by Combes \& Gobillon (2015).

${ }^{5}$ Our panel data approach builds on previous work by Henderson (1997) and Dumais et al. (1997). See also Combes (2000) and Dekle (2002). A panel data approach is also used in a recent working paper by Lee (2015) which uses data on U.S. manufacturing industries from 1880-1990 to study static agglomeration forces.
} 
deficiency. ${ }^{6}$ These new data, which we digitized from original sources, cover 31 of the largest English cities (based on 1851 population) for the period 1851-1911. This empirical setting offers several important advantages. One advantage is the very limited level of government regulation and interference in the British economy during this period due to the strong free-market ideology that dominated British policymaking and the small size of the central government. ${ }^{7}$ A second important advantage is that we are able to study agglomeration using consistent data over many decades. Studying agglomeration over a long time period is desirable because the time needed to build new housing, factories, and infrastructure means that it may take years for cities to respond to changes in local productivity levels. Our data are also quite detailed; they come from a full census and cover nearly the entire private sector economy, including manufacturing, transportation, retail, and services. A third advantage is that we are able to study a long-established urban system. This contrasts with the U.S., where the open western frontier meant that the U.S. city system was in transition until the middle of the 20th century. ${ }^{8}$ Our setting was also characterized by a relatively open economy with high levels of migration into and between cities. ${ }^{9}$

Fourth, we provide new results on the strength of different types of agglomeration and congestion forces for one empirical setting. We find that (1) cross-industry effects were important, and occurred largely through the presence of local suppliers and occupationally similar labor pools, (2) the net effect of within-industry agglomeration forces was generally negative, and (3) city size had a clear negative relationship to city growth. The presence of local buyers appears to have had little positive influence on city-industry growth. We provide a variety of tests examining the robustness of

\footnotetext{
${ }^{6}$ Recently, other databases of this type have been developed using data from the U.S. County Business Patterns by Duranton et al. (2014) and from the U.S. Census of Manufacturers by Lee (2015) and others.

${ }^{7}$ This contrasts with modern settings, where the list of confounding factors includes place-based government policies, local land-use regulations such as zoning, environmental policies that vary across locations, local tax incentives, variation in the local burden of national taxation, as well as many other types of regulation. These factors can also affect city growth, making it more difficult to identify and quantify the role of agglomeration forces. To cite some examples, Kline \& Moretti (2013) describe the impact of place-based government policies in the U.S. The role of local land use regulations is highlighted by Gyourko et al. (2008). Local environmental policies are studied by Henderson (1996) and Chay \& Greenstone (2005), among others. Greenstone \& Moretti (2003) describe the impact of local tax incentives, while Albouy (2009) describes how federal tax incentives distort urban growth.

${ }^{8}$ See Desmet \& Rappaport (Forthcoming). In contrast, Dittmar (2011) finds that Zipf's Law emerged in European cities between 1500 and 1800, well before the beginning of our study period.

${ }^{9}$ See, e.g., Baines (1994) and Long \& Ferrie (2004).
} 
these results. For example, we show that our main results are robust to dropping particular cities or particular industries. They are also robust to using an alternative set of matrices measuring cross-industry connections, alternative functional forms for modeling spillovers, or alternative industry definitions. We also show that incorporating cross-city effects, such as market potential or cross-city industry spillovers, has little impact on our results.

Fifth, we introduce a novel approach for measuring the combined strength of the many cross-industry agglomeration forces represented in our model. This is valuable because it provides a convenient way to assess the aggregate strength of these effects and may be useful for studying how these effects vary in different circumstances. Our results suggest that a lower-bound estimate of the agglomeration forces captured by our empirical model are equivalent to a decadal city-size divergence rate of $1.6-2.3 \%$. To our knowledge this is the first paper to show how to measure the combined strength of these many cross-industry connections.

It is important to understand at the outset that the goal of this paper is to assess the role of agglomeration economies in driving city employment growth in different industries, and thereby contributing to overall city growth. Because our interest is in city growth, our analysis focuses specifically on employment as the outcome variable of interest. This is the natural object for our analysis, and one of the few types of data that can be observed at a local level, for many locations, over long time periods. ${ }^{10}$ While the contribution of agglomeration economies to employment growth is generated through improved productivity, there is not necessarily a one-to-one mapping between productivity and employment growth. For example, under certain circumstances productivity improvements may reduce employment growth. Thus, our results should not be interpreted as providing a full description of the productivity effects of agglomeration economies.

It is also important to note that this study focuses on dynamic agglomeration economies, i.e., the influence of the current level of economic activity on future growth. This approach is motivated by the endogenous growth literature, and in particular the work of Lucas (1988), who emphasized the important role that localized learning in cities is likely to play in generating sustained economic growth. In some sense our exercise can be thought of as a step towards identifying the patterns that characterize

\footnotetext{
${ }^{10}$ Other types of data, such as wages and rents, are more difficult to obtain in a consistent way at the local level over long periods.
} 
endogenous growth at the urban level. This approach contrasts with work studying static agglomeration effects, where the level of employment or output in one sector influences the level in another sector. While static agglomeration effects are worthy of study, ultimately they cannot provide a theory of sustained urban growth. ${ }^{11}$

This paper analyzes agglomeration patterns across sectors spanning the entire private-sector economy in all of the largest urban centers in England for a period of sixty years. This broad approach allows us to estimate general patterns and to assess their importance for long-run city development. An alternative strand of work on agglomeration economies focuses on overcoming identification issues by comparing outcomes in similar locations, where some locations receive a plausibly exogenous shock to the level of local economic activity (e.g., Greenstone et al. (2010) and Kline \& Moretti (2013)). This approach has the advantage of more cleanly identifying the causal impact of changes in local economic activity, but it may also be less generalizable and more difficult to apply to policy analysis. Thus, we view our broader approach, which follows the work of Glaeser et al. (1992), Henderson et al. (1995)), and more recently Ellison et al. (2010), as complementary to studies that improve identification by focusing on specific shocks to local economic activity.

The next section presents our theoretical framework while the empirical setting is discussed in Section 3. Section 4 describes the data. In Section 5 we conduct a preliminary analysis that applies existing methodologies to our data. We then introduce our preferred empirical approach in Section 6. Section 7 presents the main results, while Section 8 examines the impact of city size and shows how this can be used to calculate the aggregate strength of the agglomeration forces in our model. Section 9 concludes.

\section{Theory}

While this paper is primarily empirical, a theoretical model is useful in disciplining the empirical specification. Grounding our analysis in theory can also help us interpret

\footnotetext{
${ }^{11}$ Some discussion of static vs. dynamic agglomeration forces is provided in Combes \& Gobillon (2015). Lee (2015) provides a recent example of a study focusing on static agglomeration forces. He finds that static localized inter-industry spillovers were small and declining in the U.S. across the 20th century. This suggests that static agglomeration forces are unlikely to be behind the growth of cities during this period.
} 
the results while being transparent about potential concerns.

The model is dynamic in discrete time. The dynamics of the model are driven by spillovers within and across industries which depend on industry employment and a matrix of parameters reflecting the extent to which any industry benefits from learning generated by employment in other industries (i.e., learning-by-doing spillovers). ${ }^{12}$ These dynamic effects are external to firms, so they will not influence the static allocation of economic activity across space that is obtained given a distribution of technology levels. Thus, we can begin by solving the allocation of employment across space in any particular period. We then consider how the allocation in one period affects the evolution of technology and thus, the allocation of employment in the next period. The benefit of such a simple dynamic system is that it allows the model to incorporate a rich pattern of inter-industry connections.

The theory focuses on localized spillovers that affect industry technology and thereby influence industry growth rates. In this respect it is related to the endogenous growth literature, particularly Romer (1986) and Lucas (1988). This is obviously not the only potential agglomeration force that may lie behind our results; alternative models may yield an estimation equation that matches the one we apply. However, because we are interested in dynamic agglomeration, focusing on technology growth is the natural starting point.

As is standard in urban theories, we assume that goods are freely traded across locations and workers are free to move between cities. To keep things simple, our baseline model omits some additional features, such as savings and capital investment, or intermediate inputs, that one might want to consider. In the Appendix, we explore the impact of adding capital or intermediate goods. ${ }^{13}$

\footnotetext{
${ }^{12}$ We have also explored models where technological progress is based on R\&D effort exerted by firms and the new technologies generated through R\&D have spillover benefits for other local industries. Models of this type can generate the same basic estimating equation that we obtain from our learning-by-doing model, but to keep the theory succinct we focus only on the simpler learning-by-doing spillover model here.

${ }^{13}$ The inclusion of these elements does not change the basic estimating equation that we obtain as long as we maintain the assumption of free mobility across locations, though it can change the interpretation of the parameter estimates.
} 


\subsection{Allocation within a static period}

We begin by describing how the model allocates population and economic activity across geographic space within a static period, taking technology levels as given. The economy is composed of many cities indexed by $c=\{1, \ldots C\}$ and many industries indexed by $i=\{1, \ldots I\}$. Each industry produces one type of final good so final goods are also indexed by $i$.

Individuals are identical and consume an index of final goods given by $D_{t}$. The corresponding price index is $P_{t}$. These indices take a CES form,

$$
D_{t}=\left(\sum_{i} \gamma_{i t} x_{i t}^{\frac{\sigma-1}{\sigma}}\right)^{\frac{\sigma}{\sigma-1}} \quad, \quad P_{t}=\left(\sum_{i} \gamma_{i t}^{\sigma} p_{i t}^{1-\sigma}\right)^{\frac{1}{1-\sigma}}
$$

where $x_{i}$ is the quantity of good $i$ consumed, $\gamma_{i t}$ is a time-varying preference parameter that determines the importance of the different final goods to consumers, $p_{i t}$ is the price of final good $i$, and $\sigma$ is the (constant) elasticity of substitution between final goods. It follows that the overall demand for any final good is,

$$
x_{i t}=D_{t} P_{t}^{\sigma} p_{i t}^{-\sigma} \gamma_{i t}^{\sigma} .
$$

Production is undertaken by many perfectly competitive firms in each industry, indexed by $f$. Output by firm $f$ in industry $i$ is given by,

$$
x_{i c f t}=A_{i c t} L_{i c f t}^{\alpha} R_{i c f t}^{1-\alpha},
$$

where $A_{i c t}$ is technology, $L_{i c f t}$ is labor input, and $R_{i c f t}$ is another input which we call resources. These resources play the role of locational fundamentals in our model. Note that technology is not specific to any particular firm but that it is specific to each industry-location. This represents the idea that within industry-locations, firms are able to monitor and copy their competitors relatively easily, while information flows more slowly across locations.

Labor can move costlessly across locations to achieve spatial equilibrium. This is a standard assumption in urban economic models and one that seems reasonable over the longer time horizons that we consider. The overall supply of labor to the economy depends on an exogenous outside option wage $\bar{w}_{t}$ that can be thought of 
as the wage that must be offered to attract immigrants or workers from rural areas to move to the cities. ${ }^{14}$ Thus, more successful cities, where technology grows more rapidly, will experience greater population growth.

We also incorporate city-specific factors into our framework. Here we have in mind city-wide congestion forces (e.g., housing prices), city-wide amenities, and the quality of city institutions. We incorporate these features in a reduced-form way by including a term $\lambda_{c t}>0$ that represents a location-specific factor that affects the firm's cost of employing labor. The effective wage rate paid by firms in location $c$ is then $\bar{w}_{t} \lambda_{c t}$. In practice, this term will capture any fixed or time-varying city amenities or disamenities that affect all industries in the city.

In contrast to labor, resources are fixed geographically. They are also industryspecific, so that in equilibrium $\sum_{f} R_{i c f t}=\bar{R}_{i c}$, where $\bar{R}_{i c}$ is fixed for each industrylocation and does not vary across time, though the level of $\bar{R}_{i c}$ does vary across locations. This approach follows Jones (1975) and has recently been used to study the regional effects of international trade by Kovak (2013) and Dix-Carneiro \& Kovak (2015). These fixed resources will be important for generating an initial distribution of industries across cities in our model, and allowing multiple cities to compete in the same industry in any period despite variation in technology levels across cities.

Firms solve:

$$
\max _{L_{i c f t}, R_{i c f t}} p_{i t} A_{i c t} L_{i c f t}^{\alpha} R_{i c f t}^{1-\alpha}-\bar{w}_{t} \lambda_{c t} L_{i c f t}-r_{i c t} R_{i c f t}
$$

Using the first order conditions, and summing over all firms in a city-industry, we obtain the following expression for employment in industry $i$ and location $c^{15}$ :

$$
L_{i c t}=A_{i c t}^{\frac{1}{1-\alpha}} p_{i t}^{\frac{1}{1-\alpha}}\left(\frac{\alpha}{\bar{w}_{t} \lambda_{c t}}\right)^{\frac{1}{1-\alpha}} \bar{R}_{i c} .
$$

This expression tells us that employment in any industry $i$ and location $c$ will depend on technology in that industry-location, the fixed resource endowment for that

\footnotetext{
${ }^{14}$ This feature will capture demographic growth and the movement of workers across cities and countries, an important feature of the empirical setting that we consider.

${ }^{15}$ With constant returns to scale production technology and external spillovers, we are agnostic about the size of individual firms in the model. We require only that there are sufficiently many firms, and no firms are too large, so that the assumption of perfect competition between firms holds.
} 
industry-location, factors that affect the industry in all locations $\left(p_{i t}\right)$, city-specific factors $\left(\lambda_{c t}\right)$, and factors that affect the economy as a whole $\left(\bar{w}_{t}\right)$.

To close the static model, we need only ensure that income in the economy is equal to expenditures. This occurs when,

$$
D_{t} P_{t}+M_{t}=\bar{w}_{t} \sum_{c} \lambda_{c t} \sum_{i} L_{i c t}+\sum_{i} \sum_{c} r_{i c t} \bar{R}_{i c}
$$

where $M_{t}$ represents net expenditures on imports. For a closed economy model we can set $M_{t}$ to zero and then solve for the equilibrium price levels in the economy. ${ }^{16}$ Alternatively, we can consider a (small) open economy case where prices are given and solve for $M_{t}$. We are agnostic between these two approaches.

\subsection{Dynamics: Technology growth over time}

Technological progress in the model occurs through localized learning-by-doing spillovers that are external to firms. One implication is that firms are not forward looking when making their employment decisions within any particular period. Following the approach of Glaeser et al. (1992), we write the growth rate in technology as,

$$
\ln \left(\frac{A_{i c t+1}}{A_{i c t}}\right)=S_{i c t}+\epsilon_{i c t}
$$

where $S_{i c t}$ represent the amount of spillovers available to a city-industry in a period. Some of the factors that we might consider including in this term are:

$$
S_{i c t}=f(\quad \text { within-industry spillovers, cross-industry spillovers, }
$$

\footnotetext{
${ }^{16}$ To solve for the price levels in the closed economy case, we use the first order conditions from the firm's maximization problem and Equation 3 to obtain,

$$
p_{i t}=\left(\frac{\alpha}{\bar{w}_{t}}\right)^{\frac{\alpha}{\alpha \sigma-\alpha-\sigma}}\left(\sum_{c} A_{i c t}^{\frac{1}{1-\alpha}} \bar{R}_{i c} \lambda_{c t}^{\frac{\alpha}{\alpha-1}}\right)^{\frac{1-\alpha}{\alpha \sigma-\alpha-\sigma}}\left(D_{t} P_{t}^{\sigma}\right)^{\frac{\alpha-1}{\alpha \sigma-\alpha-\sigma}} \gamma_{i t}^{\frac{\sigma(\alpha-1)}{\alpha \sigma-\alpha-\sigma}}
$$

This equation tells us that in the closed-economy case, changes in the price level for goods produced by industry $i$ will depend on both shifts in the level of demand for goods produced by industry $i$ represented by $\gamma_{i t}$, as well as changes in the overall level of technology in that industry (adjusted for resource abundance), represented by the summation over $A_{i c t}$ terms.
} 
national industry technology growth, city-level aggregate spillovers) .

We can use Equation 4 to translate the growth in (unobservable) city-industry technology into the growth of (observable) city-industry employment. We start with Equation 3 for period $t+1$, take logs, plug in Equation 4, and then plug in Equation 3 again (also in logs), to obtain,

$$
\begin{aligned}
\ln \left(L_{i c t+1}\right)-\ln \left(L_{i c t}\right) & =\left(\frac{1}{1-\alpha}\right)\left[S_{i c t}+\left[\ln \left(P_{i t+1}\right)-\ln \left(p_{i t}\right)\right]\right. \\
& \left.+\left[\ln \left(\lambda_{c t+1}\right)-\ln \left(\lambda_{c t}\right)\right]+\left[\ln \left(\bar{w}_{t+1}\right)-\ln \left(\bar{w}_{t}\right)\right]+e_{i c t}\right]
\end{aligned}
$$

where $e_{i c t}=\epsilon_{i c t+1}-\epsilon_{i c t}$ is the error term. Note that by taking a first difference here, the locational fundamentals term $\bar{R}_{i c}$ has dropped out. We are left with an expression relating growth in a city-industry to spillovers, city-wide growth trends, national industry growth, and an aggregate national wage term.

The last step we need is to place more structure on the spillovers term. Existing empirical evidence provides little guidance on what form this function should take. In the absence of empirical guidance, we choose a fairly simple approach in which technology growth is a linear function of log employment, so that

$$
S_{i c t}=\sum_{k} \tau_{k i} \max \left(\ln \left(L_{k c t}\right), 0\right)+\xi_{i t}+\psi_{c t},
$$

where each $\tau_{k i} \in(0,1)$ is a parameter that determines the level of spillovers from industry $k$ to industry $i$. While admittedly arbitrary, this functional form incorporates a number of desirable features. If there is very little employment in industry $k$ in location $c\left(L_{k c t} \leq 1\right)$, then industry $k$ makes no contribution to technology growth in industry $i$. Similarly, if $\tau_{k i}=0$ then industry $k$ makes no contribution to technology growth in industry $i$. The marginal benefit generated by an additional unit of employment is also diminishing as employment rises. This functional form does rule out complementarity between technological spillovers from different industries. While such complementarities may exist, an exploration of these more complex interactions is beyond the scope of the current paper. 
One feature of Equation 4 is that it will exhibit scale effects. While this may be a concern in other types of models, it is a desirable feature in a model of agglomeration economies, where these positive scale effects will be balanced by offsetting congestion forces, represented by the $\lambda_{c t}$ terms.

Plugging Equation 6 into Equation 5, we obtain our estimation equation:

$$
\begin{aligned}
\ln \left(L_{i c t+1}\right)-\ln \left(L_{i c t}\right) & =\left(\frac{1}{1-\alpha}\right)\left[\tau_{i i} \ln \left(L_{i c t}\right)+\sum_{k \neq i} \tau_{k i} \ln \left(L_{k c t}\right)\right. \\
& +\left[\ln \left(P_{i t+1}\right)-\ln \left(P_{i t}\right)\right]+\xi_{i t} \\
& +\left[\ln \left(\lambda_{c t+1}\right)-\ln \left(\lambda_{c t}\right)\right]+\psi_{c t} \\
& \left.+\left[\ln \left(\bar{w}_{t+1}\right)-\ln \left(\bar{w}_{t}\right)\right]\right]+e_{i c t} .
\end{aligned}
$$

This equation expresses the change in log employment in industry $i$ and location $c$ in terms of (1) within-industry spillovers generated by employment in industry $i,(2)$ cross-industry spillovers from other industries, (3) national industry-specific factors that affect industry $i$ in all locations, (4) city-specific factors that affect all industries in a location, and (5) aggregate changes in the wage (and thus national labor supply) that affect all industries and locations. To highlight that this expression incorporates both within and cross-industry spillovers we have pulled the within-industry spillover term out of the summation.

This expression for city-industry growth will motivate our empirical specification. One feature that is worth noting here is that we have two factors, city-level aggregate spillovers $\left(\psi_{c t}\right)$ and other time-varying city factors $\left(\lambda_{c t}\right)$, both of which vary at the city-year level. Empirically we will not be able to separate these positive and negative effects and so we will only be able to identify their net impact. Similarly, we cannot separate positive and negative effects that vary at the industry-year level. Note that the inclusion of the $\xi_{i t}$ term in Eq. 7 allows for the possibility that some industries were growing much faster nationally than others, an important feature of the empirical setting that we consider.

Note that in the absence of spillovers, and with common technologies across locations, the city size distribution in this model will be determined by the distribution of 
local resource endowments. Once local technology spillovers are added, city sizes will be determined by a combination of the initial resource endowment and the evolving technology levels. This hybrid of locational fundamentals and increasing returns is consistent with some existing empirical results (e.g., Davis \& Weinstein (2002) and Bleakley \& Lin (2012)). Once spillovers are included, the dynamics of the system are complex and depend crucially on the matrix of $\tau_{k i}$ parameters. ${ }^{17}$ Estimating these parameters is the goal of our empirical exercise.

While our model provides a theoretically-grounded estimation approach, this is not the only potential set of agglomeration forces that can yield an estimation equation that matches the one that we will apply. There are at least two promising alternative theories that may yield similar expressions. One such theory could combine static inter-industry connections, such as pecuniary spillovers through intermediategoods sales, with changing transport costs. A second alternative combines static agglomeration forces with a friction that results in a slow transition towards a static equilibrium. Our empirical exercises cannot make a sharp distinction between the mechanisms described in our framework and these alternatives, so they should not be interpreted as a direct test of the particular agglomeration mechanism described by the theory. Rather, our empirical results will provide evidence on the pattern of within and cross-industry agglomeration benefits and provide some evidence on the types of inter-industry connections that matter. Further work will be needed to unpack the specific mechanisms through which these inter-industry benefits occur.

\section{Empirical setting}

The empirical setting used in this paper was chosen because of the rich data available as well as the particularly clean environment it provides for testing models of agglomeration. Relative to modern developed countries, British cities in the early 19th and 20th centuries had few local regulatory constraints on economic growth. For example,

\footnotetext{
${ }^{17}$ The dynamics of our model will also depend crucially on city-size congestion forces, which are not fully modeled here. Because the primary goals of this paper are empirical, we leave a full exploration of these dynamics for future work. It is also worth noting that our model has the potential to reproduce some of the patterns of city and city-industry growth documented in Duranton (2007). In particular, under certain configurations of the matrix of spillover parameters our model will feature a churning of industries across cities accompanied by slower changes in relative city size. As in Duranton (2007), any such churning will be driven by cross-industry spillovers.
} 
the first national zoning laws were not introduced in Britain until 1909, near the very end of our study period. ${ }^{18}$ Other regulations, such as environmental controls, were also limited. ${ }^{19}$ Of course, the government did have a role to play in the economy during this period. Examples of important national government programs include the Poor Law, which provided support for unemployed workers and the destitute, the Factory Acts, which regulated safety conditions in factories and limited child labor, and tariff policy. Importantly, however, most of these policies applied fairly evenly across the country. At the local level, government regulation was relatively weak and primarily directed towards sanitary improvements (Platt (1996)).

Lee (1984) reports that, in 1881, the middle of our study period, the primary, secondary and tertiary sectors employed 12.5\%, 52.6\% and 34.7\% of British workers, respectively. Thus, in terms of economic structure, among modern economies the setting that we study was most similar to heavily industrialized developing and middle-income countries. ${ }^{20}$ As a result, our setting can potentially be used to shed light on such economies, while offering data that are richer and cover a longer period than those available in most modern developing economies. An additional benefit of focusing on a historical setting is that eventually our results can be compared to Britain in the modern period to begin understanding how agglomeration forces evolve as countries develop. However, in this study we end our study period in 1911 for two reasons. First, this is the last census year before the First World War, which brought massive disruption to the British urban system. Second, between 1911 and the first census after the Second World War it is difficult to generate consistent data series.

There are two other features of the empirical setting that should be noted before we move on. First, this setting was characterized by high levels of population mobility and rapid urbanization. ${ }^{21}$ Second, this mobility was due in part to the highly developed British transportation system, which connected all of the cities in our database.

\footnotetext{
${ }^{18}$ See Platt (1996), Ch. 6.

${ }^{19}$ See Thorsheim (2006) for details on environmental regulations in Britain during this period.

${ }^{20}$ In China, for example, employment shares of the primary, secondary and tertiary sector in 2012 was $33.6 \%, 30.3 \%$ and $36.1 \%$ respectively, according to the CIA's World Fact Book. Other similar examples are Iran, with primary, tertiary and secondary shares of $16.3 \%, 35.1 \%$ and $48.6 \%$ respectively, and Malaysia, with shares of $11 \%, 36 \%$ and $53 \%$.

${ }^{21}$ During this period the British population was "highly mobile" in the words of Long \& Ferrie (2003). while Baines (1985) shows that population growth in cities was due in large part to the arrival of new migrants, coming both from the English countryside as well as Ireland, Scotland and Wales.
} 
This system was relatively stable across our study period. Due in part to the stability of this system, as well as the importance of local resources such as coal, existing work suggests that changes in transport costs had little impact on the location of industry in Britain during this period (Crafts \& Mulatu (2006)).

\section{Data}

The main database used in this study was constructed from more than a thousand pages of original British Census of Population summary reports. ${ }^{22}$ The decennial Census data were collected by trained registrars during a relatively short time period, usually a few days in April of each census year. As part of the census, individuals were asked to state their occupation, but the reported occupations correspond more closely to industries than to what we think of as occupations today. ${ }^{23}$ A unique feature of this database is that the information is drawn from a full census. Virtually every person in the cities we study provided information on their occupation and all of these answers are reflected in the employment counts in our data. ${ }^{24}$

The database includes 31 cities for which occupation data were reported in each year from 1851-1911, containing 28-34\% of the English population over the period we study. The geographic extent of these cities changes over time as the cities grow, a feature that we view as desirable for the purposes of our study. ${ }^{25}$ Appendix 10.2 provides a list of the cities included in the database, as well as a map showing the

\footnotetext{
${ }^{22}$ This study uses the most updated version of this database (v2.0). These data and further documentation can be found at http://www.econ.ucla.edu/whanlon/ under Research.

${ }^{23}$ Examples from 1851 include "Banker", "Glass Manufacture" or "Cotton manufacture". The database does include a few occupations that do not directly correspond to industries, such as "Labourer", "Mechanic", or "Gentleman", but these are a relatively small share of the population. These categories are not included in the analysis. In 1921 the Census office renamed what had previously been called "occupation" to be "industry" and then introduced a new set of data reflecting occupation in the modern sense.

${ }^{24}$ This contrasts with data based on census samples, which often covers $5 \%$ or $1 \%$ of the available data. We have experimented with data based on a census sample (from the U.S.) and found that, when cutting the data to the city-industry level, sampling error has a substantial effect on the consistency and robustness of the results.

${ }^{25}$ Other studies in the same vein, such as Michaels et al. (2013), also use metropolitan boundaries that expand over time. The alternative is working with fixed geographic units. While that may be preferred for some types of work, given the growth that characterizes most of the cities in our sample, using fixed geographic units would mean either that the early observations would include a substantial portion of rural land surrounding the city, or that a substantial portion of city growth would not be part of our sample in the later years. Either of these options is undesirable.
} 
location of these cities in England. In general, our analysis industries cover the majority of the working population of the cities, with most of the remainder employed by the government or in agriculture.

The industries in the database span manufacturing, food processing, services and professionals, retail, transportation, construction, mining, and utilities. Because the occupational categories listed in the census reports varied over time, we combined multiple industries in order to construct consistent industry groupings over the study period. This process generates 26 consistent private sector occupation categories. ${ }^{26}$ Of these, 23 can be matched to the connections matrices used in the analysis. Table 5 in Appendix 10.2 describes the industries included in the database.

This study also requires a set of matrices measuring the pattern of connections between industries. These measures should reflect the channels through which ideas may flow between industries. Existing literature provides some guidance here. Marshall (1890) suggested that firms may benefit from connections operating through input-output flows, the sharing of labor pools, or other types of technology spillovers. The use of input-output connections is supported by recent literature showing that firms share information with their customers or suppliers. ${ }^{27}$ To reflect this channel, we use an input-output table constructed by Thomas (1987) based on the 1907 British Census of Production (Britain's first industrial census). ${ }^{28}$ We construct two variables: $\operatorname{IOin}_{i j}$, which gives the share of industry $i$ 's intermediate inputs that are sourced from industry $j$, and IOout ${ }_{i j}$ which gives the share of industry $i$ 's sales of intermediate goods that are purchased by industry $j$. One drawback of using these matrices is that they are for intermediate goods; they will not capture the pattern of capital goods flows.

Another channel for knowledge flow is the movement of workers, who may carry ideas between industries or generate other dynamic benefits. ${ }^{29}$ To reflect this chan-

\footnotetext{
${ }^{26}$ Individual categories in the years were combined into industry groups based on (1) the census' occupation classes, and (2) the name of the occupation. Further details of this procedure are available at http://www. econ.ucla.edu/whanlon/.

${ }^{27}$ For example, Javorcik (2004) and Kugler (2006) provide evidence that the presence of foreign firms (FDI) affects the productivity of upstream and downstream domestic firms.

${ }^{28}$ For robustness exercises, we have also collected an input-output table for 1841 constructed by Horrell et al. (1994) with 12 more aggregated industry categories. See Appendix 10.2 for more details.

${ }^{29}$ Research by Poole (2013) and Balsvik (2011), using data from Brazil and Norway, respectively, has highlighted this channel of knowledge flow.
} 
nel, we construct two different measures of the similarity of the workforces used by different industries. The first measure is based on the demographic characteristics of workers (their age and gender) from the 1851 Census. These features had an important influence on the types of jobs a worker could hold during the period we study. ${ }^{30}$ For any two industries, our demographic-based measure of labor force similarity, $E M P_{i j}$, is constructed by dividing workers in each industry into these four available bins (male/female and over20/under20) and calculating the correlation in shares across the industries. ${ }^{31}$ A second measure of labor-force similarity, based on the occupations found in each industry, is more similar to the measures used in previous studies. This measure is built using U.S. census data from 1880, which reports the occupational breakdown of employment by industry. We map the U.S. industry categories to the categories available in our analysis data. Then, for any two industries our occupation-based measure of labor force similarity, $O C C_{i j}$ is the correlation in the vector of employment shares for each occupation.

Both the demographic-based and occupation-based labor force similarity measures are meant to capture the idea that firms can benefit from sharing similar labor pools with other local industries. However, these two measures are meant to reflect two different dimensions along which labor pooling can be constrained. The demographicbased measure reflects the fact that the set of industries available to workers can be constrained by their demographic characteristics, particularly in a historical setting such as the one we consider. The occupation-based measure reflects a different type of constraint, which is more dependent on a worker's education, experience and ability. Note that two industries could use two sets of demographically similar workforces but with completely different occupations, or vice versa, so it is plausible that one channel could matter when the other does not.

\footnotetext{
${ }^{30}$ The importance of the contribution made by industry demographics to agglomeration forces during the period that we study was specifically addressed by Marshall (1890). He gives as an example the benefits that flowed between textiles and the metals and machinery industry due to the fact that the textile industries employed substantial amounts of female and child labor while metal and heavy machinery industry jobs were almost exclusively reserved for adult males.

${ }^{31}$ This is the most detailed breakdown by age and gender available in our data.
} 


\section{Preliminary analysis}

Before moving on to the main analysis, it is useful to begin by analyzing the data using standard tools from the existing literature. One natural starting point is to apply the agglomeration measure from Ellison \& Glaeser (1997) to our data. These results, described in Appendix 10.2 Tables 8-9, show that the agglomeration patterns observed in our data are similar to those documented in modern studies. Specifically, Britain's main manufacturing and export industries, such as Textiles, Metal \& Machines, and Shipbuilding, show high levels of geographic agglomeration. Many non-traded services or retail industries, including Merchants, Agents, Etc., Construction, and Shopkeepers, Salesmen, Etc. show low levels of agglomeration. Overall, the median level of industry agglomeration is between 0.02 and 0.026 , which is comparable to the levels reported for the modern U.S. economy by Ellison \& Glaeser (1997) and somewhat larger than the levels reported for the modern British economy by Faggio et al. (Forthcoming). ${ }^{32}$

Next, we investigate how results obtained using long-difference regressions, in the spirit of Glaeser et al. (1992) and Henderson et al. (1995), compare to existing results. These long-difference regression results, which are presented in Appendix 10.3, are generally similar to the findings reported by Glaeser et al. (1992), which suggest that firms are likely to benefit primarily from spillovers across industries, rather than within industries. Our results contrast with those presented in Henderson et al. (1995), which finds evidence that within-industry effects were more important. As we will see, these basic patterns are largely consistent with the results obtained using our preferred estimation strategy, which we introduce next.

\footnotetext{
${ }^{32}$ Using industry data for 459 manufacturing industries at the four-digit level and 50 states, Ellison \& Glaeser (1997) calculate a mean agglomeration index of 0.051 and a median of 0.026. For Britain, Faggio et al. (Forthcoming) calculate industry agglomeration using 94 3-digit manufacturing industries and 84 urban travel-to-work areas. They obtain a mean agglomeration index of 0.027 and a median of 0.009. Kim (1995) calculates an alternative measure of agglomeration for the U.S. during the late 19th and early 20th centuries, but given that he studies only manufacturing industries, and given the substantial differences between his industry definitions and our own, it is difficult to directly compare to his results.
} 


\section{Empirical approach}

The starting point for our analysis is based on Equation 7, which represents the growth rate of a city-industry as a function of within and cross-industry agglomeration effects as well as time-varying city-specific and national industry-specific factors. Rewriting this as a regression equation we have,

$$
\triangle \ln \left(L_{i c t+1}\right)=\tilde{\tau}_{i i} \ln \left(L_{i c t}\right)+\sum_{k \neq i} \tilde{\tau}_{k i} \ln \left(L_{k c t}\right)+\theta_{c t}+\chi_{i t}+e_{i c t},
$$

where $\triangle$ is the first difference operator, $\tilde{\tau}_{i i}$ and $\tilde{\tau}_{k i}$ include $1 /(1-\alpha), \theta_{c t}$ is a full set of city-year effects and $\chi_{i t}$ is a full set of industry-year effects. The first term on the right hand side represents within-industry spillovers, while the second term represents cross-industry spillovers. ${ }^{33}$

One issue with Equation 8 is that there are too many parameters for us to credibly estimate given the available data. In order to reduce the number of parameters, we need to put additional structure on the spillover terms. As discussed in the previous section, we follow recent literature in this area, particularly Ellison et al. (2010), by parameterizing the connections between industries using the available input-output and labor force similarity matrices: ${ }^{34}$

$$
\tilde{\tau}_{k i}=\beta_{1} \text { IOin }_{k i}+\beta_{2} \text { IOout }_{k i}+\beta_{3} E M P_{k i}+\beta_{4} O C C_{k i} \quad \forall i, k
$$

Substituting this into Eq. 8 we obtain:

\footnotetext{
${ }^{33}$ We purposely omitted the last term of Equation $7, \Delta \ln \left(\bar{w}_{t}\right)$, because although it could be estimated as a year-specific constant, it would be collinear with both the (summation of) industryyear and city-year effects. Moreover, in any given year we also need to drop one of the city or industry dummies in order to avoid collinearity. In all specifications we chose to drop the industryyear dummies associated with the "General services" sector.

${ }^{34}$ Adding an error term to this equation would imply heteroskedastic standard errors, a possibility that is accommodated by our econometric approach, but would not otherwise alter the basic estimation approach suggested by the theory.
} 


$$
\begin{aligned}
\triangle \ln \left(L_{i c t+1}\right) & =\tilde{\tau}_{i i} \ln \left(L_{i c t}\right)+\beta_{1} \sum_{k \neq i} \text { IOin }_{k i} \ln \left(L_{k c t}\right)+\beta_{2} \sum_{k \neq i} \text { IOout }_{k i} \ln \left(L_{k c t}\right) \\
& +\beta_{3} \sum_{k \neq i} E M P_{k i} \ln \left(L_{k c t}\right)+\beta_{4} \sum_{k \neq i} O C C_{k i} \ln \left(L_{k c t}\right)+\theta_{c t}+\chi_{i t}+e_{i c t} .
\end{aligned}
$$

Instead of a large number of parameters measuring spillovers across industries, Equation 9 now contains only four parameters multiplying four (weighted) summations of log employment. Summary statistics for the cross-industry spillover terms are available in Appendix Table 6 while the correlations between the cross-industry terms are available in Appendix Table 7.

There is a clear parallel between the specification in Equation 9 and the empirical approach used in the convergence literature (Barro \& Sala-i Martin (1992)). A central debate in this literature has revolved around the inclusion of fixed effects for the cross-sectional units (see, e.g., Caselli et al. (1996)). In our context, the inclusion of such characteristics could help control for location and industry-specific factors that affect the growth rate of industry and are correlated with initial employment levels. However, the inclusion of city-industry fixed effects in Equation 9 will introduce a mechanical bias in our estimated coefficients (Hurwicz (1950), Nickell (1981)). This bias is a particular concern in a setting where the time-series is limited. Solutions to these issues have been offered by Arellano \& Bond (1991), Blundell \& Bond (1998), and others, yet these procedures can also generate biased results, as shown by Hauk Jr. \& Wacziarg (2009). In a recent review, Barro (2015) uses data covering 40-plus years and argues (p. 927) that in this setting, "the most reliable estimates of convergence rates come from systems that exclude country fixed effects but include an array of X variables to mitigate the consequence of omitted variables." Our approach essentially follows this advice, but with the additional advantage that we have two cross-sectional dimensions, which allows for the inclusion of flexible controls in the form of timevarying city and industry effects.

There are two issues to address at this point. First, there could be measurement error in $L_{i c t}$. Since this variable appears both on the left and right hand side, this would mechanically generate an attenuation bias in our within-industry spillover estimates. Moreover, since $L_{i c t}$ is correlated with the other explanatory variables, such measurement error would also bias the remaining estimates. We deal with measure- 
ment error in $L_{i c t}$ on the right hand side by instrumenting it with lagged city-industry employment. ${ }^{35}$ Under the assumption that the measurement error in any given cityindustry pair is iid across cities and time, our instrument is $L_{i c t}^{\text {Inst }}=L_{i c t-1} \times g_{i-c t}$, where $L_{i c t-1}$ is the lag of $L_{i c t}$ and $g_{i-c t}$ is the decennial growth rate in industry $i$ computed using employment levels in all cities except city c, as in Bartik (1991).

Second, we are also concerned that there may be omitted variables that affect both the level of employment in industry $j$ and the growth in employment in industry $i$. Such variables could potentially bias our estimated coefficients on both the crossindustry and (when $j=i$ ) the within-industry spillovers. For instance, if there is some factor not included in our model which causes growth in two industries $i$ and $k \neq i$ in the same city, a naive estimation would impute such growth to the spillover effect from $k$ to $i$, thus biasing the estimated spillover upward. Our lagged instrumentation approach can also help us deal with these concerns. Specifically, when using instruments with a one-decade lag to address endogeneity concerns the exclusion restriction is that there is not some omitted variable that is correlated with employment in some industry $k$ in period $t$ and affects employment growth in industry $i$ from period $t+1$ to $t+2$. Moreover, the omitted variable cannot affect growth in all industries in a location, else it would be captured by the city-year fixed effect, nor can it affect the growth rate of industry $i$ in all cities. ${ }^{36}$ Thus, while our approach does not allow us to rule out all possible confounding factors, it allows us to narrow the set of potential confounding forces relative to most previous work in this area. Now, for the cross-industry case, the summation terms in Eq. 9 such as $\sum_{k \neq i} I O i n_{k i} \ln \left(L_{k c t}\right)$ are instrumented with $\sum_{k \neq i} I O i n_{k i} \ln \left(L_{k c t}^{\text {Inst }}\right)$, where $L_{k c t}^{\text {Inst }}$ is as described above.

The estimation is performed using OLS or, when using instruments, two-stage least squares. Correlated errors are a concern in these regressions. Specifically, we are concerned about serial correlation, which Bertrand et al. (2004) argue can be a serious concern in panel data regressions, though this is perhaps less of a concern for us given the relatively small time dimension in our data. A second concern is that industries within the same city are likely to have correlated errors. A third concern, highlighted by Conley (1999) and more recently by Barrios et al. (2012), is spatial

\footnotetext{
${ }^{35}$ This approach is somewhat similar to the approach introduced by Bartik (1991) and has been suggested by Combes et al. (2011).

${ }^{36}$ The results are not sensitive to the length of the lag used in the instrumentation. We have experimented with two- and three-decade lags and obtained essentially the same results.
} 
correlation occurring across cities. Here the greatest concern is that error terms may be correlated within the same industry across cities (though the results presented in Appendix 10.5.8 suggest that cross-city effects are modest).

To deal with all of these concerns we use multi-dimensional clustered standard errors following work by Cameron et al. (2011) and Thompson (2011). We cluster by (1) city-industry, which allows for serial correlation; (2) city-year, which allows for correlated errors across industries in the same city and year; and (3) industry-year, which allows for spatial correlation across cities within the same industry and year. This method relies on asymptotic results based on the dimension with the fewest number of clusters. In our case this is 23 industries $\times 6$ years $=138$, which should be large enough to avoid serious small-sample concerns.

In order to conduct underidentification and weak-instrument tests while clustering standard errors in multiple dimensions, we have produced new statistical code implementing the approach from Kleibergen \& Paap (2006). This was necessary because existing statistical packages are unable to calculate these tests correctly when clustering by more than two dimensions. The procedure used to generate these test statistics is described in Appendix 10.4.2.

Finally, we may be concerned about how well our estimation procedure performs in a data set of the size available in this study. To assess this, we conduct a series of Monte Carlo simulations in which we construct 500 new data sets with a size and error structure based on the true data, but with known spillover parameter values. We then apply our estimation procedure to these simulated data in order to obtain a distribution of placebo coefficient estimates, which can then be compared to the estimates obtained using the true data. These simulations, which are described in more detail in Appendix 10.4.1, suggest that our estimation procedure performs well in datasets with a size and error structure similar to the true data.

To simplify the exposition, we will hereafter collectively refer to the set of regressors $\ln \left(L_{i c t}\right)$ for $i=1 \ldots I$ as the within variables. Similarly, with a small abuse of notation the term $\sum_{k \neq i} \operatorname{IOin}_{k i} \ln \left(L_{k c t}\right)$ is referred to as IOin, and so on for IOout, $E M P$, and $O C C$. We collectively refer to the latter terms as the between regressors since they are the parametrized counterpart of the spillovers across industries. 


\section{Main results}

Our main regression results are based on the specification described in Equation 9. The estimation strategy involves using four measures for the pattern of cross-industry spillovers: forward input-output linkages, backward input-output linkages, and two measures of labor force similarity. Our main results, in Table 1, consider all four channels simultaneously, while Appendix 13 presents regressions including one channel at a time. In Columns 1-3 of Table 1 we estimate a single coefficient reflecting within-industry spillovers, while Columns 4-6 present results in which we estimate industry-specific within-industry effects. These heterogeneous within-industry coefficients, which are not reported in Table 1, will be explored later. Columns 1 and 4 presents OLS results. In Column 2 and 5 we instrument the within-industry terms. ${ }^{37}$ In Column 3 and 6 we use instruments for both the within-industry and cross-industry terms.

These results show strong positive effects operating through forward input-output connections, suggesting that local suppliers play an important role in industry growth. The importance of local suppliers to industry growth is perhaps the clearest and most robust result emerging from our analysis. There is little evidence of positive effects operating through local buyers. The results also provide some evidence that the presence of other industries using similar occupations can have dynamic benefits. Also, the results in Columns 1-3 suggest that own-industry employment is negatively related to subsequent growth. In addition, comparing the results in Columns 1-3 with those in Columns 4-6 shows that allowing for heterogeneity in the within-industry effects does appear to be important. Finally, a comparison across columns for each spillover measure shows that the IV results do not differ from the OLS results in a statistically significant way, suggesting that any measurement error or omitted variables concerns addressed by instruments are not generating substantial bias in the OLS results. Moreover, the test statistics presented at the bottom of Table 1 suggests that our instruments are sufficiently strong.

Based on the results from Column 6 of Table 1, our preferred specification, a one

\footnotetext{
${ }^{37}$ We do not report first-stage results for our instrumental variables regressions because these involve a very large number of first-stage regressions. Instead, for each specification we report the test statistics for the Lagrange Multiplier underidentification test based on Kleibergen \& Paap (2006) as well as the test static for weak instruments test based on the Kleibergen-Paap Wald statistic. It is clear from these statistics that weak instruments are not a substantial concern in these specifications.
} 
standard deviation increase in the presence of local suppliers increases city-industry growth by $14.4 \%$. Turning to the occupational similarity channel, a one standard deviation increase in the presence of occupationally-similar local industries leads to a $14.8 \%$ increase in city industry growth when using the results from Column 6 of Table 1. Thus, both of these channels appear to exert a substantial positive effect on city-industry growth.

Table 1: Main results for cross-industry connections

\begin{tabular}{|c|c|c|c|c|c|c|}
\hline & (1) & $(2)$ & $(3)$ & $(4)$ & $(5)$ & $(6)$ \\
\hline $\begin{array}{l}\text { Log employment in } \\
\text { local supplier } \\
\text { industries }\end{array}$ & $\begin{array}{c}0.0421 \\
(0.0283)\end{array}$ & $\begin{array}{c}0.0450 \\
(0.0304)\end{array}$ & $\begin{array}{c}0.0388 \\
(0.0283)\end{array}$ & $\begin{array}{c}0.1601^{* * *} \\
(0.0464)\end{array}$ & $\begin{array}{c}0.1401^{* * *} \\
(0.0473)\end{array}$ & $\begin{array}{c}0.1457^{* * *} \\
(0.0472)\end{array}$ \\
\hline $\begin{array}{l}\text { Log employment in } \\
\text { local buyer } \\
\text { industries }\end{array}$ & $\begin{array}{c}0.0334 \\
(0.0301)\end{array}$ & $\begin{array}{c}0.0020 \\
(0.0319)\end{array}$ & $\begin{array}{l}-0.0062 \\
(0.0300)\end{array}$ & $\begin{array}{l}-0.0481 \\
(0.0693)\end{array}$ & $\begin{array}{l}-0.0888 \\
(0.0700)\end{array}$ & $\begin{array}{l}-0.1145 \\
(0.0725)\end{array}$ \\
\hline $\begin{array}{l}\text { Log employment in local } \\
\text { industries using } \\
\text { demographically } \\
\text { similar workers }\end{array}$ & $\begin{array}{c}0.0036 \\
(0.0229)\end{array}$ & $\begin{array}{c}0.0036 \\
(0.0241)\end{array}$ & $\begin{array}{l}-0.0099 \\
(0.0240)\end{array}$ & $\begin{array}{c}0.0445 \\
(0.0693)\end{array}$ & $\begin{array}{l}0.1145^{*} \\
(0.0616)\end{array}$ & $\begin{array}{c}0.0691 \\
(0.0605)\end{array}$ \\
\hline $\begin{array}{l}\text { Log employment in local } \\
\text { industries using } \\
\text { similar occupations }\end{array}$ & $\begin{array}{c}0.0413 \\
(0.0363)\end{array}$ & $\begin{array}{c}0.0309 \\
(0.0341)\end{array}$ & $\begin{array}{c}0.0270 \\
(0.0345)\end{array}$ & $\begin{array}{c}0.1580^{* *} \\
(0.0777)\end{array}$ & $\begin{array}{c}0.1698^{* *} \\
(0.0845)\end{array}$ & $\begin{array}{l}0.1503^{*} \\
(0.0854)\end{array}$ \\
\hline $\begin{array}{l}\text { Log own-industry } \\
\text { employment }\end{array}$ & $\begin{array}{c}-0.0871^{* * *} \\
(0.0321)\end{array}$ & $\begin{array}{l}-0.0514^{*} \\
(0.0279) \\
\end{array}$ & $\begin{array}{l}-0.0490^{*} \\
(0.0285)\end{array}$ & & & \\
\hline Observations & 4,253 & 3,544 & 3,539 & 4,253 & 3,539 & 3,539 \\
\hline Estimation & ols & 2 sls & 2sls & ols & 2 sls & 2sls \\
\hline Instrumented & none & wtn & wtn-btn & none & wtn & wtn-btn \\
\hline Within terms & homog & homog & homog & heter & heter & heter \\
\hline KP under & & 24.86 & 25.45 & & 22.09 & 24.52 \\
\hline KP weak & & 4677.9 & 858.6 & & 52.36 & 35.68 \\
\hline
\end{tabular}

Multi-level clustered standard errors by city-industry, city-year, and industry-year in parenthesis. Significance levels: ${ }^{* * *} \mathrm{p}<0.01,{ }^{* *} \mathrm{p}<0.05,{ }^{*} \mathrm{p}<0.1$. All cross-industry and within-industry connection variables have been standardized for comparability. Heterogeneous regressors within are included in Columns 4-6 but not displayed. City-time and industry-time effects are included in all regressions but not displayed. 2SLS regressions use lagged instruments. Note that the number of observations falls for the instrumented regressions because the instruments require a lagged employment term. Thus, data from 1851 are not available for these regressions. Acronyms: wtn $=$ within, btn = between. "KP under id." denotes the test statistic for the Lagrange Multiplier underidentification test based on Kleibergen \& Paap (2006). "KP weak id." denotes the test statistic for a weak instruments test based on the Kleibergen-Paap Wald statistic. 
Our analysis can also help us understand the strength of within-industry spillovers, reflected in the $\ln \left(L_{i c t}\right)$ term in Equation $8 .^{38}$ When analyzing these results, it is important to keep in mind that they reflect the net effect of within-industry agglomeration forces, which may be generated through a balance between agglomeration forces and negative forces such as competition or mean-reversion due to the diffusion of technologies across cities. We cannot identify the strength of local withinindustry agglomeration forces independent of counteracting forces. However, it is the net strength of these forces, which we are able to estimate, that is relevant for understanding the contribution of within-industry agglomeration forces to city growth. Thus, our results suggest that within-industry agglomeration effects generally do not make a positive contribution to city employment growth.

We have already seen, in Table 1 Columns 1-3, that the average within-industry effect across all industries is negative, but there is also evidence that allowing heterogeneity in these effects is important. We explore these heterogeneous withinindustry effects in Figure 1, which presents coefficients and 95\% confidence intervals for industry-specific within-industry spillover coefficients from regressions corresponding to Column 6 of Table 1. In only one industry, shipbuilding, do we observe any evidence of positive within-industry effects. This industry was characterized by increasing returns and strong patterns of geographic concentration. All other industries exhibit slower growth in locations where initial industry employment was large, after controlling for other forces. Within-industry agglomeration benefits, it would appear, are more the exception than the rule.

The results presented so far describe coefficients generated using all industries, where each industry is given equal weight. We have also calculated weighted regressions, where the set of observations for each city-industry is weighted based on employment in that city-industry at the beginning of each period. These results, available in Appendix 10.5.4, show qualitatively similar results to those shown above for the importance of local suppliers term, with only slightly smaller estimated coefficients. This provides confidence that our main findings are not being driven by small cities or industries. The weighted results also show stronger evidence of a negative effect through the presence of local buyers, but this finding appears to be quite sensitive to the set of industries included in the analysis. The agglomeration bene-

\footnotetext{
${ }^{38}$ In a static context these are often referred to as localization economies.
} 
Figure 1: Strength of within-industry effects by industry

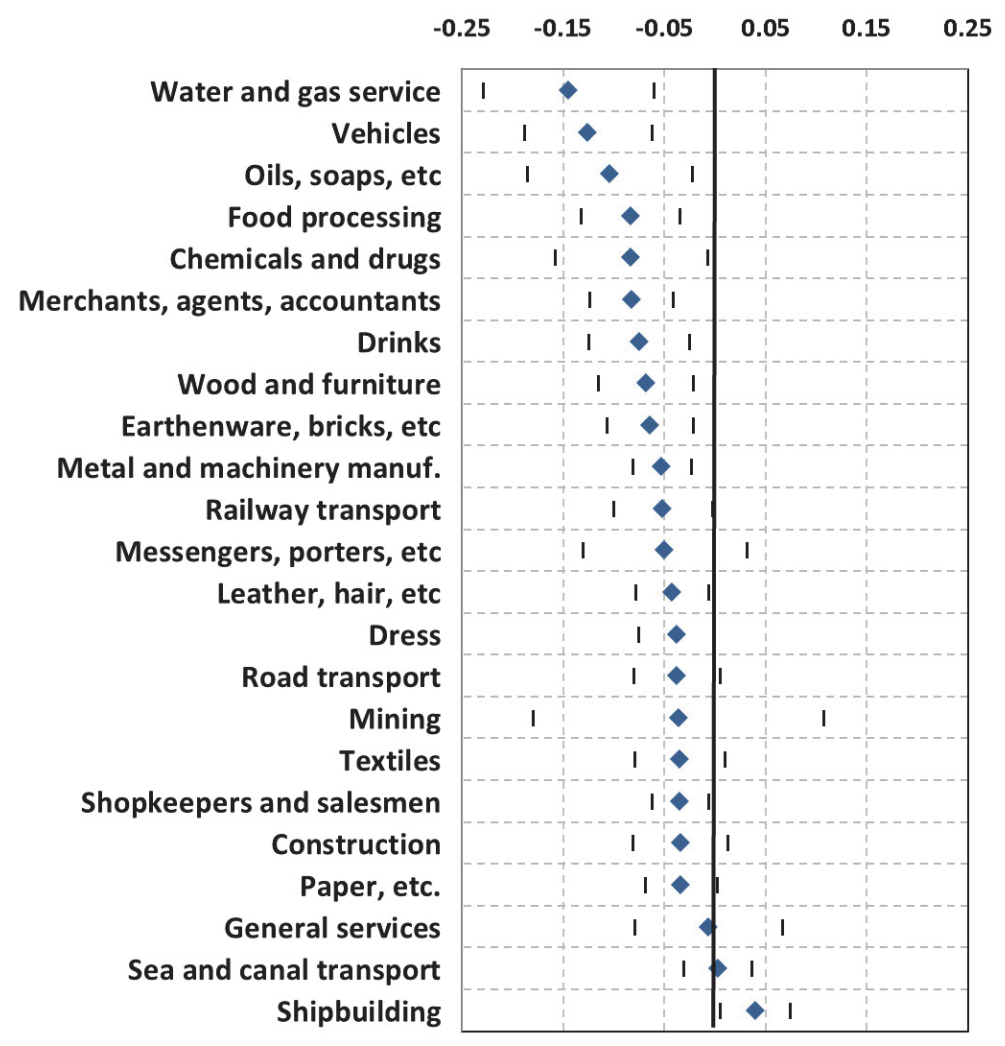

Results correspond to the regression described in Column 6 of Table 1. This figure displays coefficient estimates and $95 \%$ confidence intervals based on standard errors clustered by city-industry, city-year, and industry-year. The regression includes a full set of city-year and industry-year effects as well as between terms. Both the within and between terms are instrumented using one-decade lags.

fits from occupationally similar industries disappear when weighting by city-industry size, suggesting that labor market pooling benefits may be larger for small industries or in small cities.

We have also investigated the robustness of our results to dropping individual industries or individual cities from the analysis database (see Appendix 10.5.2). These exercises show that the significance of the estimates on the importance of local suppliers and occupationally-similar industries are robust to dropping any city or any industry. However, the estimated coefficient and confidence levels for the impact of local buyer industries is sensitive to the exclusion of particular industries. Specifically, when shipbuilding is excluded we observe that the coefficient on local buyer indus- 
tries becomes positive but not statistically significant. ${ }^{39}$ This suggests that in general the presence of local buyers may have a mild positive effect on industry growth. In addition, we have explored the sensitivity of our results to using alternative concave functional relationships such as a square root or fifth root in place of the log specification used in our main results. These results, available upon request, show that our findings are not sensitive to these alternatives. Also, in Appendix 10.5.5 we provide results where, as the outcome variable, we look at city-industry employment growth over two or three-decade differences. These deliver results that are quite similar to those shown in Table 1.

We have also explored the robustness of our results to the use of alternative connections matrices. In particular, in Appendix 10.5.7 we present results obtained while using the less detailed input-output table constructed by Horrell et al. (1994), which covers 12 more aggregated industry categories in 1841. When using this alternative matrix we continue to find evidence of positive effects generated by the presence of local suppliers. These results also suggest that local buyers may generate positive benefits, but as before this result appears to be sensitive to the set of industries included in the analysis.

It is also possible to split our data in order to look at how agglomeration forced differ across time. In Appendix 10.5.6 we present results splitting the data in 1881. In these results we observe similar patterns in both the early and late years, though the strength of the impact of local supplier industries and other occupationally similar local industries increases in the later period. That may indicate that these agglomeration channels strengthened as the country developed, or they may be related to the introduction of many new Second Industrial Revolution technologies, in areas such as chemicals and electronics, during the 1881-1911 period.

The results discussed so far reveal average patterns across all industries. An additional advantage of our empirical approach is that it is also possible to estimate industry-specific coefficients in order to look for (1) heterogeneity in the industries that benefit from each type of inter-industry connection or (2) heterogeneity in the industries that produce each type of inter-industry connections. In Appendix 10.5.3, we estimate industry-specific coefficients for both spillover-benefiting and spilloverproducing industries and then compare them to a set of available industry character-

\footnotetext{
${ }^{39}$ Shipbuilding stands out relative to the other industries because it is particularly reliant on local geography.
} 
istics such as firm size, export and final goods sales shares, and labor or intermediate cost shares. With only 23 estimated industry coefficients we cannot draw strong conclusions from these relationships. However, our results do suggest several interesting patterns. The only clear result is that industries that benefit from or produce spillovers for other industries using occupationally-similar labor pools tend to have a higher labor cost to sales ratio, a finding that seems very reasonable. We also observe a consistent negative relationship between firm size and all types of inter-industry connections. While this relationship is not statistically significant, it is consistent across all spillover types and it fits well with previous work highlighting the importance of inter-industry connections for smaller firms (e.g., Chinitz (1961)).

In Appendix 10.5.3 we look at how the estimated industry-specific within-industry coefficients are related to industry characteristics. With such a small number of industry coefficients we cannot draw strong conclusions from these results. However, we do observe some evidence that within-industry connections are more important in industries with larger firm sizes, which contrasts with the consistent negative relationship that we observe between firm size and cross-industry spillovers.

While the analysis described above focuses on spillovers occurring within cities, we have also explored the possibility that there may be important cross-city effects. To explore cross-city effects, we have run additional regressions including variables measuring market size as well as cross-industry spillovers occurring across cities. Our results, reported in Appendix 10.5.8, suggest that cross-city effects are much weaker than within-city forces. This makes sense given that we think that the shape of cities reflects the rapidly decaying strength of local agglomeration forces. We also find that accounting for cross-city effects has little impact on our estimates of the strength of within-city agglomeration forces.

\section{Strength of the agglomeration forces}

In this section we examine the relationship between city size and city-industry growth and show how our city-year effects can be used to construct a summary measure of the aggregate strength of the many cross-industry agglomeration forces present in our model. In standard urban models, the impact of agglomeration forces is balanced

by congestion forces related to city size, operating through channels such as higher 
housing prices or greater commute times. In our model, we have been largely agnostic about the form of the congestion forces, which will be captured primarily by the city-time effects. Thus, examining these estimated city-time coefficients offers an opportunity for assessing the net impact of dynamic congestion or agglomeration force related to overall city size. ${ }^{40}$ Also, the difference between these estimated citytime effects and city growth rates must be due to the impact of the agglomeration forces in the estimation equation. As a result, comparing the estimated city-time effects to actual city growth rates allows us to quantify the combined strength of the many cross-industry agglomeration forces captured by our measures.

To gain some intuition into this comparative exercise, consider the graphs in Figure 2. The dark blue diamond symbols in each graph describe, for each decade starting in 1861, the relationship between the actual growth rate of city working population and the log of city population at the beginning of the decade. The slopes of the fitted lines for these series fluctuate close to zero, suggesting that on average Gibrat's Law holds for the cities in our data.

We want to compare the relationship between city size and city growth in the actual data, as shown by the dark blue diamonds in Figure 2, to the relationship between these variables obtained while controlling for within and cross-industry agglomeration forces. This can be done using the estimated city-time effects represented by $\theta_{c t}$ in Eq. 9. The red squares in Figure 2 describe the relationship between the estimated city-year coefficients for each decade, $\hat{\theta}_{c t}$, and the log of city population at the beginning of each decade. In essence, these are showing us the relationship between city size and city growth after controlling for national industry growth trends and the agglomeration forces included in our model.

We can draw three lessons from these graphs. First, in all years the fitted lines based on the $\hat{\theta}_{c t}$ terms slope downward more steeply than the fitted lines for actual city growth. This suggests that, once we control for cross-industry agglomeration forces, city size is negatively related to city growth, consistent with the idea that there are dynamic city-size congestion forces. Second, the difference between the slopes of the two fitted lines can be interpreted as the aggregate effect of the various agglomeration forces in our model averaged across cities. Put simply, if we can add up the strength of the convergence force in any period and compare it to the actual

\footnotetext{
${ }^{40}$ These results will reflect only the net impact of city size, including both congestion and agglomeration forces.
} 
Figure 2: City size and city growth
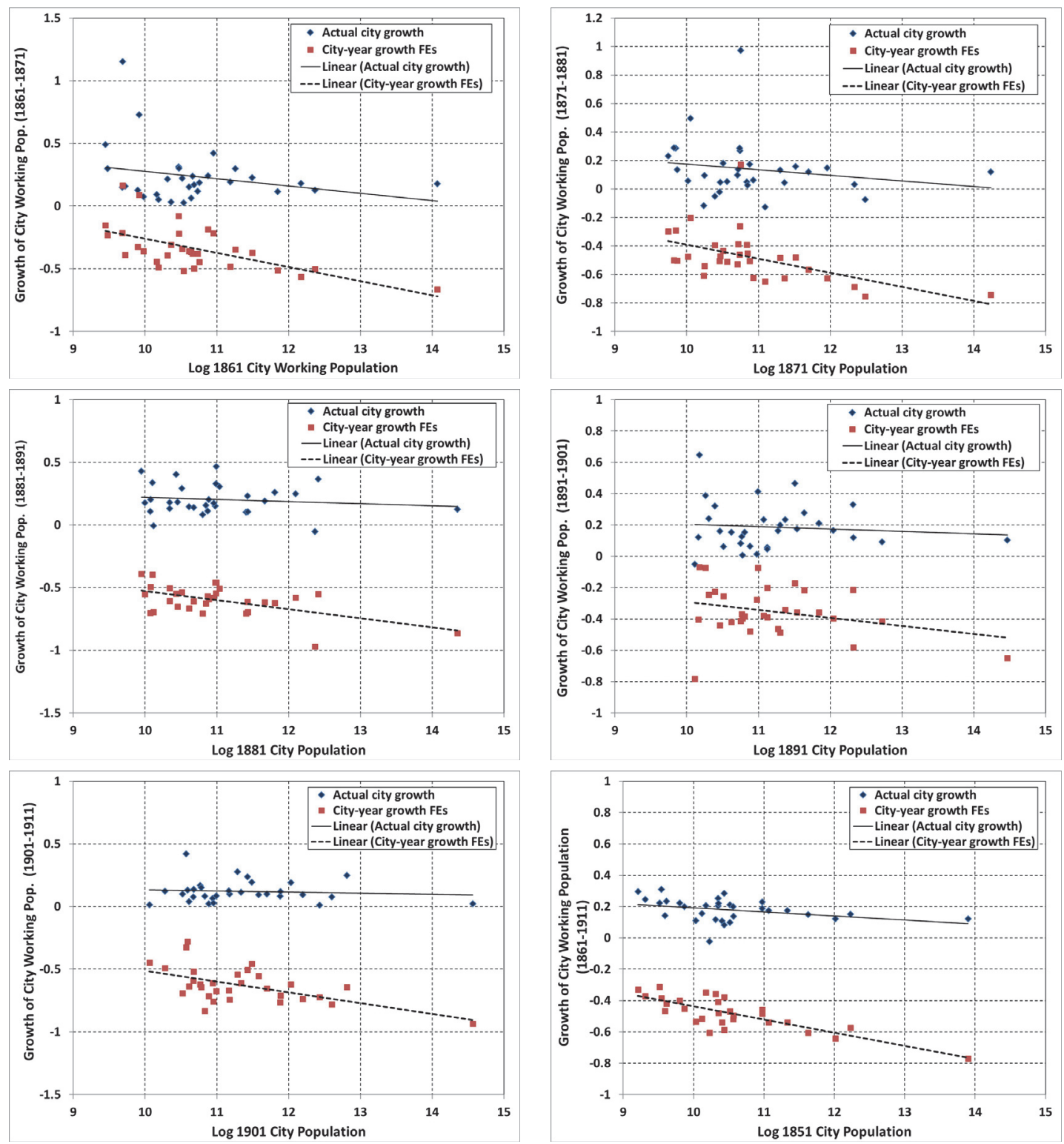

Solid lines: Fitted lines comparing actual city growth over a decade to the log of city size at the beginning of the decade. Dotted lines: Fitted lines comparing estimated coefficients from citytime effects for each decade to the log of city size at the beginning of the decade. Blue diamonds: Plot the actual city growth over a decade against the log of city population at the beginning of the decade. Red squares: Plot the estimated city-time coefficients over the same decade (the $\theta_{c t}$ terms estimated using Eq. 9) against the log of city population at the beginning of the decade. The bottom right-hand panel compares the log of city population in 1851 to the average of city growth rates over the entire 1861-1911 period and the average of city-time fixed effects across the entire 1861-1911 period. 
pattern of city growth, then the difference must be equal to the strength of the agglomeration forces. Third, the patterns described in Figure 2 appear to be close to linear in logs, suggesting that these forces do not differ dramatically across different city sizes.

The strength of these effects can be quantified in terms of the implied convergence rate following the approach of Barro \& Sala-i Martin (1992). We run,

$$
\begin{aligned}
& \hat{\theta}_{c t}=a_{0}+a_{1} \ln \left(L_{c t}\right)+\epsilon_{c t} \\
& \tilde{\theta}_{c t}=b_{0}+b_{1} \ln \left(L_{c t}\right)+\epsilon_{c t}
\end{aligned}
$$

where $\hat{\theta}_{c t}$ is the estimated city-time effect for the decade from $t$ to $t+1$ from a regression based on Eq. 9 (but omitting the within terms, which clearly represent a convergence rather than a divergence force), $L_{c t}$ is the working population of the city in year $t$, and $\tilde{\theta}_{c t}$ is the industry-demeaned growth rate of city $c$ from $t$ to $t+1 .^{41}$ These regressions are run separately for each decade from 1861 to 1911, either with or without weighting each observation by initial city-industry employment, and using lagged values as instruments as in the main results. Convergence rates are then calculated using the estimated $a_{1}$ and $b_{1}$ coefficients. A comparison of the $a_{1}$ and $b_{1}$ coefficients describes, at the city level, the impact of accounting for cross-industry spillovers.

Results based on unweighted regressions are presented in the top panel of Table 2. The two left-hand columns describe the results from Equation 10 and the annualized city-size divergence rate implied by these estimates. The next two columns describe similar results based on Equation 11. The difference between these two city-size divergence rates, given in the right-hand column, describes the aggregate strength of the agglomeration force reflected in the cross-industry terms. These results suggest that the strength of city agglomeration forces, in terms of the implied divergence rate, was 2.0-2.3\% per decade. In the bottom panel of Table 2 we calculate similar results except that the $\hat{\theta}_{c t}$ terms are obtained using regressions in which each observation is weighted based on the employment in the city-industry at the beginning of each period. These results suggest a slightly weaker agglomeration force, equal to an

\footnotetext{
${ }^{41}$ I.e., $\tilde{\theta}_{c t}$ is the estimated value of $\theta_{c t}$ obtained from the regression $\triangle \ln \left(L_{i c t+1}\right)=\theta_{c t}+\chi_{i t}+e_{i c t}$.
} 
implied divergence rate of $1.6-1.7 \%$ per decade.

Table 2: Aggregate strength of the agglomeration forces

Results based on un-weighted regressions

\begin{tabular}{|c|c|c|c|c|c|}
\hline & \multicolumn{2}{|c|}{ Results based on $\theta$ ct } & \multicolumn{2}{|c|}{ Results for actual city growth } & \multirow{2}{*}{$\begin{array}{l}\text { Aggregate strength of } \\
\text { agglomeration force } \\
\text { (implied divergence } \\
\text { rate per decade) }\end{array}$} \\
\hline & $\begin{array}{l}\text { Estimated } \\
\text { city-size } \\
\text { coefficient }\end{array}$ & $\begin{array}{c}\text { Implied } \\
\text { divergence } \\
\text { Beta }\end{array}$ & $\begin{array}{l}\text { Estimated } \\
\text { city-size } \\
\text { coefficient }\end{array}$ & $\begin{array}{c}\text { Implied } \\
\text { divergence } \\
\text { Beta }\end{array}$ & \\
\hline $1861-1871$ & -0.076 & $7.86 \%$ & -0.056 & $5.71 \%$ & $2.15 \%$ \\
\hline $1871-1881$ & -0.062 & $6.38 \%$ & -0.042 & $4.26 \%$ & $2.12 \%$ \\
\hline 1881-1891 & -0.035 & $3.60 \%$ & -0.015 & $1.53 \%$ & $2.07 \%$ \\
\hline 1891-1901 & -0.014 & $1.43 \%$ & 0.006 & $-0.61 \%$ & $2.04 \%$ \\
\hline $1901-1911$ & -0.046 & $4.70 \%$ & -0.023 & $2.37 \%$ & $2.33 \%$ \\
\hline
\end{tabular}

Results based on regressions weighted by city-industry size in 1851

\begin{tabular}{|c|c|c|c|c|c|}
\hline & Results based & on $\theta$ ct & Results for acts & l city growth & Aggregate strength of \\
\hline & $\begin{array}{l}\text { Estimated city- } \\
\text { size coefficient }\end{array}$ & $\begin{array}{c}\text { Implied } \\
\text { divergence } \\
\text { Beta }\end{array}$ & $\begin{array}{l}\text { Estimated } \\
\text { city-size } \\
\text { coefficient }\end{array}$ & $\begin{array}{c}\text { Implied } \\
\text { divergence } \\
\text { Beta }\end{array}$ & $\begin{array}{l}\text { agglomeration force } \\
\text { (implied divergence } \\
\text { rate per decade) }\end{array}$ \\
\hline 1861-1871 & -0.066 & $6.86 \%$ & -0.051 & $5.23 \%$ & $1.63 \%$ \\
\hline $1871-1881$ & -0.052 & $5.29 \%$ & -0.036 & $3.61 \%$ & $1.67 \%$ \\
\hline $1881-1891$ & -0.037 & $3.79 \%$ & -0.021 & $2.13 \%$ & $1.66 \%$ \\
\hline $1891-1901$ & -0.026 & $2.64 \%$ & -0.010 & $1.00 \%$ & $1.64 \%$ \\
\hline $1901-1911$ & -0.018 & $1.86 \%$ & -0.002 & $0.20 \%$ & $1.65 \%$ \\
\hline
\end{tabular}

Column 1 presents the $a_{1}$ coefficients from estimating Equation 10 for each decade (cross-sectional regressions). Column 2 presents the decadal convergence rates implied by these coefficients. Column 3 presents the $b_{1}$ coefficients from estimating Equation 11 and Column 4 presents the decadal divergence rates implied by these coefficients. Column 5 gives the aggregate strength of the divergence force due to the agglomeration economies, which is equal to the difference between the decadal divergence coefficients in Columns 2 and 4. Results in the top panel are unweighted, while results in the bottom panel are from regressions in which each city-industry observation is weighted by the employment in that city-industry at the beginning of the period.

We can use a similar exercise to estimate the aggregate strength of the convergence force due to within-industry effects. We begin by estimating,

$$
\triangle \ln \left(L_{i c t+1}\right)=\tilde{\tau}_{i i} \ln \left(L_{i c t}\right)+\theta_{c t}^{W I T H I N}+\chi_{i t}+e_{i c t} .
$$

which is just Eq. 9 with the cross-industry terms omitted. Next, we use the estimated values of $\theta_{c t}^{W I T H I N}$ to estimate, 


$$
\hat{\theta}_{c t}^{W I T H I N}=d_{0}+d_{1} \ln \left(L_{c t}\right)+\epsilon_{c t} .
$$

We then calculate the convergence force associated with the within-industry terms using the same approach that we used previously, i.e. we compare the $d_{1}$ coefficients with the slopes estimated using Eq. 11. Table 3 describes the results. The negative measured divergence force in this table highlights that within-industry effects, on net, act as a convergence force. The strength of this force is sensitive to whether the regressions are weighted, which suggests that the negative within-industry employment effects are likely to vary with initial city-industry employment.

Table 3: Aggregate strength of convergence forces due to the within-industry effects

\section{Results based on un-weighted regressions}

\begin{tabular}{|c|c|c|c|c|c|}
\hline & \multicolumn{2}{|c|}{ Results based on $\theta^{\text {WITHIN }}$} & \multicolumn{2}{|c|}{ Results for actual city growth } & \multirow{2}{*}{$\begin{array}{l}\text { Aggregate strength of } \\
\text { agglomeration force } \\
\text { (implied divergence } \\
\text { rate per decade) }\end{array}$} \\
\hline & $\begin{array}{l}\text { Estimated city-size } \\
\text { coefficient }\end{array}$ & $\begin{array}{c}\text { Implied } \\
\text { divergence } \\
\text { Beta }\end{array}$ & $\begin{array}{c}\text { Estimated city- } \\
\text { size } \\
\text { coefficient }\end{array}$ & $\begin{array}{c}\text { Implied } \\
\text { divergence } \\
\text { Beta }\end{array}$ & \\
\hline $1861-1871$ & -0.004 & $0.43 \%$ & -0.056 & $5.71 \%$ & $-5.28 \%$ \\
\hline $1871-1881$ & 0.009 & $-0.87 \%$ & -0.042 & $4.26 \%$ & $-5.13 \%$ \\
\hline $1881-1891$ & 0.034 & $-3.38 \%$ & -0.015 & $1.53 \%$ & $-4.91 \%$ \\
\hline $1891-1901$ & 0.056 & $-5.41 \%$ & 0.006 & $-0.61 \%$ & $-4.80 \%$ \\
\hline $1901-1911$ & 0.025 & $-2.48 \%$ & -0.023 & $2.37 \%$ & $-4.85 \%$ \\
\hline
\end{tabular}

Results based on regressions weighted by city-industry size in 1851

\begin{tabular}{|c|c|c|c|c|c|}
\hline & Results based & on $\theta^{\text {WITHIN }}$ & Results for ac & al city growth & Aggregate strength of \\
\hline & $\begin{array}{l}\text { Estimated city } \\
\text { size coefficient }\end{array}$ & $\begin{array}{c}\text { Implied } \\
\text { divergence } \\
\text { Beta }\end{array}$ & $\begin{array}{l}\text { Estimated } \\
\text { city-size } \\
\text { coefficient }\end{array}$ & $\begin{array}{c}\text { Implied } \\
\text { divergence } \\
\text { Beta } \\
\end{array}$ & $\begin{array}{c}\text { agglomeration force } \\
\text { (implied divergence } \\
\text { rate per decade) }\end{array}$ \\
\hline $1861-1871$ & -0.048 & $4.91 \%$ & -0.051 & $5.23 \%$ & $-0.33 \%$ \\
\hline $1871-1881$ & -0.033 & $3.38 \%$ & -0.036 & $3.61 \%$ & $-0.24 \%$ \\
\hline $1881-1891$ & -0.019 & $1.92 \%$ & -0.021 & $2.13 \%$ & $-0.21 \%$ \\
\hline $1891-1901$ & -0.008 & $0.81 \%$ & -0.010 & $1.00 \%$ & $-0.20 \%$ \\
\hline 1901-1911 & 0.000 & $-0.01 \%$ & -0.002 & $0.20 \%$ & $-0.21 \%$ \\
\hline
\end{tabular}

Column 1 presents the $d_{1}$ coefficients from estimating Equation 13 for each decade (cross-sectional regressions). Column 2 presents the decadal divergence rates implied by these coefficients. Column 3 presents the $b_{1}$ coefficients from estimating Equation 11 and Column 4 presents the decadal divergence rates implied by these coefficients. Column 5 gives the aggregate strength of the divergence force due to the agglomeration economies, which is equal to the difference between the decadal convergence coefficients. The negative values in Column 5 indicate that within-industry effects are, on net, a source of convergence across cities. Results in the top panel are unweighted, while results in the bottom panel are from regressions in which each city-industry observation is weighted by the employment in that city-industry at the beginning of the period. 
One caveat to keep in mind when assessing these results is that there are likely to be agglomeration forces not captured by our estimation, which would lead us to understate the strength of the agglomeration forces. Also, some congestion forces may also be captured by our cross-industry terms. Similarly, there may be some agglomeration forces captured by the within-industry terms, which will also not be reflected in our results. Thus, the strength of the cross-industry agglomeration force measured here is likely to be a lower bound on the true values.

\section{Conclusion}

In the introduction, we posed a number of questions about the nature of localized agglomeration forces. The main contribution of this study is to provide a theoretically grounded empirical approach that can be used to address these questions and the detailed city-industry panel data needed to implement it. We can now provide some answers for the particular empirical setting that we study. First, we find evidence that cross-industry agglomeration economies were more important than within-industry agglomeration forces for generating city employment growth. Within-industry effects are, on net, generally negative. This suggests that local clusters of firms working in the same industry, which have attracted substantial attention, are unlikely to deliver dynamic benefits. Second, our results suggest that industries grow more rapidly when they co-locate with their suppliers or with other industries that use occupationallysimilar workforces. This result is in line with arguments made by Jacobs (1969), as well as recent empirical findings. We document a clear negative relationship between city size and city growth that appears once we account for agglomeration forces related to a city's industrial composition. This suggests that Gibrat's law is generated by a balance between agglomeration and dispersion forces. An estimate of the overall strength of the agglomeration forces captured by our approach, in terms of the implied annual divergence rate in city size, is $1.6-2.3 \%$ per decade.

The techniques introduced in this paper can be applied in any setting where sufficiently rich long-run city-industry panel data can be constructed. Recent work has made progress in constructing data of this type for the U.S. in both the modern and historical period. Applying our approach to these emerging data sets is another promising avenue for future work. 


\section{Acknowledgments and Funding Sources}

We thank David Albouy, Pierre-Philippe Combes, Dora Costa, Don Davis, Jonathan Dingel, Gilles Duranton, Glenn Ellison, Ben Faber, Pablo Fajgelbaum, Edward Glaeser, Laurent Gobillon, Richard Hornbeck, Matt Kahn, Petra Moser, Alex Whalley and seminar participants at Columbia, UCLA, Harvard, UC Merced, UC San Diego, the NBER Innovation group, the NBER Urban Economics group, the CURE conference at Brown University, and the Urban Economics Association Annual Conference, for helpful comments and suggestions. Reed Douglas provided excellent research assistance. Funding for this project was provided by a grant from UCLA's Ziman Center for Real Estate and the National Science Foundation (CAREER Grant No. 1552692). 


\section{References}

Albouy, David. 2009. The Unequal Geographic Burden of Federal Taxation. Journal of Political Economy, 117(4), pp. 635-667.

Amiti, Mary, \& Cameron, Lisa. 2007. Economic Geography and Wages. Review of Economics and Statistics, 89(1), pp. 15-29.

Arellano, Manuel, \& Bond, Stephen. 1991. Some tests of specification for panel data: Monte Carlo evidence and an application to employment equations. The Review of Economic Studies, 58(2), $277-297$.

Baines, Dudley. 1985. Migration in a Mature Economy. Cambridge, UK: Cambridge University Press.

Baines, Dudley. 1994. Population, Migration and Regional Development, 1870-1939. In: Floud, R, \& McCloskey, D (eds), The Economic History of Britain Since 1700, second edition edn. Cambridge University Press.

Balsvik, Ragnhild. 2011. Is labor mobility a channel for spillovers from multinationals? Evidence from Norwegian manufacturing. Review of Economics and Statistics, 93(1), 285-297.

Barrios, Thomas, Diamond, Rebecca, Imbens, Guido, \& Kolesar, Michal and. 2012. Clustering, Spatial Correlations and Randomized Inference. Journal of the American Statistical Association, 107(498), 578-591.

Barro, Robert J. 2015. Convergence and Modernisation. Economic Journal, 125(585), 911 - 942.

Barro, Robert J., \& Sala-i Martin, Xavier. 1992. Convergence. Journal of Political Economy, 100(2), pp. 223-251.

Bartik, Timothy J. 1991. Who Benefits from State and Local Economic Development Policies? Kalamazoo, MI: W.E. Upjohn Institute for Employment Research.

Beach, B., \& Hanlon, W.W. 2016 (June). Coal Smoke and Mortality in an Early industrial Economy. Mimeo.

Bertrand, Marianne, Duflo, Esther, \& Mullainathan, Sendhil. 2004. How Much Should We Trust Differences-in-Differences Estimates? The Quarterly Journal of Economics, 119(1), pp. 249-275.

Bleakley, Hoyt, \& Lin, Jeffrey. 2012. Portage: Path Dependence and Increasing Returns in U.S. History. Quarterly Journal of Economics, 127(May), 587-644.

Blundell, Richard, \& Bond, Stephen. 1998. Initial Conditions and Moment Restrictions in Dynamic Panel Data Models. Journal of Econometrics, 87(1), 115 - 143.

Cameron, A. C., Gelbach, J.B., \& Milller, D. L. 2011. Robust Inference with Multi-Way Clustering. Journal of Business and Economic Statistics, 29(2), 238-249.

Caselli, Francesco, Esquivel, Gerardo, \& Lefort, Fernando. 1996. Reopening the Convergence Debate: A New Look at Cross-Country Growth Empirics. Journal of Economic Growth, 1(3), pp. 363-389.

Chay, Kenneth Y., \& Greenstone, Michael. 2005. Does Air Quality Matter? Evidence from the Housing Market. Journal of Political Economy, 113(2), pp. 376-424.

Chinitz, Benjamin. 1961. Contrasts in Agglomeration: New York and Pittsburgh. The American Economic Review, 51(2), pp. 279-289.

Combes, Pierre-Philippe. 2000. Economic Structure and Local Growth: France, 1984-1993. Journal 
of Urban Economics, 47(3), 329 - 355.

Combes, Pierre-Philippe, \& Gobillon, Laurent. 2015. The Empirics of Agglomeration Economies. Pages pp. 247-348 of: Duranton, Gilles, Henderson, Vernon, \& Strange, William (eds), Handbook of Urban and Regional Economics, vol. 5. Elsevier.

Combes, Pierre-Philippe, Duranton, Gilles, \& Gobillon, Laurent. 2008. Spatial Wage Disparities: Sorting Matters!. Journal of Urban Economics, 63(2), 723 - 742.

Combes, Pierre-Philippe, Duranton, Gilles, \& Gobillon, Laurent. 2011. The Identification of Agglomeration Economies. Journal of Economic Geography, 11(2), 253 - 266.

Combes, Pierre-Philippe, Duranton, Gilles, Gobillon, Laurent, Puga, Diego, \& Roux, Sebastien. 2012. The Productivity Advantages of Large Cities: Distinguishing Agglomeration from Firm Selection. Econometrica, 80(6), pp. 2543-2594.

Conley, Timothy G. 1999. GMM Estimation with Cross Sectional Dependence. Journal of Econometrics, 92(1), $1-45$.

Crafts, Nicholas, \& Mulatu, Abay. 2006. How Did the Location of Industry Respond to Falling Transport Costs in Britain before World War I? The Journal of Economic History, 66(3), pp. 575-607.

Davis, Donald R, \& Weinstein, David E. 2002. Bones, bombs, and break points: The geography of economic activity. American Economic Review, 92(5), 1269-1289.

Dekle, Robert. 2002. Industrial Concentration and Regional Growth: Evidence from the Prefectures. The Review of Economics and Statistics, 84(2), pp. 310-315.

Desmet, Klaus, \& Rappaport, Jordan. Forthcoming. The Settlement of the United States, 1800-2000: The Long Transition Towards Gibrat's Law. Journal of Urban Economics.

Dittmar, Jeremiah E. 2011 (August). Cities, Markets, and Growth: The Emergence of Zipf's Law. Working Paper.

Dix-Carneiro, Rafael, \& Kovak, Brian. 2015 (January). Trade Reform and Regional Dynamics: Evidence from 25 Years of Brazilian Matched Employer-Employee Data. NBER Working Paper No. 20908.

Dumais, Guy, Ellison, Glenn, \& Glaeser, Edward L. 1997 (November). Geographic Concentration as a Dynamic Process. NBER Working Paper No. 6720.

Dumais, Guy, Ellison, Glenn, \& Glaeser, Edward L. 2002. Geographic Concentration as a Dynamic Process. The Review of Economics and Statistics, 84(2), pp. 193-204.

Duranton, Gilles. 2007. Urban Evolutions: The Fast, the Slow, and the Still. American Economic Review, 97(1), 197-221.

Duranton, Gilles, Morrow, Peter M., \& Turner, Matthew A. 2014. Roads and Trade: Evidence from the US. The Review of Economic Studies, 81(2), 681-724.

Ellison, G., Glaeser, E., \& Kerr, W. 2010. What Causes Industry Agglomeration? Evidence from Coagglomeration Patterns. American Economic Review, 100(3), pp. 1195-1213.

Ellison, Glenn, \& Glaeser, Edward L. 1997. Geographic concentration in US manufacturing industries: A dartboard approach. Journal of Political Economy, 105(5), 889-927.

Faggio, Guilia, Silva, Olmo, \& Strange, William. Forthcoming. Heterogeneous Agglomeration. Review of Economics and Statistics. 
Glaeser, Edward L., \& Mare, David C. 2001. Cities and Skills. Journal of Labor Economics, 19(2), pp. 316-342.

Glaeser, Edward L, Kallal, Hedi D, Scheinkman, Jose A, \& Shleifer, Andrei. 1992. Growth in Cities. Journal of Political Economy, 100(6), 1126-1152.

Greenstone, Michael, \& Moretti, Enrico. 2003 (July). Bidding for Industrial Plants: Does Winning a 'Million Dollar Plant' Increase Welfare? NBER Working Paper No. 9844.

Greenstone, Michael, Hornbeck, Richard, \& Moretti, Enrico. 2010. Identifying Agglomeration Spillovers: Evidence from Million Dollar Plants. Journal of Political Economy, 118(3), pp. $536-598$.

Gyourko, Joseph, Saiz, Albert, \& Summers, Anita. 2008. A new measure of the local regulatory environment for housing markets: The Wharton Residential Land Use Regulatory Index. Urban Studies, 45(3), 693-729.

Hanson, Gordon H. 2005. Market potential, increasing returns and geographic concentration. Journal of International Economics, 67(1), 1 - 24.

Hauk Jr., William R., \& Wacziarg, Romain. 2009. A Monte Carlo Study of Growth Regressions. Journal of Economic Growth, 14(2), pp. 103-147.

Henderson, J. Vernon. 1996. Effects of Air Quality Regulation. The American Economic Review, 86(4), pp. 789-813.

Henderson, J Vernon. 1997. Externalities and Industrial Development. Journal of Urban Economics, 42(3), 449-470.

Henderson, V, Kuncoro, A, \& Turner, M. 1995. Industrial Development in Cities. Journal of Political Economy, 103(5), 1067-1090.

Horrell, Sara, Humphries, Jane, \& Weale, Martin. 1994. An Input-Output Table for 1841. Economic History Review, 47(3), 545-566.

Hurwicz, Leonid. 1950. Least-Squares Bias in Time Series. In: Koopmans, Tjalling C. (ed), Statistical Inference in Dynamic Economic Models. New York: Wiley.

Jacks, David S., Meissner, Christopher M., \& Novy, Dennis. 2008. Trade Costs, 1870-2000. The American Economic Review, Papers 83 Proceedings, 98(2), pp. 529-534.

Jacobs, Jane. 1969. The Economy of Cities. New York: Vintage Books.

Javorcik, Beata S. 2004. Does Foreign Direct Investment Increase the Productivity of Domestic Firms? In Search of Spillovers through Backward Linkages. The American Economic Review, 94(3), 605-627.

Jones, Ronald W. 1975. Income Distribution and Effective Protection in a Multicommodity Trade Model. Journal of Economic Theory, 11(1), 1 - 15.

Kim, Sukkoo. 1995. Expansion of Markets and the Geographic Distribution of Economic Activities The Trends in US Regional Manufacturing Structure, 1860-1987. Quarterly Journal of Economics , 110(4), 881-908.

Kleibergen, Frank, \& Paap, Richard. 2006. Generalized Reduced Rank Tests Using the Singular Value Decomposition. Journal of Econometrics, 133, 97-126.

Kleibergen, F. ans Schaffer, M.E. 2010. Rankest: Module for Testing the Rank of a Matrix using the Kleibergen-Paap rk Statistic. Available at: http://ideas.repec.org/c/boc/bocode/s456865.html. 
Kline, Patrick, \& Moretti, Enrico. 2013. Local Economic Development, Agglomeration Economies, and the Big Push: 100 Years of Evidence from the Tennessee Valley Authority. Quarterly Journal of Economics.

Kovak, Brian K. 2013. Regional Effects of Trade Reform: What is the Correct Measure of Liberalization? American Economic Review, 103(5), 1960-1976.

Kugler, Maurice. 2006. Spillovers from Foreign Direct Investment: Within or Between Industries? Journal of Development Economics, 80(2), 444-477.

Lee, C.H. 1984. The service sector, regional specialization, and economic growth in the Victorian economy. Journal of Historical Geography, 10(2), 139 - 155.

Lee, Jamie. 2015 (January). Measuring Agglomeration: Products, People and Ideas in U.S. Manufacturing, 1880-1990. Mimeo.

Long, Jason, \& Ferrie, Joseph. 2003. Labour Mobility. In: Mokyr, Joel (ed), Oxford Encyclopedia of Economic History. New York: Oxford University Press.

Long, Jason, \& Ferrie, Joseph. 2004 (March). Geographic and Occupational Mobility in Britain and the U.S., 1850-1881. Working Paper.

Lopez, R, \& Sudekum, J. 2009. Vertical Industry Relations, Spillovers, and Productivity: Evidence from Chilean Plants. Journal of Regional Science, 49(4), pp. 721-747.

Lucas, Robert E. 1988. On the Mechanics of Economic Development. Journal of Monetary Economics, 22(1), 3-42.

Marshall, Alfred. 1890. Principles of Economics. New York: Macmillan and Co.

Michaels, Guy, Rauch, Ferdinand, \& Redding, Stephen. 2013 (January). Task Specialization in U.S. Cities from 1880-2000. NBER Working Paper No. 18715.

Nickell, Stephen. 1981. Biases in Dynamic Models with Fixed Effects. Econometrica, 49(6), pp. 1417-1426.

Platt, R.H. 1996. Land Use and Society. Washington, DC: Island Press.

Poole, Jennifer P. 2013. Knowledge Transfers from Multinational to Domestic Firms: Evidence from Worker Mobility. The Review of Economics and Statistics, 95(2).

Romer, PM. 1986. Increasing Returns and Long-run Growth. Journal of Political Economy, 94(5), 1002-1037.

Rosenthal, S., \& Strange, W. 2004. Evidence on the Nature and Sources of Agglomeration Economies. In: Henderson, JV., \& Thisse, JF. (eds), Handbook of Regional and Urban Economics. Elsevier.

Rosenthal, Stuart S, \& Strange, William C. 2001. The Determinants of Agglomeration. Journal of Urban Economics, 50(2), 191-229.

Rosenthal, Stuart S., \& Strange, William C. 2003. Geography, Industrial Organization, and Agglomeration. The Review of Economics and Statistics, 85(2), pp. 377-393.

Thomas, Mark. 1987. An Input-Output Approach to the British Economy, 1890-1914. Ph.D. thesis, Oxford University.

Thompson, Samuel B. 2011. Simple Formulas for Standard Errors that Cluster by both Firm and Time. Journal of Financial Economics, 99(1), 1 - 10.

Thorsheim, Peter. 2006. Inventing Pollution. Athens, Ohio: Ohio University Press. 


\section{Appendix (For Online Publication Only)}

\subsection{Theory appendix}

The main text presents a simple theoretical framework used to motivate our analysis. In this appendix, we show that we can add additional complexity to the model without substantially changing the final estimating equation. In particular, we introduce capital and intermediate inputs into the production function. The new production function is,

$$
x_{i c f t}=A_{i c t} L_{i c f t}^{\alpha} K_{i c f t}^{\beta} I_{i c f t}^{\gamma} R_{i c f t}^{1-\alpha-\beta-\gamma},
$$

where we have introduced capital inputs, $K_{i c f t}$, and intermediate inputs $I_{i c f t}$, into the production function, while retaining the same basic Cobb-Douglas structure. The parameters $\alpha, \beta$, and $\gamma$ determine the relative importance of these inputs in the production process of each industry. For now, we make the simplifying assumption that these parameters are constant across all industries, but at the end of this section we discuss the possibility that they may differ across industries. In this extended model, we make the same assumptions about technology, labor and resources as in the baseline model.

Capital is mobile across locations with a national price given by $r_{t}$. The overall supply of capital in the economy is $\bar{K}_{t}$. While we could model the evolution of this object, doing so would merely distract from the key focus of our theory. ${ }^{42}$ Thus, to keep things simple we take the overall supply of capital in any given period as exogenously given. The income from capital is assumed to be spread evenly across individuals.

The set of intermediate inputs used in production differs across industries, but within each industry, all firms use inputs in the same fixed proportions. Because we assume free trade, this feature is a result, rather than an assumption. Let Z be an input-output matrix, with element $z_{i j}$ such that $I_{i t}$ units of intermediate input to industry $i$ requires $I_{i t} z_{i j}$ units of output from industry $j$, i.e., the production function

\footnotetext{
${ }^{42}$ Moreover, the substantial level of international capital flows that took place during the period that we study suggest that a closed economy model of the evolution of this quantity may be inappropriate for the empirical setting.
} 
for intermediate inputs is Leontief. Then total intermediate demand for the output from industry $j$ is equal to $x_{j t}^{I O}=\sum_{i} I_{i t} z_{i j}$. With costless trade, each industry will face a national-level industry-specific intermediate input price in each period, denoted $q_{i t}$.

The resulting firm optimization problem is,

$$
\max _{L_{i c f t}, K_{i c f t}, I_{i c f t}, R_{i c f t}} p_{i t} A_{i c t} L_{i c f t}^{\alpha} K_{i c f t}^{\beta} I_{i c f t}^{\gamma} R_{i c f t}^{1-\alpha-\beta-\gamma}-\bar{w}_{t} \lambda_{c t} L_{i c f t}-r_{t} K_{i c f t}-q_{i t} I_{i c f t}-d_{i c t} R_{i c f t} .
$$

Using the first order conditions, and summing over all firms in a city-industry, we obtain the following expression for employment in industry $i$ and location $c$,

$$
L_{i c t}=A_{i c t}^{\rho} p_{i t}^{\rho}\left(\frac{\alpha}{\bar{w}_{t} \lambda_{c t}}\right)^{\rho(1-\beta-\gamma)}\left(\frac{\beta}{r_{t}}\right)^{\rho \beta}\left(\frac{\gamma}{q_{i t}}\right)^{\rho \gamma} \bar{R}_{i c},
$$

where $\rho=1 /(1-\gamma-\beta-\alpha)>0$. This expression tells us that, as in the baseline model, employment in any industry $i$ and location $c$ will depend on technology in that industry-location, the fixed resource endowment for that industry-location, factors that affect the industry in all locations $\left(p_{i t}, q_{i t}\right)$, city-specific factors $\left(\lambda_{c t}\right)$, and factors that affect the economy as a whole $\left(\bar{w}_{t}, r_{t}\right)$. Note that $\rho$ represents the inverse of the exponent on fixed city-industry resources. Thus, we can see that the impact of a city-specific shock that increases costs (higher $\lambda_{c t}$ ) on city-industry employment will be greater the less important are fixed city-industry resources in production, i.e., when industries are able to more easily move production to other cities.

Equilibrium within a period is defined as the set of prices $\left\{P_{t}, p_{i t}, r_{t}, q_{i t}, d_{i c t}\right\}$ and quantities $\left\{D_{t}^{F}, x_{i c t}, L_{i c f t}, K_{i c f t}, I_{i c f t}, R_{i c f t}\right\}$ such that given the set of technologies $\left\{A_{i c t}\right\}$,

1) The first order conditions of the firm optimization problem are satisfied

2) Labor markets clear in each city, i.e., $\sum_{i} \sum_{f} L_{i c f t}=L_{c} t$ for all $c$

3) The capital market clears, i.e., $\sum_{c} \sum_{i} \sum_{f} K_{i c f t}=\bar{K}_{t}$

4) Local resource markets clear, i.e., $\sum_{f} R_{i c f t}=\bar{R}_{i c}$ for all $i$ and $c$

5) Output markets clear, i.e., $\sum_{c} \sum_{f} x_{i c f t}=x_{i t}=x_{t}^{F}+x_{i t}^{I O}$

6) Total income (after any savings) is equal to total final goods expenditures 
Equilibrium condition (6) requires that,

$$
D_{t} P_{t}+M_{t}+B_{t}=\sum_{c} \sum_{i} \bar{w}_{t} \lambda_{c t} L_{i c t}+\sum_{c} \sum_{i} r_{t} \bar{K}_{i c t}+\sum_{c} \sum_{i} d_{i c t} \bar{R}_{i c}
$$

where $M_{t}$ represents net expenditures on imports and $B_{t}$ represents the (exogenously given) amount of savings in the period. For a closed economy model we can set $M_{t}$ to zero and then solve for the equilibrium price levels in the economy. Alternatively, we can consider a (small) open economy case where prices are given and solve for $M_{t}$. We are agnostic between these two approaches.

We continue to use the same expression describing the evolution of technology as in the baseline model (Equation 4). Starting with Equation 14 for period $t+1$, taking logs, plugging in Equation 4, and then plugging in Equation 14 again (also in logs), we obtain,

$$
\begin{aligned}
\ln \left(L_{i c t+1}\right)-\ln \left(L_{i c t}\right) & =\rho S_{i c t}+\rho\left[\ln \left(p_{i t+1}\right)-\ln \left(p_{i t}\right)\right] \\
& -\rho(1-\beta-\gamma)\left[\ln \left(\lambda_{c t+1}\right)-\ln \left(\lambda_{c t}\right)\right] \\
& +\rho(1-\beta-\gamma)\left[\ln \left(\bar{w}_{t+1}\right)-\ln \left(\bar{w}_{t}\right)\right] \\
& -\rho \beta\left[\ln \left(r_{t+1}\right)-\ln \left(r_{t}\right)\right]+\rho \gamma\left[\ln \left(q_{i t+1}\right)-\ln \left(q_{i t}\right)\right]+e_{i c t} .
\end{aligned}
$$

where $e_{i c t}=\epsilon_{i c t+1}-\epsilon_{i c t}$ is the error term.

Finally, plugging Equation 6 into Equation 15, we obtain,

$$
\begin{aligned}
\ln \left(L_{i c t+1}\right)-\ln \left(L_{i c t}\right) & =\rho \tau_{i i} \ln \left(L_{i c t}\right)+\rho \sum_{k \neq i} \tau_{k i} \ln \left(L_{k c t}\right) \\
& +\rho\left[\ln \left(p_{i t+1}\right)-\ln \left(p_{i t}\right)\right] \\
& +\rho \gamma\left[\ln \left(q_{i t+1}\right)-\ln \left(q_{i t}\right)\right]+\rho \xi_{i t} \\
& +\rho(1-\beta-\gamma)\left[\ln \left(\lambda_{c t+1}\right)-\ln \left(\lambda_{c t}\right)\right]+\rho \psi_{c t} \\
& +\rho(1-\beta-\gamma)\left[\ln \left(\bar{w}_{t+1}\right)-\ln \left(\bar{w}_{t}\right)\right] \\
& +\rho \beta\left[\ln \left(r_{t+1}\right)-\ln \left(r_{t}\right)\right]+e_{i c t} .
\end{aligned}
$$


This expression mirrors the estimating equation given in Equation 7 up to the parameters $\rho, \beta$ and $\gamma$. As in our baseline estimating equation, the change in employment growth is expressed as a function of the initial level of employment, a set of national industry-specific factors, a set of city-specific factors that affect all industries, and national wage and capital rental rates that affect all industries and all cities.

We can use this expression to consider some of the assumptions made in the main text in more detail. First, consider the possibility that trade costs, rather than technology spillovers, might be driving the effects we observe. To represent this, suppose that we modified the model to incorporate trade costs while at the same time eliminating technology spillovers. Ignoring for now general equilibrium effects, Equation 16 tells us that trade costs will affect city-industries through either the price of inputs (e.g., through local suppliers) or the price of outputs (e.g., through market access). With trade costs, both the input and the output prices faced by firms in industry $i$ can vary across cities.

Now, focusing on the input prices side, suppose that there are two cities, A and $\mathrm{B}$, and that City A has many more of industry $i$ suppliers than city B so that the cost of intermediate inputs to industry $i$ is lower in City A than in City B. From Equation 14 we can see that, all else equal, this implies that employment in industry $i$ will be larger in City A than in City B in some initial period: this is static agglomeration. However, as we roll the model forward, Equation 15 shows that, absent other changes, industry $i$ will not grow faster in City A than in City B. In the absence of other effects, input-output connections alone cannot act as a dynamic agglomeration force. Where input-output connections can generate dynamic agglomeration is by transmitting the effects of other changes, such as falling transport costs. However, falling trade costs cannot be a sustained force of dynamic agglomeration, since trade costs are bounded below by zero and were fairly stable over at least part of the period we study. ${ }^{43}$ This suggests that input-output connections and trade costs can be an important static force, but these forces are unlikely to generate the dynamic agglomeration patters studied here.

In a world of static inter-industry agglomeration forces, the growth in industry $i$ must be driven by growth in industry $j$, rather than the level of industry $j$. But this

\footnotetext{
${ }^{43}$ Crafts \& Mulatu (2006) conclude that, "falling transport costs had only weak effects on the location of industry in the period 1870 to 1911." Jacks et al. (2008) find a rapid fall in external trade costs prior to 1880 , with a much slower decline thereafter.
} 
raises questions about the causes of the initial growth in industry $j$. Ultimately, a world of static agglomeration forces is a world of exogenous city-industry growth. In contrast, dynamic agglomeration offers an explanation for city industry growth, just as endogenous growth theory offers an explanation for aggregate growth.

\section{Variation in Industry Production Function Parameters}

A second interesting extension to consider is the possibility that the share of each input in the production function varies across industries. In particular, suppose that we allow the production function parameters to vary across industries. Indexing these parameters by $i$, we now have the following expression for city-industry employment growth,

$$
\begin{aligned}
\ln \left(L_{i c t+1}\right)-\ln \left(L_{i c t}\right) & =\rho_{i} \tau_{i i} \ln \left(L_{i c t}\right)+\rho_{i} \sum_{k \neq i} \tau_{k i} \ln \left(L_{k c t}\right) \\
& +\rho_{i}\left[\ln \left(p_{i t+1}\right)-\ln \left(p_{i t}\right)\right]+\rho_{i} \gamma_{i}\left[\ln \left(q_{i t+1}\right)-\ln \left(q_{i t}\right)\right]+\rho_{i} \xi_{i t} \\
& +\rho_{i}\left(1-\beta_{i}-\gamma_{i}\right)\left[\ln \left(\lambda_{c t+1}\right)-\ln \left(\lambda_{c t}\right)\right]+\rho_{i} \psi_{c t} \\
& +\rho_{i}\left(1-\beta_{i}-\gamma_{i}\right)\left[\ln \left(\bar{w}_{t+1}\right)-\ln \left(\bar{w}_{t}\right)\right] \\
& +\rho_{i} \beta_{i}\left[\ln \left(r_{t+1}\right)-\ln \left(r_{t}\right)\right]+e_{i c t} .
\end{aligned}
$$

We can see that the impact of spillovers on city-industry growth in this setting will depend on the industry-specific parameter $\rho_{i}$, where $\rho_{i}=1 /\left(1-\gamma_{i}-\beta_{i}-\alpha_{i}\right)>0$. This parameter is the inverse of the exponent on local resources. Thus, the more important are fixed local resources in the production process, the weaker will be the impact of spillover on city-industry employment growth. This makes sense because when fixed local resources are important it is more difficult to shift industry employment across locations.

The estimates obtained in the empirical portion of this paper will reflect the impact of spillover reflected in city-industry employment, which will incorporate both the spillover term and the importance of fixed local resources. In further work, it would be interesting to separate these two factors, which is possible when sufficient data are available to estimate industry-specific input parameters. However, for city growth the relevant value is the coefficient that we estimate, which reflects the combination of 
the strength of spillovers and the extent to which industry employment can respond to those spillovers.

\subsection{Data appendix}

Table 4: Cities in the primary analysis database

\begin{tabular}{|c|c|c|c|}
\hline City & $\begin{array}{r}\text { Population } \\
\text { in } 1851 \\
\end{array}$ & $\begin{array}{r}\text { Working population } \\
\text { in } 1851\end{array}$ & $\begin{array}{r}\text { Workers in analysis } \\
\text { industries in } 1851\end{array}$ \\
\hline Bath & 54,240 & 27,623 & 22,836 \\
\hline Birmingham & 232,841 & 111,992 & 94,188 \\
\hline Blackburn & 46,536 & 26,211 & 24,279 \\
\hline Bolton & 61,171 & 31,211 & 28,576 \\
\hline Bradford & 103,778 & 58,408 & 54,685 \\
\hline Brighton & 69,673 & 32,949 & 27,151 \\
\hline Bristol & 137,328 & 64,025 & 53,361 \\
\hline Derby & 40,609 & 19,299 & 16,354 \\
\hline Gateshead & 25,568 & 10,003 & 8,373 \\
\hline Halifax & 33,582 & 18,058 & 16,171 \\
\hline Huddersfield & 30,880 & 13,922 & 12,132 \\
\hline Hull & 84,690 & 36,983 & 30,810 \\
\hline Ipswich & 32,914 & 14,660 & 11,745 \\
\hline Leeds & 172,270 & 83,570 & 73,696 \\
\hline Leicester & 60,584 & 31,140 & 28,097 \\
\hline Liverpool & 375,955 & 165,300 & 137,759 \\
\hline London & $2,362,236$ & $1,088,285$ & 880,602 \\
\hline Manchester & 401,321 & 204,688 & 183,406 \\
\hline Newcastle-upon-Tyne & 87,784 & 38,564 & 32,136 \\
\hline Northampton & 26,657 & 13,626 & 11,839 \\
\hline Norwich & 68,195 & 34,114 & 29,032 \\
\hline Nottingham & 57,407 & 33,967 & 30,538 \\
\hline Oldham & 72,357 & 38,853 & 35,911 \\
\hline Portsmouth & 72,096 & 31,345 & 18,536 \\
\hline Preston & 69,542 & 36,864 & 32,696 \\
\hline Sheffield & 135,310 & 58,551 & 51,092 \\
\hline South shields & 28,974 & 11,114 & 9,895 \\
\hline Southampton & 35,305 & 14,999 & 11,845 \\
\hline Stockport & 53,835 & 30,128 & 27,676 \\
\hline Sunderland & 63,897 & 24,779 & 21,302 \\
\hline Wolverhampton & 49,985 & 22,727 & 19,495 \\
\hline
\end{tabular}


Figure 3: Map showing the location of cities in the analysis database

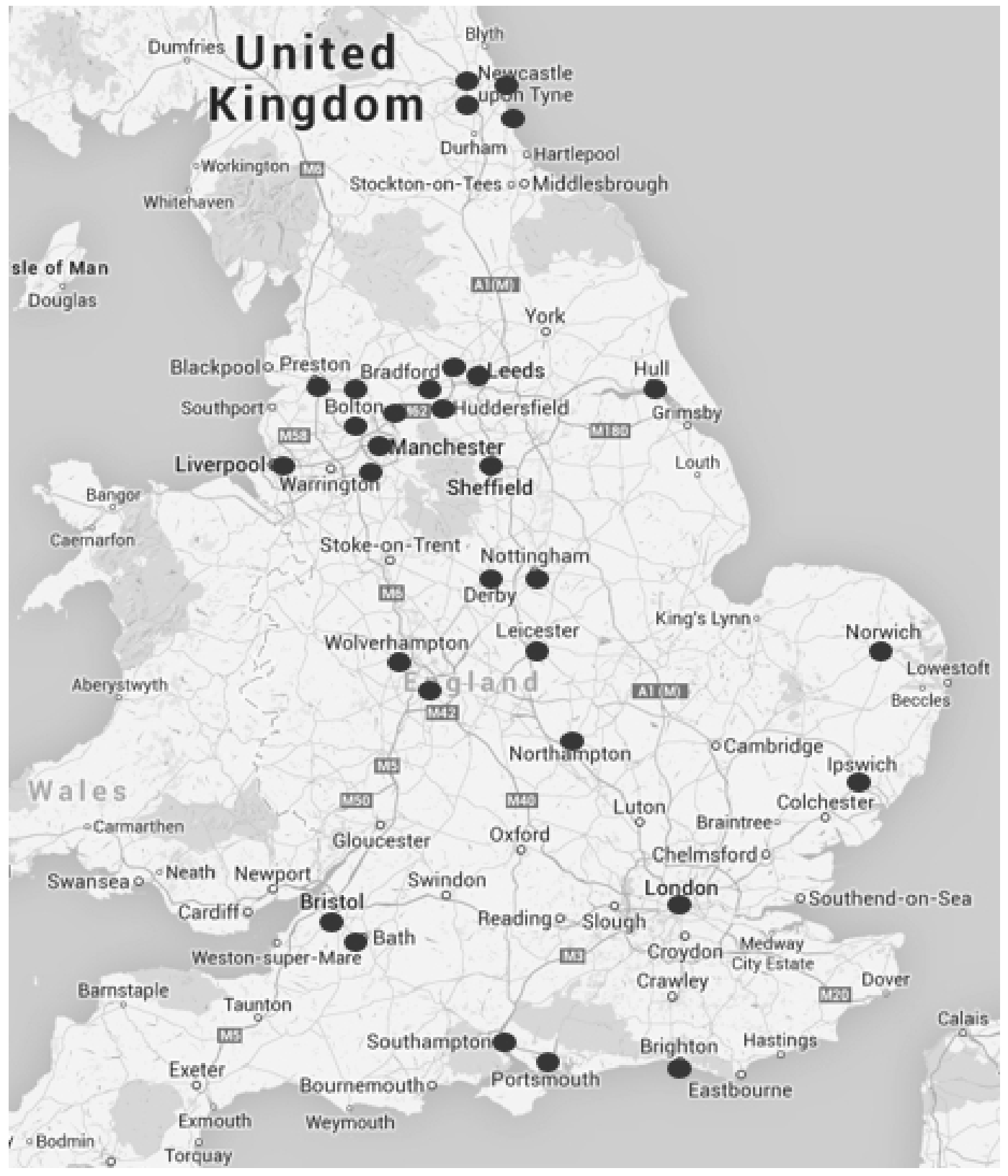


Table 5: Industries in the primary analysis database with 1851 employment

Manufacturing

Chemicals \& drugs

Clothing, shoes, etc.

Instruments \& jewelry*

Earthenware \& bricks

Leather \& hair goods

Metal \& Machines

Oil, soap, etc.

Paper and publishing

Shipbuilding

Textiles

Vehicles

Wood \& furniture

Food, etc.

Food processing

Spiritous drinks, etc.

Tobacconists*

\section{Services and Professional}

11,501 Professionals*

40,733

328,669 General services

458,808

31,048 Merchant, agent, accountant, etc.

19,580 Messenger, porter, etc.

62,564

72,155

26,737

Shopkeeper, salesmen, etc.

27,232

167,052

12,188

42,578

Transportation services

14,498

Railway transport

10,699

315,646

Road transport

40,106

9,021

Sea \& canal transport

66,360

69,648

\section{Others industries}

113,610 Construction

137,056

8,179

Mining

18,413

3,298

Water \& gas services

3,914

Industries marked with $\mathrm{a}^{*}$ are available in the database but are not used in the baseline analysis because they cannot be linked to categories in the 1907 British input-output table. 
Table 6: Summary statistics for the cross-industry spillover terms

\begin{tabular}{lrrrrr}
\hline \hline \multicolumn{4}{c}{ Main analysis matrices and industry categories } \\
& Obs. & Mean & SD & Min & Max \\
\hline$\triangle \ln \left(L_{i c t+1}\right)$ & 4,253 & 0.20 & 0.38 & -5.42 & 3.57 \\
$\ln \left(L_{i c t+1}\right)$ & 4,253 & 6.51 & 1.94 & 0.00 & 13.01 \\
$\sum_{k \neq i}$ IO $_{k i} \ln \left(L_{k c t}\right)$ & 4,253 & 7.94 & 2.45 & 2.06 & 19.60 \\
$\sum_{k \neq i}$ IOout $_{k i} \ln \left(L_{k c t}\right)$ & 4,253 & 7.70 & 5.98 & 0.00 & 42.77 \\
$\sum_{k \neq i} E M P_{k i} \ln \left(L_{k c t}\right)$ & 4,253 & 99.71 & 42.21 & -91.74 & 190.24 \\
$\sum_{k \neq i}$ OC $C_{k i} \ln \left(L_{k c t}\right)$ & 4,253 & 36.00 & 25.47 & -1.10 & 110.35 \\
\hline
\end{tabular}

Alternative 1841 IO matrix with aggregated industries

\begin{tabular}{lrrrrr} 
& Obs. & Mean & SD & Min & Max \\
\hline$\triangle \ln \left(L_{i c t+1}\right)$ & 2,222 & 0.20 & 0.34 & -3.31 & 3.57 \\
$\ln \left(L_{i c t+1}\right)$ & 2,222 & 7.34 & 1.89 & 1.79 & 13.44 \\
$\sum_{k \neq i}$ IOin $1841_{k i} \ln \left(L_{k c t}\right)$ & 2,222 & 2.72 & 2.79 & 0.00 & 12.10 \\
$\sum_{k \neq i}$ IOout $1841_{k i} \ln \left(L_{k c t}\right)$ & 2,222 & 3.94 & 3.88 & 0.00 & 11.76 \\
$\sum_{k \neq i} E M P_{k i} \ln \left(L_{k c t}\right)$ & 2,222 & 49.39 & 24.75 & -29.16 & 95.01 \\
$\sum_{k \neq i}$ OCC $C_{k i} \ln \left(L_{k c t}\right)$ & 2,222 & 24.83 & 16.46 & -0.66 & 66.92 \\
\hline
\end{tabular}

Note: We report cross-city summary statistics for 1861-1911 because we only report instrumented cross-city regression results in the main text, which means that 1851 is used only to construct lagged values. For the others, we report summary statistics using the full 1851-1911 period since we report both OLS and instrumented results.

It is also useful to look at the correlation between the cross-industry terms included in Eq. 9. These correlations are described in Table 7 below for the set of cross-industry terms used in the main analysis. In general we can see that the correlations between these variables are not too high, with the greatest correlation showing up between the IOin and IOout terms.

Table 7: Correlations between cross-industry terms used in the main analysis

\begin{tabular}{lcccc}
\hline \hline & IOin & IOout & EMP & OCC \\
\hline IOin & 1.0000 & & & \\
IOout & 0.5478 & 1.0000 & & \\
EMP & 0.1218 & 0.1789 & 1.0000 & \\
OCC & 0.0741 & -0.1783 & 0.3035 & 1.0000 \\
\hline \hline
\end{tabular}




\subsection{Preliminary results appendix}

This appendix presents some preliminary analyses, starting with results obtained when using the industry agglomeration index from Ellison \& Glaeser (1997). Table 8 presents agglomeration patterns using all cities, while Table 9 presents alternative results obtained while excluding London.

Table 8: Industry agglomeration patterns based on the Ellison \& Glaeser index

\begin{tabular}{lrrrrrrr}
\hline Industry & $\mathbf{1 8 5 1}$ & $\mathbf{1 8 6 1}$ & $\mathbf{1 8 7 1}$ & $\mathbf{1 8 8 1}$ & $\mathbf{1 8 9 1}$ & $\mathbf{1 9 0 1}$ & $\mathbf{1 9 1 1}$ \\
\hline Textiles & $\mathbf{0 . 1 6 6}$ & 0.178 & 0.182 & 0.195 & 0.182 & 0.159 & 0.150 \\
Mining & 0.143 & 0.167 & 0.150 & 0.199 & 0.213 & 0.200 & 0.197 \\
Metal \& machines & $\mathbf{0 . 0 9 4}$ & $\mathbf{0 . 0 8 9}$ & 0.086 & 0.093 & 0.087 & 0.079 & 0.088 \\
Shipbuilding & 0.081 & 0.079 & 0.121 & 0.142 & 0.197 & 0.252 & 0.253 \\
Paper \& publishing & 0.077 & 0.067 & 0.067 & 0.049 & 0.045 & 0.035 & 0.026 \\
Professionals & 0.070 & 0.047 & 0.057 & 0.050 & 0.043 & 0.030 & 0.037 \\
Sea \& canal transport & 0.056 & 0.057 & 0.058 & 0.086 & 0.066 & 0.080 & 0.077 \\
Instruments \& jewelry & 0.053 & 0.054 & 0.051 & 0.050 & 0.037 & 0.024 & 0.023 \\
Chemicals \& drugs & 0.052 & 0.019 & 0.043 & 0.043 & 0.006 & 0.041 & 0.027 \\
Road transport & 0.038 & 0.031 & 0.029 & 0.020 & 0.021 & 0.010 & 0.010 \\
Oil, soap, etc. & 0.028 & 0.017 & 0.008 & 0.007 & 0.008 & 0.024 & 0.041 \\
Leather, hair, etc. goods & 0.026 & 0.020 & 0.025 & 0.026 & 0.023 & 0.023 & 0.039 \\
Vehicles & 0.021 & 0.012 & 0.006 & 0.005 & 0.033 & 0.049 & 0.053 \\
General services & 0.020 & 0.020 & 0.016 & 0.022 & 0.020 & 0.025 & 0.026 \\
Tobacco & 0.020 & 0.022 & 0.010 & -0.008 & -0.008 & 0.011 & 0.016 \\
Earthenware \& bricks & 0.018 & 0.026 & 0.032 & 0.024 & 0.015 & 0.009 & 0.007 \\
Wood \& furniture & 0.016 & 0.015 & 0.022 & 0.019 & 0.015 & 0.009 & 0.010 \\
Drinks & 0.012 & 0.011 & 0.010 & 0.017 & 0.008 & 0.001 & -0.002 \\
Food processing & 0.009 & 0.004 & 0.003 & 0.001 & 0.001 & 0.001 & 0.001 \\
Clothing, shoes, etc. & 0.006 & 0.007 & 0.006 & 0.005 & 0.008 & 0.007 & 0.008 \\
Shopkeepers, salesmen, etc. & 0.006 & 0.001 & -0.003 & -0.003 & -0.004 & -0.004 & -0.004 \\
Construction & 0.004 & 0.004 & 0.002 & 0.003 & 0.002 & 0.001 & 0.002 \\
Merchants, agents, etc. & -0.044 & -0.052 & -0.047 & -0.054 & -0.053 & -0.055 & -0.060 \\
\hline Median & 0.026 & 0.020 & 0.025 & 0.022 & 0.020 & 0.024 & 0.026 \\
Mean & 0.042 & 0.039 & 0.041 & 0.043 & 0.042 & 0.044 & 0.045 \\
\hline
\end{tabular}

This table reports industry agglomeration in each year based on the index from Ellison \& Glaeser (1997). This approach adjusts for the size of plants in an industry using an industry Herfindahl index. We construct these Herfindahl indices using the firm size data reported in the 1851 Census and apply the same Herfindahl for all years, since firm-size data are not reported in later Censuses. This may introduce bias for some industries, such as shipbuilding, where evidence suggests that the average size of firms increased substantially over the study period. Some analysis industries are not included in this table due to lack of firm size data. 
Table 9: Industry agglomeration patterns excluding London

\begin{tabular}{lrrrrrrr}
\hline Industry & $\mathbf{1 8 5 1}$ & $\mathbf{1 8 6 1}$ & $\mathbf{1 8 7 1}$ & $\mathbf{1 8 8 1}$ & $\mathbf{1 8 9 1}$ & $\mathbf{1 9 0 1}$ & $\mathbf{1 9 1 1}$ \\
\hline Shipbuilding & 0.154 & 0.166 & 0.161 & 0.158 & 0.162 & 0.184 & 0.162 \\
Instruments \& jewelry & 0.152 & 0.172 & 0.145 & 0.163 & 0.093 & 0.056 & 0.045 \\
Sea \& canal transport & 0.150 & 0.175 & 0.161 & 0.199 & 0.173 & 0.164 & 0.143 \\
Oil, soap, etc. & 0.075 & 0.051 & 0.031 & 0.027 & 0.032 & 0.066 & 0.068 \\
Chemicals \& Drugs & 0.071 & 0.040 & 0.044 & 0.030 & 0.015 & 0.025 & 0.028 \\
Metal \& machines & 0.056 & 0.041 & 0.034 & 0.034 & 0.031 & 0.027 & 0.026 \\
Textiles & 0.046 & 0.047 & 0.045 & 0.050 & 0.049 & 0.049 & 0.049 \\
Mining & 0.044 & 0.052 & 0.035 & 0.041 & 0.043 & 0.037 & 0.038 \\
Leather, hair, etc. & 0.018 & 0.019 & 0.029 & 0.026 & 0.026 & 0.022 & 0.020 \\
Earthenware \& bricks & 0.015 & 0.010 & 0.008 & 0.007 & 0.009 & 0.010 & 0.010 \\
Vehicles & 0.015 & 0.023 & 0.014 & 0.017 & 0.046 & 0.052 & 0.074 \\
Road transport & 0.010 & 0.013 & 0.008 & 0.007 & 0.005 & 0.002 & 0.002 \\
Clothing, shoes, etc. & 0.009 & 0.008 & 0.010 & 0.014 & 0.023 & 0.017 & 0.017 \\
Drinks & 0.009 & 0.008 & 0.009 & 0.007 & 0.005 & 0.003 & 0.001 \\
Tobacco & 0.008 & 0.003 & -0.002 & 0.018 & 0.018 & 0.042 & 0.072 \\
Shopkeepers, salesmen, et & 0.006 & 0.002 & 0.001 & 0.004 & 0.000 & -0.001 & -0.003 \\
Food processing & 0.006 & 0.004 & 0.002 & 0.002 & 0.002 & 0.002 & 0.003 \\
Wood \& furniture & 0.006 & 0.005 & 0.005 & 0.003 & 0.004 & 0.004 & 0.004 \\
Paper \& publishing & 0.004 & 0.004 & 0.003 & 0.004 & 0.004 & 0.004 & 0.005 \\
Construction & 0.003 & 0.002 & 0.001 & 0.001 & 0.001 & 0.001 & 0.001 \\
General services & 0.003 & 0.000 & -0.001 & -0.002 & -0.002 & -0.002 & -0.002 \\
Professionals & -0.006 & -0.007 & -0.007 & -0.007 & -0.008 & -0.008 & -0.008 \\
Merchants, agents, etc. & -0.048 & -0.050 & -0.052 & -0.063 & -0.066 & -0.067 & -0.067 \\
\hline Median & 0.010 & 0.010 & 0.009 & 0.014 & 0.015 & 0.017 & 0.017 \\
Mean & 0.035 & 0.034 & 0.030 & 0.032 & 0.029 & 0.030 & 0.030 \\
\hline
\end{tabular}

This table reports industry agglomeration in each year based on the index from Ellison \& Glaeser (1997). This approach adjusts for the size of plants in an industry using an industry Herfindahl index. We construct these Herfindahl indices using the firm size data reported in the 1851 Census and apply the same Herfindahl for all years, since firm-size data are not reported in later Censuses. Some analysis industries are not included in this table due to lack of firm size data.

Next, we consider results from long-difference regressions following Glaeser et al. (1992) and Henderson et al. (1995). Table 10 presents results obtained using the approach from Glaeser et al. (1992). We cannot perfectly match their specification because we lack systematic wage data as well as information about firm sizes within each city-industry. However, where we do have data the variables presented in Table 10 are constructed to mirror those presented in Table 3 of Glaeser et al. (1992). 
These results are estimated for all industries in our data as well as for manufacturing industries only, which drops the service, transportation and construction sectors.

The results in Table 10 indicate that city-industries grew more slowly in locations in which they were initially large or made up an unusually large share of local employment. These patterns are similar to those obtained in Glaeser et al. (1992). As in their study, we find that national industry growth is a strong predictor of local industry growth. We find mixed evidence on whether the share of employment in the five other largest industries in a location positively impacts city-industry employment growth. These vary substantially depending on whether we include all industries or focus only on manufacturing industries. ${ }^{44}$

Next, we consider results from long-difference regressions following the approach from Table 1 of Henderson et al. (1995). These results, in Table 11, provide some evidence that industries grew more slowly in locations in which they were initially more concentrated. This is the opposite of the finding obtained by Henderson et al. (1995). We find mixed evidence on whether local diversity increased industry growth, though the effects tend to be positive and statistically significant when focusing only on manufacturing industries. Overall, our results appear to be more in-line with the findings of Glaeser et al. (1992), which suggest that spillovers occur primarily between, rather than within industries.

\footnotetext{
${ }^{44}$ Many of the top-5 industries in each city are not manufacturing, so limiting to manufacturing substantially changes the share of the top- 5 industries.
} 
Table 10: Long-difference regression results following Glaeser et al. (1992)

\begin{tabular}{|c|c|c|c|c|c|c|}
\hline \multicolumn{7}{|c|}{ DV: Ln(City-industry emp. in final year/City-industry emp. in initial year) } \\
\hline \multirow{2}{*}{$\begin{array}{l}\text { Years: } \\
\text { Industries }\end{array}$} & \multicolumn{2}{|c|}{ 1851-1911 } & \multicolumn{2}{|c|}{$1851-1881$} & \multicolumn{2}{|c|}{ 1881-1911 } \\
\hline & $\begin{array}{l}\text { All ind. } \\
\text { (1) }\end{array}$ & $\begin{array}{l}\text { Manuf. } \\
\text { (2) }\end{array}$ & $\begin{array}{l}\text { All ind. } \\
\text { (3) }\end{array}$ & $\begin{array}{l}\text { Manuf. } \\
\text { (4) }\end{array}$ & All ind. & $\begin{array}{l}\text { Manuf. } \\
(6)\end{array}$ \\
\hline $\begin{array}{l}\text { Ln(Industry emp. in all } \\
\text { cities in final year / } \\
\text { Industry emp. in all } \\
\text { cities in initial year) }\end{array}$ & $\begin{array}{l}1.099^{* * *} \\
(0.0528)\end{array}$ & $\begin{array}{l}1.099^{* * *} \\
(0.0686)\end{array}$ & $\begin{array}{l}1.060^{* * *} \\
(0.0544)\end{array}$ & $\begin{array}{l}1.045^{* * *} \\
(0.0947)\end{array}$ & $\begin{array}{l}0.997^{* * *} \\
(0.0603)\end{array}$ & $\begin{array}{l}0.986^{* * *} \\
(0.0587)\end{array}$ \\
\hline $\begin{array}{l}\text { Employment in the } \\
\text { city-industry in } \\
\text { the initial year (mil) }\end{array}$ & $\begin{array}{l}-2.965^{*} \\
(1.556)\end{array}$ & $\begin{array}{c}-0.341 \\
(1.586)\end{array}$ & $\begin{array}{l}-0.926 \\
(0.766)\end{array}$ & $\begin{array}{c}0.367 \\
(1.026)\end{array}$ & $\begin{array}{c}-1.348^{* *} \\
(0.623)\end{array}$ & $\begin{array}{l}-0.703^{*} \\
(0.419)\end{array}$ \\
\hline $\begin{array}{l}\text { City-ind shr. of city } \\
\text { emp. relative to } \\
\text { industry's share of } \\
\text { emp. in all cities } \\
\text { in initial year }\end{array}$ & $\begin{array}{r}-0.109^{* *} \\
(0.0481)\end{array}$ & $\begin{array}{l}-0.0289 \\
(0.0374)\end{array}$ & $\begin{array}{c}-0.0531^{* *} \\
(0.0241)\end{array}$ & $\begin{array}{r}-0.00472 \\
(0.0170)\end{array}$ & $\begin{array}{c}-0.0492^{* *} \\
(0.0245)\end{array}$ & $\begin{array}{r}-0.0353^{*} \\
(0.0214)\end{array}$ \\
\hline $\begin{array}{l}\text { Cities' other top- } 5 \\
\text { industry share of } \\
\text { city employment in } \\
\text { initial year }\end{array}$ & $\begin{array}{l}-0.143 \\
(0.319)\end{array}$ & $\begin{array}{c}1.079 * * * \\
(0.230)\end{array}$ & $\begin{array}{c}0.192 \\
(0.206)\end{array}$ & $\begin{array}{c}0.837^{* * *} \\
(0.154)\end{array}$ & $\begin{array}{l}-0.221 \\
(0.209)\end{array}$ & $\begin{array}{l}0.217^{*} \\
(0.120)\end{array}$ \\
\hline Constant & $\begin{array}{l}0.277 \\
(0.267)\end{array}$ & $\begin{array}{c}-0.472^{* * *} \\
(0.161)\end{array}$ & $\begin{array}{r}-0.0255 \\
(0.163)\end{array}$ & $\begin{array}{c}-0.347^{* * *} \\
(0.0999)\end{array}$ & $\begin{array}{l}0.281^{*} \\
(0.155)\end{array}$ & $\begin{array}{c}0.0103 \\
(0.0767)\end{array}$ \\
\hline Observations & 802 & 461 & 804 & 463 & 804 & 804 \\
\hline
\end{tabular}

$\overline{\text { Results obtained from long-difference regressions with robust standard errors. Significance levels: }}$ *** $\mathrm{p}<0.01,{ }^{* *} \mathrm{p}<0.05,{ }^{*} \mathrm{p}<0.1$. 
Table 11: Long-difference regression results following Henderson et al. (1995)

\begin{tabular}{lcccccc}
\hline \hline & \multicolumn{7}{c}{ DV: Ln(City-industry emp. in final year) } \\
Years: & \multicolumn{2}{c}{$1851-1911$} & \multicolumn{2}{c}{$1851-1881$} & 1881-1911 \\
Industries & All & Manuf. & All & Manuf. & All & Manuf. \\
& ind. & only & ind. & only & ind. & only \\
& $(1)$ & $(2)$ & $(3)$ & $(4)$ & $(5)$ & $(6)$ \\
\hline $\begin{array}{l}\text { Ln(City-industry emp. } \\
\text { in initial year) }\end{array}$ & $0.828^{* * *}$ & $0.852^{* * *}$ & $0.896^{* * *}$ & $0.894^{* * *}$ & $0.965^{* * *}$ & $0.978^{* * *}$ \\
& $(0.0252)$ & $(0.0324)$ & $(0.0171)$ & $(0.0220)$ & $(0.0159)$ & $(0.0201)$ \\
Concentration in & -0.465 & -0.216 & -0.0381 & 0.196 & $-0.839^{* * *}$ & $-0.634^{* *}$ \\
initial year: & $(0.351)$ & $(0.400)$ & $(0.247)$ & $(0.288)$ & $(0.223)$ & $(0.262)$ \\
city-industry share & & & & & & \\
of city employment & & & & & & \\
& & & & & & \\
Lack of diversity: & -0.00466 & $1.110^{* * *}$ & 0.0875 & $0.759^{* * *}$ & 0.0195 & $0.465^{*}$ \\
HHI in initial year & $(0.315)$ & $(0.357)$ & $(0.212)$ & $(0.223)$ & $(0.239)$ & $(0.279)$ \\
& & & & & & \\
Constant & $2.313^{* * *}$ & $1.844^{* * *}$ & $1.252^{* * *}$ & $1.064^{* * *}$ & $0.878^{* * *}$ & $0.679^{* * *}$ \\
& $(0.180)$ & $(0.212)$ & $(0.116)$ & $(0.137)$ & $(0.130)$ & $(0.149)$ \\
\hline Observations & 802 & 461 & 804 & 463 & 804 & 463 \\
\hline \hline
\end{tabular}

Results obtained from long-difference regressions with robust standard errors. Significance levels: $* * * \mathrm{p}<0.01, * * \mathrm{p}<0.05, * \mathrm{p}<0.1$.

\subsection{Empirical approach appendix}

\subsubsection{Monte Carlo simulations}

We use Monte Carlo simulations to assess how well our estimation strategy performs in datasets displaying the size and characteristics of our data. The basic idea is to generate datasets that mimic our real data, but obtained from a data generating process (DGP) with known parameter values. We then apply our estimation strategy to these placebo data sets, recover parameter estimates, and compare them to the estimates obtained in the true data. This allows us to assess the ability of our estimation strategy to obtain unbiased results and accurate confidence intervals.

We begin by estimating our baseline regression specification, Eq. 9, in order to obtain a set of industry-year effects $\left(\hat{\phi}_{i t}\right)$, city-year $\left(\hat{\theta}_{c t}\right)$ effects, and estimated residuals $\hat{\varepsilon}_{c i t}$. These ingredients will be used to simulate new datasets in which the city-year and industry-year effects are held constant at the estimated values, and the error terms are drawn from a multivariate Normal distribution whose parameters are 
computed using the estimated residuals.

\section{Step 1 - constructing the simulated error term}

We want to generate a simulated error vector that displays correlation within the city-year (CY), industry-year (IY) and city-industry (CI) dimensions but is uncorrelated across these dimensions. In other words, we need to draw entire vectors of errors $\varepsilon_{c i t}$ from a multivariate distribution whose covariance matrix $\Omega$ has zeros if two observations do not share any cluster, and non-zeros if they share at least a cluster. We follow Cameron et al. (2011) and construct such multi-clustered covariance matrix $\Omega$ as the sum of four single-clustered covariance matrices. ${ }^{45}$

$$
\Omega=\Omega^{C Y}+\Omega^{I Y}+\Omega^{C I}-2 \Omega^{C I T}
$$

Notice that if we sort the observations by a given dimension of clustering $x$, $\Omega^{x}$ has a block diagonal structure. For example, $\Omega^{C Y}$ consists of blocks of zeros if the corresponding observations are not in the same city-year cluster, and blocks along the diagonal with elements potentially different from zero if the corresponding observations are from the same city-year pair. We denoted these non-zero submatrices by $W^{C Y}$ and assume that they are identical across clusters. Therefore the typical element of $W^{C Y}$ is $\sigma^{i j}=\operatorname{cov}\left(\varepsilon_{\bar{c} i \bar{t}}, \varepsilon_{\bar{c} j \bar{t}}\right) \neq 0$.

We use the estimated residuals $\hat{\varepsilon}_{c i t}$ from the baseline specification to construct the elements of each submatrix $W^{x}$. For instance, taking any two industries $i$ and $j$, we set $\hat{\sigma}^{i j}=\frac{1}{\# C Y} \sum_{C Y} \hat{\varepsilon}_{c i t} \hat{\varepsilon}_{c j t}$, where $\# C Y$ is the number of different city-year pairs. We compute the elements of $\Omega^{I Y}$ and $\Omega^{C I}$ in the same way. We take a different approach to compute the elements of $\Omega^{C I Y}$ since each cluster has only one observation, i.e. there's a single observation for each triplet city-industry-year. All the diagonal elements of $\Omega^{C I Y}$ are set to the mean squared residual, i.e. $\hat{\sigma}^{c i t}=\hat{\sigma}=\frac{1}{N} \sum_{C I Y} \hat{\varepsilon}_{c i t}^{2}$, where $N$ is the number of observations. The off-diagonal elements of $\Omega^{C I Y}$ are zeros. ${ }^{46}$

\footnotetext{
${ }^{45}$ Following Cameron et al. (2011)'s notation, with three non-nested dimensions of clustering (denoted by $A, B, C$ ) the correct formula to compute a multi-clustered covariance matrix is $\Omega^{A B C}=$ $\Omega^{A}+\Omega^{B}+\Omega^{C}-\Omega^{A \cap C}-\Omega^{A \cap B}-\Omega^{B \cap C}+\Omega^{A \cap B \cap C}$ where, for instance, the entries of $\Omega^{A}$ are non-zero if two observations share the same cluster along a single dimension $A$, while the entries of $\Omega^{A \cap B}$ are non-zero if two observations share the same cluster defined by the intersection of $A$ and $B$. In our application, notice that $\Omega^{C Y \cap I Y}=\Omega^{C Y \cap C I}=\Omega^{I Y \cap C I}=\Omega^{C I T}$, therefore the formula above collapses to four distinct terms only.

${ }^{46}$ As noted in Cameron et al. (2011), multi-clustered covariance matrices are not guaranteed to be
} 
We draw 500 vectors of error terms from the multivariate distribution $N(0, \Omega)$ and rescale each vector so that it has exactly the same mean (zero) and variance as the original residuals. The result of this procedure is a simulated error term $\tilde{\varepsilon}^{S I M}$ that displays correlated errors along the city-year, industry-year and city-industry dimensions with a variance matching that of the original estimated error term.

\section{Part 2: Simulating the data}

The next step in our procedure involves simulating a new set of data with the same dimensions as the original data and with known within-industry and cross-industry spillover parameters.

In order to generate a simulated growth rate for the first period we begin with the level of initial city-industry employment from the data and use Eq. 9 to compute a simulated employment growth rate for each city-industry. So, for example, if we let $\beta_{1}=0.05$ and all other $\beta$ terms and $\tau_{i i}$ terms to zero then growth rate of employment in city $c$ and industry $i$ is:

$$
\tilde{g}_{i c 1}=0.05 \sum_{k \neq i} I O i n_{k i} \ln \left(L_{k c 0}\right)+\hat{\phi}_{i 1}+\hat{\theta}_{c 1}+\tilde{\varepsilon}_{i c 1}^{C Y-I Y-C I}
$$

where $\operatorname{IOin}_{k i}$ is the actual input-output weight observed in the data. The shifters

$\hat{\phi}_{i t}$ and $\hat{\theta}_{c t}$ are kept constant across simulations at the values estimated in the initial regression.

We use this simulated growth rate to obtain $L_{k c 1}$, the level of city-industry employment in the following period, which is then fed back into Eq. 17 to obtain $L_{k c 2}$, and so on. We repeat the process until we generate a level of employment for each city-industry-year triplet observed in the data. This procedure delivers a simulated dataset that by construction has the desired clustered error structure and the same number of observations as the original data.

\section{Step 3: Results}

We follow this procedure to generate 500 datasets that look like the true data, but that are generated using a data generating process with known $\tau_{i i}$ and $\beta$ parameters.

positive semidefinite. When that happens, as in our case, such $\Omega$ cannot be used by a random number generator. Our solution is to replace $\Omega$ with the nearest positive semidefinite matrix computed using Matlab routine nearestSPD. 
Specifically, for the plots below we set all of the $\tau_{i i}$ and $\beta$ parameters to zero (though we have also explored alternative non-zero values). We apply our estimation strategy (as in Table 1 Column 6) to each of the simulated data sets and obtain a distribution of estimated $\tau$ and $\beta$ parameters.

Figure 4 displays the mean, $90 \%$ and $95 \%$ confidence intervals for the distribution of estimated parameters when the true underlying spillover parameters are set to zero. We can see that our estimators are unbiased. Similar unbiased patterns appear when we use alternative non-zero parameters for either the within or cross-industry spillover terms.

We can compare the distribution of estimated coefficients coming out of this counterfactual DGP with the estimates obtained using the real dataset. This allows us to asses the likelihood of observing the real dataset and the corresponding estimates under the null hypothesis that all parameters are zeros. This method provides us with an alternative way to do hypothesis testing that does not rely on our multi-dimensional clustered standard errors.

Figure 5 plots the distribution of estimated IOin parameters obtained using the 500 simulated data sets, as well as the estimate obtained from the true data. These results suggests that obtaining the point estimate for IOin of 0.0587 that we got from the true data (Table 1, Column 6) is extremely unlikely when the true parameter value is zero. The implied p-value is 0.00 and the coefficient is significantly different from zero at the $1 \%$ level.

Table 12 presents the similar results for all the other coefficients of interest and confirms the significance levels of our baseline results from Column 6 of Table 1. This is reassuring because one may wonder whether our dataset is sufficiently large to consistently estimate all the parameters of interest, especially given that the observations are potentially correlated across multiple dimensions.

\section{Discussion}

These monte carlo results can help us assess how well our approach performs on simulated data sets sharing the same size and variance as the data used in our main analysis. However, this procedure comes with obvious limitations. In particular, we are assuming that the model is correctly specified and that the error terms are clustered in a particular way. Thus, this simulation cannot be used to assess how well our procedure performs under alternative data generating processes or when standard 
errors display alternative clustering patterns.

Figure 4: Estimates and C.I.s from simulated results when all spillover parameters are zero

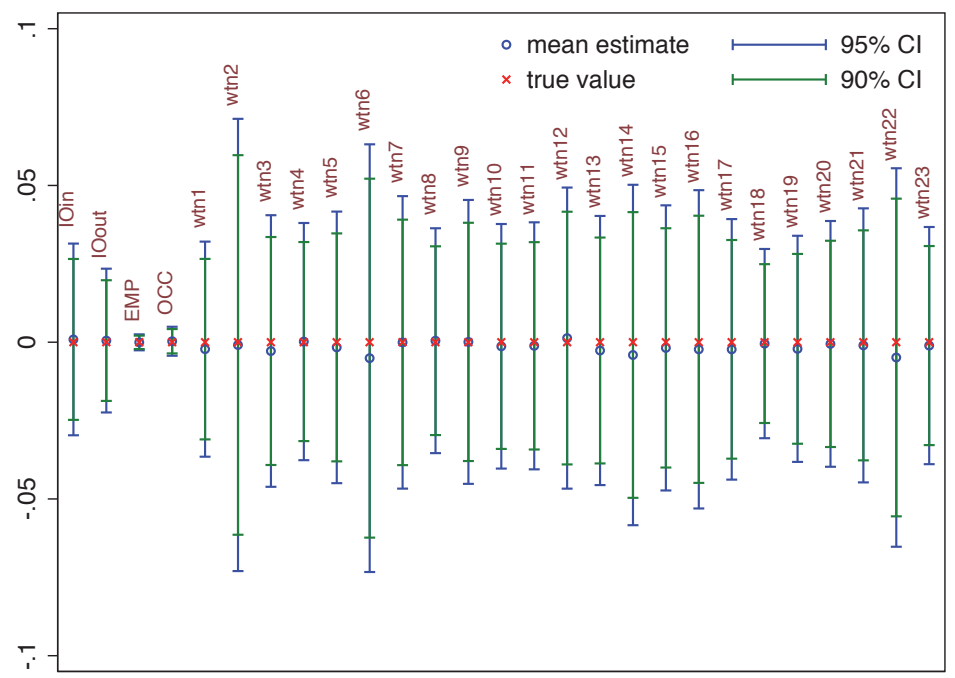

Figure 5: Simulated results with all parameters are set to zero vs. IOin estimate on real data

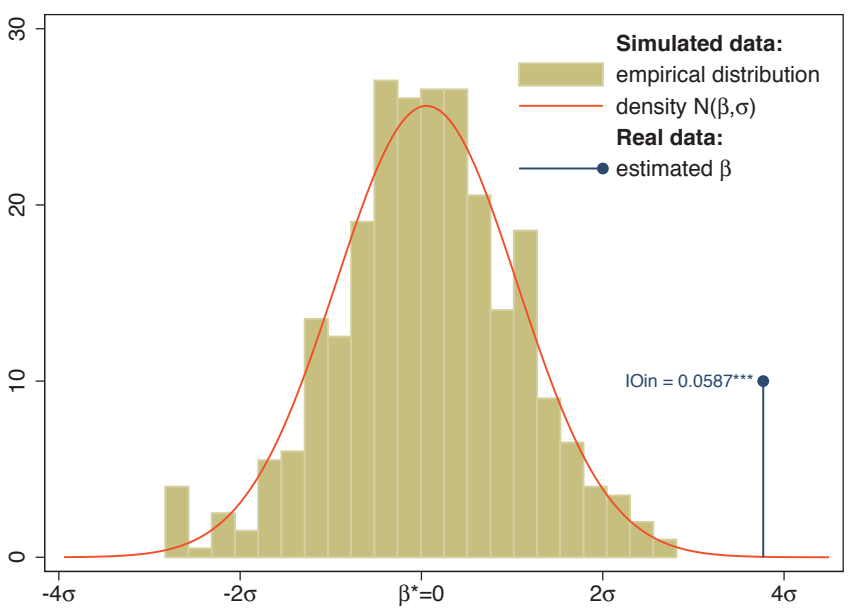


Table 12: Simulated results with all parameters are set to zero vs. parameter estimates from true data

\begin{tabular}{lcccc}
\hline \hline & \multicolumn{2}{c}{ Simulated Data } & \multicolumn{2}{c}{ True Data } \\
Variable & Mean & Std. Dev. & Coef. & p-value \\
\hline EMP & 0 & .001 & .002 & .213 \\
IOin & .001 & .016 & .059 & 0.00 \\
IOout & .001 & .012 & -.019 & .11 \\
OCC & 0 & .002 & .006 & .014 \\
wtn1 & -.002 & .018 & -.083 & 0.00 \\
wtn2 & -.001 & .037 & -.006 & .865 \\
wtn3 & -.003 & .022 & -.038 & .083 \\
wtn4 & 0 & .019 & -.083 & 0.00 \\
wtn5 & -.002 & .022 & -.035 & .117 \\
wtn6 & -.005 & .035 & -.052 & .137 \\
wtn7 & 0 & .024 & -.038 & .114 \\
wtn8 & 0 & .018 & .002 & .892 \\
wtn9 & 0 & .023 & -.05 & .031 \\
wtn10 & -.001 & .02 & -.126 & 0.00 \\
wtn11 & -.001 & .02 & .04 & .049 \\
wtn12 & .001 & .025 & -.034 & .163 \\
wtn13 & -.003 & .022 & -.083 & 0.00 \\
wtn14 & -.004 & .028 & -.104 & 0.00 \\
wtn15 & -.002 & .023 & -.043 & .066 \\
wtn16 & -.002 & .026 & -.075 & .004 \\
wtn17 & -.002 & .021 & -.069 & .001 \\
wtn18 & 0 & .015 & -.035 & .024 \\
wtn19 & -.002 & .018 & -.034 & .067 \\
wtn20 & -.001 & .02 & -.036 & .069 \\
wtn21 & -.001 & .022 & -.064 & .004 \\
wtn22 & -.005 & .031 & -.145 & 0.00 \\
wtn23 & -.001 & .019 & -.053 & .006 \\
\hline \hline
\end{tabular}

For each of the key explanatory variables, the first two columns of this table present the mean and standard deviation of the distribution of coefficient estimates obtained from applying our estimation strategy to 500 simulated datasets where the data have been generated with all spillover parameter values set to zero. Column 3 presents the coefficients estimated using the true data (as in Table 1, Column 6). Column 4 presents the p-value implied by comparing the coefficients estimated using the true data to the distribution of coefficient estimates obtained from the simulated data. 


\subsubsection{KP test appendix}

The standard errors in all of our main regressions are clustered along multiple dimensions. When using 2sls regressions, it is useful to be able to calculate the Kleibergen \& Paap (2006) test statistics for under- and weak-identification using the appropriately clustered covariance matrix. The KP statistics can easily be computed using existing Stata routines, but only for up to two non-nested dimensions of clustering (Kleibergen (2010)). None of these routines can handle a higher number of clusters so we developed our own package, which we will make available to the benefit of other researchers.

Our strategy builds on Thompson (2011) and Cameron et al. (2011) to compute a multi-clustered covariance of the orthogonality condition for any number of clusters. We then use a modified version of the Stata program ranktest to compute the appropriate KP statistics based on this covariance matrix. It can be verified that our program exactly reproduces the rk statistic (under-identification) and Wald statistic computed by ranktest in the case of two clusters. The weak-identification test statistic is then computed by transforming the Wald statistic into an F statistic. Notice that the value of our F statistic does not exactly match the one computed by ivreg2 due to the very small differences in the small sample adjustment.

\subsection{Results appendix}

\subsubsection{Results including only one spillover path at a time}

Table 13 looks at results that include only one of these at a time. Columns 1-3 include only the forward input-output linkages; Columns 1 presents OLS results; Column 2 presents results with lagged instrumentation on the within terms; and Column 3 uses lagged instrumentation for both the within and between terms. A similar pattern is used for backward input-output linkages in Columns 4-6, the demographicbased labor force similarity measure in Columns 7-9, and the occupation-based labor force similarity measure in Columns 10-12. All of these results include a full set of industry-specific within-industry terms, but these are not reported in Table 13 for space reasons. 
Table 13: OLS and IV regressions including only one spillover path at a time

\begin{tabular}{|c|c|c|c|c|c|c|}
\hline & $(1)$ & $(2)$ & (3) & (4) & (5) & (6) \\
\hline $\begin{array}{l}\text { Log employment in } \\
\text { local supplier } \\
\text { industries }\end{array}$ & $\begin{array}{c}0.1387^{* * *} \\
(0.0376)\end{array}$ & $\begin{array}{c}0.1136^{* * *} \\
(0.0400)\end{array}$ & $\begin{array}{c}0.1106^{* * *} \\
(0.0391)\end{array}$ & & & \\
\hline $\begin{array}{l}\text { Log employment in } \\
\text { local buyer } \\
\text { industries }\end{array}$ & & & & $\begin{array}{c}-0.0512 \\
(0.0657)\end{array}$ & $\begin{array}{c}-0.0966 \\
(0.0652)\end{array}$ & $\begin{array}{c}-0.1176^{*} \\
(0.0652)\end{array}$ \\
\hline Observations & 4,253 & 3.539 & 3,539 & 4,253 & 3,539 & 3,539 \\
\hline Estimation & ols & 2 sls & 2 sls & ols & 2 sls & 2 sls \\
\hline Instrumented & none & wtn & wtn-btn & none & wtn & wtn-btn \\
\hline KP under id. & & 21.02 & 28.13 & & 17.87 & 18.1 \\
\hline \multirow[t]{2}{*}{ KP weak id. } & & 51.94 & 61.7 & & 43.72 & 42.34 \\
\hline & (7) & (8) & (9) & (10) & (11) & $(12)$ \\
\hline $\begin{array}{l}\text { Log employment in local } \\
\text { industries using } \\
\text { demographically } \\
\text { similar workers }\end{array}$ & $\begin{array}{c}0.0748 \\
(0.0704)\end{array}$ & $\begin{array}{c}0.1246^{* *} \\
(0.0625)\end{array}$ & $\begin{array}{c}0.0761 \\
(0.0617)\end{array}$ & & & \\
\hline $\begin{array}{l}\text { Log employment in local } \\
\text { industries using } \\
\text { similar occupations }\end{array}$ & & & & $\begin{array}{l}0.1502^{*} \\
(0.0782)\end{array}$ & $\begin{array}{c}0.1804^{* *} \\
(0.0829)\end{array}$ & $\begin{array}{c}0.1715^{* *} \\
(0.0826)\end{array}$ \\
\hline Observations & 4,253 & 3,539 & 3,539 & 4,253 & 3,539 & 3,539 \\
\hline Estimation & ols & 2 sls & 2 sls & ols & $2 \mathrm{sls}$ & 2 sls \\
\hline Instrumented & none & wtn & wtn-btn & none & wtn & wtn-btn \\
\hline KP under id. & & 19.22 & 20.29 & & 15.72 & 16.9 \\
\hline KP weak id. & & 47.61 & 44.15 & & 37.7 & 31.96 \\
\hline
\end{tabular}

Multi-level clustered standard errors by city-industry, city-year, and industry-year in parenthesis. Significance levels: ${ }^{* * *} \mathrm{p}<0.01,{ }^{* *} \mathrm{p}<0.05,{ }^{*} \mathrm{p}<0.1$. All cross-industry connection variables have been standardized for comparability. Heterogeneous within terms, city-time and industry-time effects are included in all regressions but not displayed. 2SLS regressions use lagged instruments. Note that the number of observations falls for the instrumented regressions because the instruments require a lagged employment term. Thus, data from 1851 are not available for these regressions. Acronyms: wtn = within, btn = between. "KP under id." denotes the test statistic for the Lagrange Multiplier underidentification test based on Kleibergen \& Paap (2006). "KP weak id." denotes the test statistic for a weak instruments test based on the Kleibergen-Paap Wald statistic.

\subsubsection{Robustness of results to dropping cities or industries}

Figure 6 presents histograms of t-statistics for each cross-industry term obtained from running regressions equivalent to Column 6 of Table 1, where in each regression a different city is dropped from the dataset. This allows us to assess the extent to which our results are robust to changes in the set of cities included in the analysis. These results indicate that our estimates are not sensitive to dropping individual cities from the analysis database. 
Figure 6: Robustness to dropping one city at a time - distribution of t-statistics

IOin results

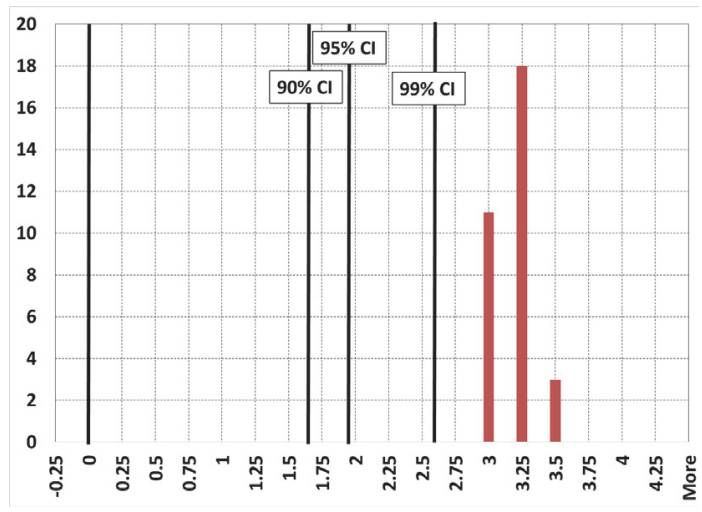

EMP results

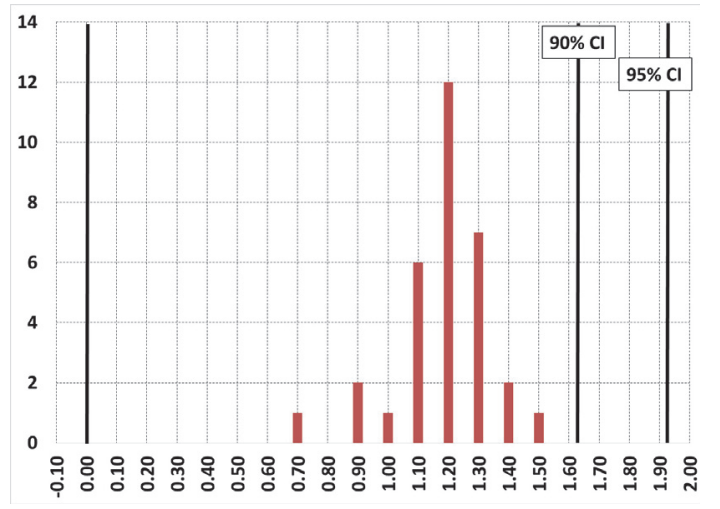

IOout results

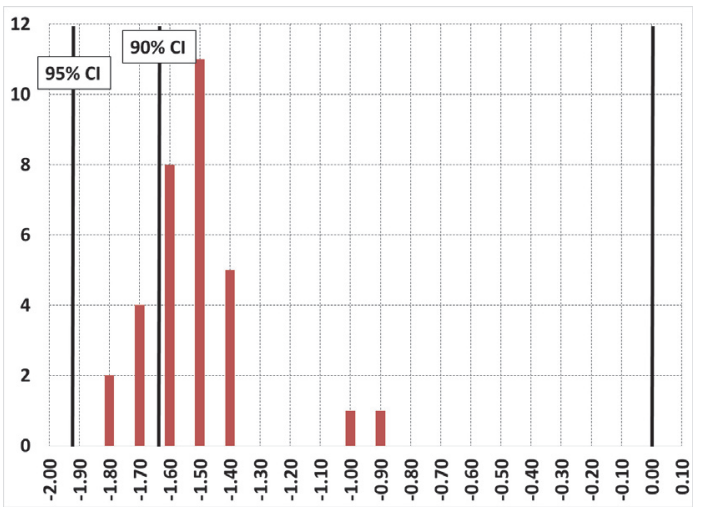

OCC results

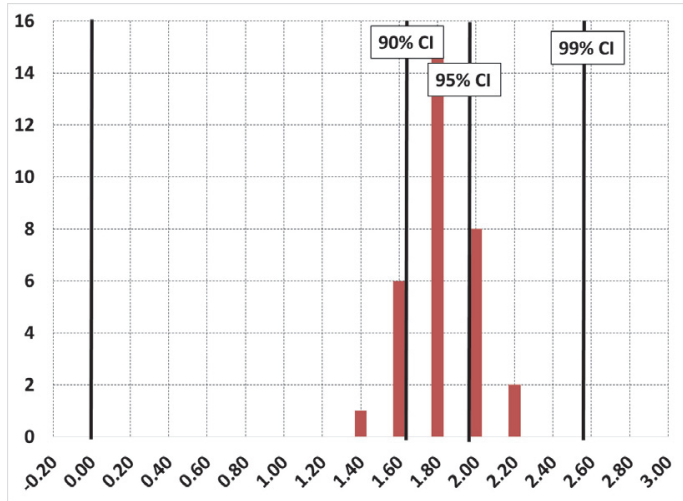

Figure 7 presents histograms of t-statistics for each cross-industry term obtained from running regressions equivalent to Column 6 of Table 1, where in each regression a different industry is dropped from the dataset. This allows us to assess the extent to which our results are robust to changes in the set of industries included in the analysis. We can see that in general our estimated coefficients are not sensitive to dropping individual industries. However, this does not apply when looking at the IO out coefficient. The top-right graph shows that when we drop shipbuilding from the data, the IO out coefficient changes substantially. In particular, the estimated coefficient changes from negative and occasionally statistically significant to positive and not statistically significant. This suggests that the negative coefficient estimated on the IO out coefficient is driven entirely by the Shipbuilding industry. This is an unusual industry because presumably it can only operate in coastal cities or those 
with access to a major navigable river. Thus, the IO out results obtained when dropping this industry seem more reasonable. These results suggest that in general the impact of local customers is weakly positive.

Overall, the results in Figure 7 indicate that our estimates are much more sensitive to dropping industries than they are to dropping cities. This suggests that heterogeneity across industries is more important than heterogeneity across cities.

Figure 7: Robustness to dropping one industry at a time - distribution of t-statistics

IOin results

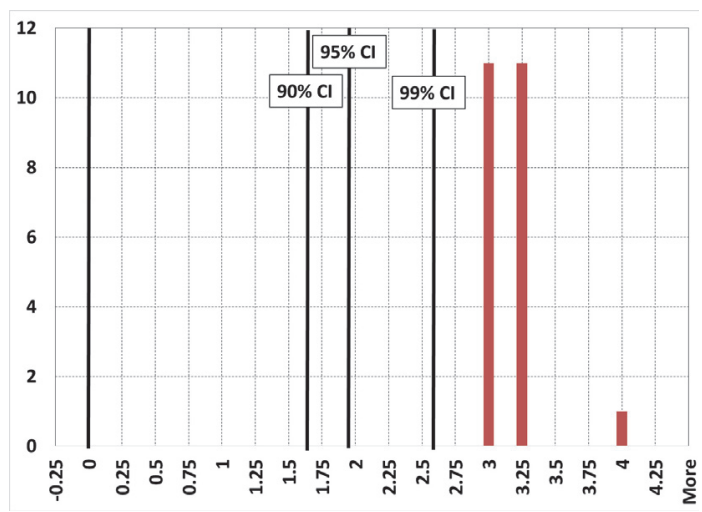

EMP results

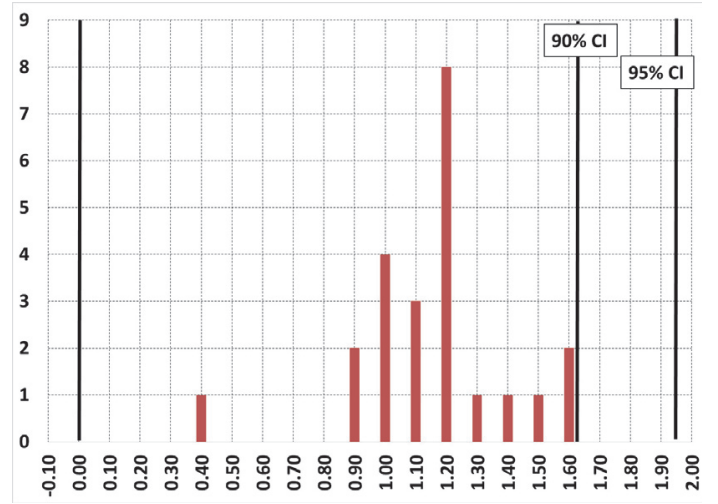

IOout results

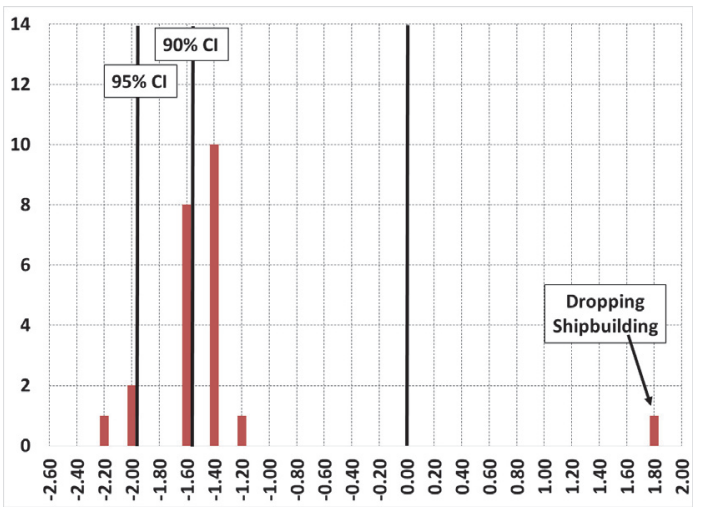

OCC results

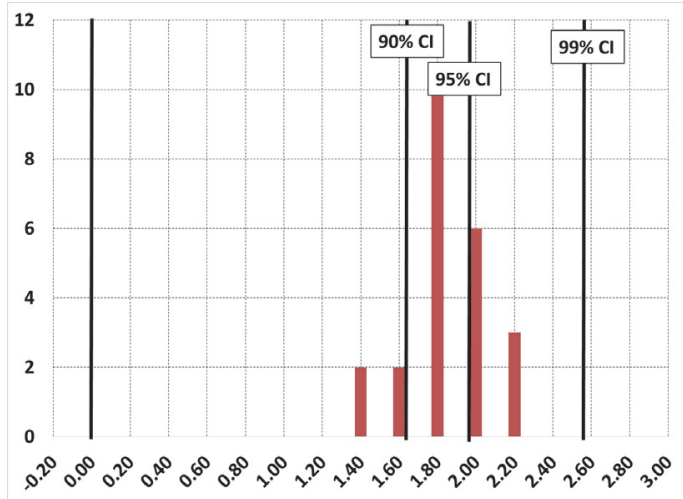

\subsubsection{Heterogeneous effects}

In this section we look at heterogeneity in the pattern of cross-industry and withinindustry effects across different industries. We begin by considering heterogeneous cross-industry effects. Specifically, we run two alternative versions of Equation 9, 


$$
\begin{aligned}
& \triangle \ln \left(L_{i c t+1}\right)=\tilde{\tau}_{i i} \ln \left(L_{i c t}\right)+\beta^{i} \sum_{k \neq i} C O N N E C T_{k i} \ln \left(L_{k c t}\right)+\theta_{c t}+\chi_{i t}+e_{i c t} \\
& \triangle \ln \left(L_{i \neq k c t+1}\right)=\tilde{\tau}_{i i} \ln \left(L_{i c t}\right)+\beta^{k} C O N N E C T_{k i} \ln \left(L_{k c t}\right)+\theta_{c t}+\chi_{i t}+e_{i c t}
\end{aligned}
$$

where $C O N N E C T_{k i}$ is one of our four measures of cross-industry connections. Equation 18 allows us to estimate industry-specific coefficients $\beta^{i}$ describing how much each industry $i$ benefits from cross-industry connections. This specification can be estimated using the same approach as was used for our baseline regressions. Using Equation 19, we estimate industry-specific coefficients $\beta^{k}$ that reflect the extent to which industry $k$ generates spillovers that benefit other industries. Estimating this value requires a different approach to avoid conflating the within and between impact of industry $k$ when estimating $\beta^{k}$. Specifically, we run separate regressions corresponding to Equation 19 for each industry $k$. In each of these regressions, only employment in industry $k$ (interacted with a cross-industry connection measure) is included as an explanatory variable and observations from industry $k$ are not included in the dependent variable.

Once the industry-specific $\beta^{i}$ and $\beta^{k}$ terms are estimated, we compare them to available measures of industry characteristics: firm size in each industry, the share of output exported, the share of output sold to households, the industry labor cost share, and the industry intermediate cost share. In each case we run a simple univariate regression where the dependent variable is the estimated industry-specific cross-industry spillover coefficient and the independent variable is one of the industry characteristics. Univariate regressions are used because we are working with a relatively small number of observations. These results can provide suggestive evidence about the characteristics of industries that produce or benefit from different types of cross-industry spillovers, but because of the small sample size we will not be able to draw any strong conclusions.

Table 14 describes the characteristics of industries that benefit from cross-industry connections. In rows 1-2, we see evidence that small firm size in an industry is associated with more cross-industry spillover benefits, but this pattern is not statistically significant at standard confidence levels. The only strong result coming out of this 
table is that industries that benefit from connections to other local industries with similar labor pools tend to have a larger labor cost share relative to overall industry sales, as well as a smaller intermediate cost share. This result seems reasonable.

Table 14: Features of industries that benefit from each type of cross-industry spillover

\begin{tabular}{lcccc}
\hline \hline & \multicolumn{3}{c}{ Coefficients from univariate regressions } \\
Spillovers channel: & $\begin{array}{c}\text { Local } \\
\text { DV }:\end{array}$ & $\begin{array}{c}\text { Local } \\
\text { bupplimaters }\end{array}$ & $\begin{array}{c}\text { industry-specific } \\
\text { Demographically } \\
\text { similar } \\
\text { labor pools }\end{array}$ & $\begin{array}{c}\text { coefficient } \\
\text { Occupationally } \\
\text { similar } \\
\text { labor pools }\end{array}$ \\
\hline Average firm size & -0.273 & $-1.100^{*}$ & -0.0303 & -0.235 \\
& $(0.330)$ & $(0.608)$ & $(0.0328)$ & $(0.945)$ \\
Median worker's firm size & -0.0217 & -0.114 & -0.00234 & -0.0333 \\
& $(0.0390)$ & $(0.0726)$ & $(0.00389)$ & $(0.111)$ \\
Share of industry output & -0.0741 & -0.0695 & -0.0150 & -0.157 \\
exported abroad & $(0.104)$ & $(0.198)$ & $(0.0107)$ & $(0.284)$ \\
Share of industry output & 0.0612 & 0.161 & 0.00689 & 0.0975 \\
sold to households & $(0.0459)$ & $(0.0932)$ & $(0.00485)$ & $(0.128)$ \\
Labor cost/output ratio & -0.101 & -0.337 & -0.0084 & $0.413^{* *}$ \\
& $(0.146)$ & $(0.274)$ & $(0.00993)$ & $(0.186)$ \\
Intermediate cost/output ratio & 0.0092 & 0.143 & -0.00059 & $-0.364^{* * *}$ \\
& $(0.107)$ & $(0.195)$ & $(0.00733)$ & $(0.122)$ \\
\hline \hline
\end{tabular}

Estimated coefficients from univariate regressions. Standard errors in parentheses. ${ }^{* * *}$ p $<0.01$, ** $\mathrm{p}<0.05, * \mathrm{p}<0.1$. The dependent variable in each regression is the estimated $\beta^{i}$ coefficient from Eq. 18. Firm size data comes from the 1851 Census of Population. The share of industry output exported or sold to households is from the 1907 input-output table. The labor cost share is constructed from industry wage bills from the 1907 Census of Manufactures. The intermediate cost share is based on the 1907 input-output table. We do not report robust standard errors because these generate smaller confidence intervals, probably due to small-sample bias. We have also explored regressions in which we weight results by the inverse of the standard error of each estimated within-industry coefficient in order to account for the precision of those estimates and these deliver similar results.

Table 15 describes the characteristics of industries that produce cross-industry connections. These results also suggest that industries with smaller firm sizes produce more beneficial cross-industry spillovers, but again, these results are not statistically significant. As before, we observe is that industries with smaller intermediate cost share relative to overall sales produce fewer cross-industry benefits to occupationally similar industries. There is some evidence that this may be linked to the importance of labor in firm inputs. 
Table 15: Features of industries that produce each type of cross-industry spillover

\begin{tabular}{|c|c|c|c|c|}
\hline \multicolumn{5}{|c|}{ Coefficients from univariate regressions } \\
\hline Spillovers channel: & $\begin{array}{c}\text { Local } \\
\text { suppliers }\end{array}$ & $\begin{array}{l}\text { Local } \\
\text { buyers }\end{array}$ & $\begin{array}{c}\text { Demographically } \\
\text { similar } \\
\text { labor pools }\end{array}$ & $\begin{array}{c}\text { Occupationally } \\
\text { similar } \\
\text { labor pools }\end{array}$ \\
\hline Average firm size & $\begin{array}{l}-1.250 \\
(1.060)\end{array}$ & $\begin{array}{l}-3.125 \\
(6.269)\end{array}$ & $\begin{array}{c}0.00417 \\
(0.180)\end{array}$ & $\begin{array}{l}-1.809 \\
(2.048)\end{array}$ \\
\hline Median worker's firm size & $\begin{array}{l}-0.140 \\
(0.125)\end{array}$ & $\begin{array}{l}-0.543 \\
(0.731)\end{array}$ & $\begin{array}{r}-0.00288 \\
(0.0211)\end{array}$ & $\begin{array}{l}-0.189 \\
(0.242)\end{array}$ \\
\hline $\begin{array}{l}\text { Share of industry output } \\
\text { exported abroad }\end{array}$ & $\begin{array}{r}-0.0495 \\
(0.349)\end{array}$ & $\begin{array}{c}-0.808 \\
(1.934)\end{array}$ & $\begin{array}{l}-0.0121 \\
(0.0556)\end{array}$ & $\begin{array}{l}-0.550 \\
(0.623)\end{array}$ \\
\hline $\begin{array}{l}\text { Share of industry output } \\
\text { sold to households }\end{array}$ & $\begin{array}{l}0.0013 \\
(0.175)\end{array}$ & $\begin{array}{l}0.0045 \\
(0.879)\end{array}$ & $\begin{array}{l}-0.0119 \\
(0.0250)\end{array}$ & $\begin{array}{l}0.483^{*} \\
(0.266)\end{array}$ \\
\hline Labor cost/output ratio & $\begin{array}{l}0.0154 \\
(0.547)\end{array}$ & $\begin{array}{c}1.224 \\
(3.101)\end{array}$ & $\begin{array}{l}-0.0296 \\
(0.0505)\end{array}$ & $\begin{array}{c}0.494 \\
(0.341)\end{array}$ \\
\hline Intermediate cost/output ratio & $\begin{array}{l}-0.305 \\
(0.354)\end{array}$ & $\begin{array}{l}-0.314 \\
(2.191)\end{array}$ & $\begin{array}{c}0.0176 \\
(0.0356)\end{array}$ & $\begin{array}{c}-0.493^{* *} \\
(0.219)\end{array}$ \\
\hline
\end{tabular}

Estimated coefficients from univariate regressions. The dependent variable in each regression is the estimated $\beta^{k}$ coefficient from Eq. 19. Standard errors in parentheses. *** $\mathrm{p}<0.01,{ }^{* *} \mathrm{p}<0.05$, $* \mathrm{p}<0.1$. Firm size data comes from the 1851 Census of Population. The share of industry output exported or sold to households is from the 1907 input-output table. The labor cost share is constructed from industry wage bills from the 1907 Census of Manufactures. The intermediate cost share is based on the 1907 input-output table. We do not report robust standard errors because these generate smaller confidence intervals, probably due to small-sample bias. We have also explored regressions in which we weight results by the inverse of the standard error of each estimated within-industry coefficient in order to account for the precision of those estimates and these deliver similar results.

Next, we undertake a similar exercise with our estimated within-industry coefficients. In Table 16 we consider some of the industry characteristics that may be related to the range of different within-industry spillover estimates we observe. Columns 1-2 focus on the role of firm size using two different measures. We observe a positive relationship between firm size in an industry and the strength of within-industry spillovers, but this results is not statistically significant due to the small number of available observations. There is also weak evidence that more labor intensive industries benefit more from within-industry spillovers. 
Table 16: Features of industries that benefit from within-industry spillovers

\begin{tabular}{|c|c|c|c|c|c|c|}
\hline \multicolumn{7}{|c|}{ DV: Estimated industry-specific within-industry spillover coefficients } \\
\hline Average firm size & $\begin{array}{c}0.172 \\
(0.198)\end{array}$ & & & & & \\
\hline Median worker's firm size & & $\begin{array}{c}0.0176 \\
(0.0233)\end{array}$ & & & & \\
\hline Exports share of industry output & & & $\begin{array}{l}-0.0313 \\
(0.0705)\end{array}$ & & & \\
\hline Households share of industry output & & & & $\begin{array}{l}-0.0247 \\
(0.0307)\end{array}$ & & \\
\hline Labor cost/output ratio & & & & \multicolumn{3}{|c|}{$\begin{array}{c}0.0699 \\
(0.0875)\end{array}$} \\
\hline Intermediate cost/output ratio & & & & & & $\begin{array}{c}-0.0304 \\
(0.0663)\end{array}$ \\
\hline Observations & 20 & 20 & 20 & 20 & 15 & 15 \\
\hline R-squared & 0.040 & 0.031 & 0.011 & 0.035 & 0.047 & 0.016 \\
\hline
\end{tabular}

Standard errors in parentheses. ${ }^{* * *} \mathrm{p}<0.01,{ }^{* *} \mathrm{p}<0.05,{ }^{*} \mathrm{p}<0.1$. The number of observations varies because the explanatory variables are drawn from different sources and are not available for all industries. The within coefficients come from the specification used in Column 6 of Table 1. Firm size data comes from the 1851 Census of Population. The export's and household's share of industry output come from the input-output table. Total labor cost and total output values come from the 1907 Census of Production. Intermediate cost is constructed based on data from the 1907 Input-Output matrix. We do not report robust standard errors because these generate smaller confidence intervals, probably due to small-sample bias. We have also explored regressions in which we weight results by the inverse of the standard error of each estimated within-industry coefficient in order to account for the precision of those estimates and these deliver similar results.

\subsubsection{Robustness: Weighted by initial city-industry employment}

Table 17 presents additional results in which each observation has been weighted by initial city-industry employment. Weights for each observation are based on employment in the city-industry at the beginning of each period. ${ }^{47}$ The estimated results on the IOin term in these weighted regressions is very similar to that found in the unweighted regressions presented in the main text. A difference between the weighted and unweighted results appears for the IOout term, which appears to be more negative in the weighted results. However, this coefficient continues to be highly sensitive to the set of industries included in the analysis, so we do not interpret this as a strong result. Another difference is that the agglomeration benefits between industries using similar occupation disappears when looking at weighted regressions. This suggests that labor market pooling benefits may be larger when the local size of an industry is small.

\footnotetext{
${ }^{47}$ This weighting approach is slightly different than the approach used in some previous drafts of this paper. In previous drafts we often weighted all observations by city-industry employment in 1851. In this draft we allow the weights to adjust over time as cities and industries grow. We believe that this is a better approach because it does not over-weight the industries or cities which were large in 1851 but were much less important 60 years later.
} 
Table 17: Weighted regression results

\begin{tabular}{|c|c|c|c|c|c|c|}
\hline & $(1)$ & $(2)$ & $(3)$ & $(4)$ & $(5)$ & $(6)$ \\
\hline $\begin{array}{l}\text { Log employment } \\
\text { in local supplier } \\
\text { industries }\end{array}$ & $\begin{array}{l}0.0522^{* *} \\
(0.0206)\end{array}$ & $\begin{array}{c}0.0644^{* * *} \\
(0.0221)\end{array}$ & $\begin{array}{c}0.0685^{* * *} \\
(0.0240)\end{array}$ & $\begin{array}{c}0.1266^{* * *} \\
(0.0350)\end{array}$ & $\begin{array}{c}0.1202^{* * *} \\
(0.0337)\end{array}$ & $\begin{array}{c}0.1367^{* * *} \\
(0.0381)\end{array}$ \\
\hline $\begin{array}{l}\text { Log employment } \\
\text { in local buyer } \\
\text { industries }\end{array}$ & $\begin{array}{c}-0.0793^{* * *} \\
(0.0264)\end{array}$ & $\begin{array}{c}-0.0938^{* * *} \\
(0.0275)\end{array}$ & $\begin{array}{c}-0.0979^{* * *} \\
(0.0282)\end{array}$ & $\begin{array}{c}-0.1979^{* * *} \\
(0.0537)\end{array}$ & $\begin{array}{c}-0.2178^{* * *} \\
(0.0498)\end{array}$ & $\begin{array}{c}-0.2392^{* * *} \\
(0.0481)\end{array}$ \\
\hline $\begin{array}{l}\text { Log emp. in local } \\
\text { industries using } \\
\text { demographically } \\
\text { similar workers }\end{array}$ & $\begin{array}{l}-0.0045 \\
(0.0119)\end{array}$ & $\begin{array}{l}-0.0048 \\
(0.0128)\end{array}$ & $\begin{array}{l}-0.0041 \\
(0.0134)\end{array}$ & $\begin{array}{c}0.0070 \\
(0.0384)\end{array}$ & $\begin{array}{c}0.0237 \\
(0.0368)\end{array}$ & $\begin{array}{c}0.0206 \\
(0.0389)\end{array}$ \\
\hline $\begin{array}{l}\text { Log emp. in local } \\
\text { industries using } \\
\text { similar occupations }\end{array}$ & $\begin{array}{l}-0.0073 \\
(0.0177)\end{array}$ & $\begin{array}{c}0.0032 \\
(0.0191)\end{array}$ & $\begin{array}{c}0.0038 \\
(0.0194)\end{array}$ & $\begin{array}{c}-0.0490 \\
(0.0476)\end{array}$ & $\begin{array}{l}-0.0296 \\
(0.0518)\end{array}$ & $\begin{array}{c}-0.0336 \\
(0.0523)\end{array}$ \\
\hline $\begin{array}{l}\text { Log own-industry } \\
\text { employment }\end{array}$ & $\begin{array}{l}-0.0311^{*} \\
(0.0175)\end{array}$ & $\begin{array}{l}-0.0284 \\
(0.0197)\end{array}$ & $\begin{array}{l}-0.0293 \\
(0.0196)\end{array}$ & & & \\
\hline Observations & 4,253 & 3,544 & 3,539 & 4,253 & 3,539 & 3,539 \\
\hline Estimation & ols & $2 \mathrm{sls}$ & 2 sls & ols & $2 \mathrm{sls}$ & 2 sls \\
\hline Instrumented & none & wtn & wtn-btn & none & wtn & wtn-btn \\
\hline wtn & homog & homog & homog & heter & heter & heter \\
\hline KP under & & 24.86 & 25.45 & & 22.09 & 24.52 \\
\hline KP weak id. & & 4677.9 & 858.61 & & 52.36 & 35.68 \\
\hline
\end{tabular}

Multi-level clustered standard errors by city-industry, city-year, and industry-year in parenthesis. Significance levels: $* * * \mathrm{p}<0.01,{ }^{* *} \mathrm{p}<0.05,{ }^{*} \mathrm{p}<0.1$. All cross-industry and within-industry connection variables have been standardized for comparability. Heterogeneous regressors within are included in Columns 4-6 but not displayed. City-year and industry-year effects are included in all regressions but not displayed. 2SLS regressions use lagged instruments. Note that the number of observations falls for the instrumented regressions in columns 3-6 because the instruments require a lagged employment term. Thus, data from 1851 are not available for these regressions. Acronyms: wtn = within, btn = between. "KP under id." denotes the test statistic for the Lagrange Multiplier underidentification test based on Kleibergen \& Paap (2006). "KP weak id." denotes the test statistic for a weak instruments test based on the Kleibergen-Paap Wald statistic. Weights for each city-industry observation are based on employment in the city-industry at the beginning of each period.

\subsubsection{Robustness: Alternative difference lengths}

While the main results are generated using city-industry growth over one-decade differences, it is also possible to consider results using longer differences. In this section we present results where the outcome variable is differenced over two or three decades. As in the main results, when using instruments those are based on a onedecade lag. In order to take advantage of as much of the data as possible, we use all 
differences of two or three decades available in the data. ${ }^{48}$

Results obtained when using two-decade differences are presented in Table 18, while those using three-decade differences are in Table 19. These results show that using two or three decade differences yields results that are quite similar to what we obtain using one-decade differences in the main text. Note that the magnitude of the estimated coefficients changes as we move to larger differences, as expected, since more city-industry growth will occur over a longer time period.

Table 18: Regression results using growth over two-decade differences

\begin{tabular}{|c|c|c|c|c|c|c|}
\hline & $(1)$ & $(2)$ & $(3)$ & $(4)$ & $(5)$ & $(6)$ \\
\hline $\begin{array}{l}\text { Log employment in } \\
\text { local supplier } \\
\text { industries }\end{array}$ & $\begin{array}{l}0.1230^{* *} \\
(0.0487)\end{array}$ & $\begin{array}{c}0.1351^{* * *} \\
(0.0492)\end{array}$ & $\begin{array}{c}0.1315^{* * *} \\
(0.0503)\end{array}$ & $\begin{array}{c}0.4374^{* * *} \\
(0.0993)\end{array}$ & $\begin{array}{c}0.4209^{* * *} \\
(0.1027)\end{array}$ & $\begin{array}{c}0.4297^{* * *} \\
(0.1039)\end{array}$ \\
\hline $\begin{array}{l}\text { Log employment in } \\
\text { local buyer } \\
\text { industries }\end{array}$ & $\begin{array}{c}0.0655 \\
(0.0705)\end{array}$ & $\begin{array}{c}0.0100 \\
(0.0665)\end{array}$ & $\begin{array}{l}-0.0052 \\
(0.0701)\end{array}$ & $\begin{array}{l}-0.0701 \\
(0.1409)\end{array}$ & $\begin{array}{l}-0.1261 \\
(0.1505)\end{array}$ & $\begin{array}{l}-0.1598 \\
(0.1511)\end{array}$ \\
\hline $\begin{array}{l}\text { Log employment in local } \\
\text { industries using } \\
\text { demographically } \\
\text { similar workers }\end{array}$ & $\begin{array}{c}0.0078 \\
(0.0388)\end{array}$ & $\begin{array}{c}0.0158 \\
(0.0475)\end{array}$ & $\begin{array}{c}0.0066 \\
(0.0474)\end{array}$ & $\begin{array}{c}0.0758 \\
(0.1187)\end{array}$ & $\begin{array}{c}0.1415 \\
(0.1160)\end{array}$ & $\begin{array}{c}0.1025 \\
(0.1219)\end{array}$ \\
\hline $\begin{array}{l}\text { Log employment in local } \\
\text { industries using } \\
\text { similar occupations }\end{array}$ & $\begin{array}{c}0.1163 \\
(0.0742)\end{array}$ & $\begin{array}{c}0.1249 \\
(0.0795)\end{array}$ & $\begin{array}{c}0.1155 \\
(0.0800)\end{array}$ & $\begin{array}{c}0.4753^{* * *} \\
(0.1504)\end{array}$ & $\begin{array}{c}0.4566^{* * *} \\
(0.1653)\end{array}$ & $\begin{array}{c}0.4432^{* * *} \\
(0.1700)\end{array}$ \\
\hline $\begin{array}{l}\text { Log own-industry } \\
\text { employment }\end{array}$ & $\begin{array}{c}-0.1138^{* *} \\
(0.0445) \\
\end{array}$ & $\begin{array}{c}-0.0919^{* *} \\
(0.0466) \\
\end{array}$ & $\begin{array}{l}-0.0904^{*} \\
(0.0473) \\
\end{array}$ & & & \\
\hline Observations & 3,549 & 2,839 & 2,834 & 3,549 & 2,834 & 2,834 \\
\hline Estimation & ols & $2 \mathrm{sls}$ & 2 sls & ols & 2 sls & 2sls \\
\hline instrumented & none & wtn & wtn-btn & none & wtn & wtn-btn \\
\hline KP under & & 21 & 22.13 & & 25.1 & 24.39 \\
\hline KP weak & & 4437.31 & 917.31 & & 67.79 & 46.35 \\
\hline \multicolumn{7}{|c|}{$\begin{array}{l}\text { Multi-level clustered standard errors by city-industry, city-year, and industry-year in parenthesis. Significance } \\
\text { levels: } * * * \mathrm{p}<0.01, * * \mathrm{p}<0.05, * \mathrm{p}<0.1 \text {. All cross-industry and within-industry connection variables have been } \\
\text { standardized for comparability. Heterogeneous regressors within are included in Columns } 4-6 \text { but not displayed. } \\
\text { City-time and industry-time effects are included in all regressions but not displayed. 2SLS regressions use lagged } \\
\text { instruments. Note that the number of observations falls for the instrumented regressions because the instruments } \\
\text { require a lagged employment term. Thus, data from } 1851 \text { are not available for these regressions. Acronyms: wtn = } \\
\text { within, btn = between. "KP under id." denotes the test statistic for the Lagrange Multiplier underidentification } \\
\text { test based on Kleibergen \& Paap }(2006) \text {. "KP weak id." denotes the test statistic for a weak instruments test based }\end{array}$} \\
\hline
\end{tabular}

\footnotetext{
${ }^{48}$ One advantage of this is that it avoids an arbitrary dependence on the initial year. To illustrate this point, suppose we use non-overlapping two-decade differences starting in 1851 vs. starting in 1861. In that case those differences will use completely different data points which will depend arbitrarily on the start date. By using overlapping differences we avoid this arbitrary element. However, it does introduce serial correlation in our data, which will be addressed by the fact that our standard errors allow serial correlation within city-industries across all periods.
} 
Table 19: Regression results using growth over three-decade differences

\begin{tabular}{|c|c|c|c|c|c|c|}
\hline & $(1)$ & $(2)$ & (3) & (4) & $(5)$ & $(6)$ \\
\hline $\begin{array}{l}\text { Log employment in } \\
\text { local supplier } \\
\text { industries }\end{array}$ & $\begin{array}{c}0.2125^{* * *} \\
(0.0699)\end{array}$ & $\begin{array}{c}0.2366^{* * * *} \\
(0.0728)\end{array}$ & $\begin{array}{c}0.2387^{* * *} \\
(0.0741)\end{array}$ & $\begin{array}{c}0.6364^{* * *} \\
(0.1436)\end{array}$ & $\begin{array}{c}0.6597^{* * *} \\
(0.1576)\end{array}$ & $\begin{array}{c}0.6699^{* * *} \\
(0.1611)\end{array}$ \\
\hline $\begin{array}{l}\text { Log employment in } \\
\text { local buyer } \\
\text { industries }\end{array}$ & $\begin{array}{c}0.0470 \\
(0.0976)\end{array}$ & $\begin{array}{l}-0.0092 \\
(0.1116)\end{array}$ & $\begin{array}{l}-0.0469 \\
(0.1118)\end{array}$ & $\begin{array}{l}-0.1396 \\
(0.2017)\end{array}$ & $\begin{array}{l}-0.2486 \\
(0.2294)\end{array}$ & $\begin{array}{l}-0.2864 \\
(0.2383)\end{array}$ \\
\hline $\begin{array}{l}\text { Log employment in local } \\
\text { industries using } \\
\text { demographically } \\
\text { similar workers }\end{array}$ & $\begin{array}{c}0.0131 \\
(0.0594)\end{array}$ & $\begin{array}{c}0.0226 \\
(0.0727)\end{array}$ & $\begin{array}{c}0.0170 \\
(0.0720)\end{array}$ & $\begin{array}{c}0.0763 \\
(0.1601)\end{array}$ & $\begin{array}{c}0.2338 \\
(0.1599)\end{array}$ & $\begin{array}{c}0.2045 \\
(0.1646)\end{array}$ \\
\hline $\begin{array}{l}\text { Log employment in local } \\
\text { industries using } \\
\text { similar occupations }\end{array}$ & $\begin{array}{l}0.1888^{*} \\
(0.1054)\end{array}$ & $\begin{array}{l}0.2117^{*} \\
(0.1186)\end{array}$ & $\begin{array}{c}0.1938 \\
(0.1213)\end{array}$ & $\begin{array}{c}0.6377^{* * *} \\
(0.1984)\end{array}$ & $\begin{array}{c}0.7300^{* * *} \\
(0.2219)\end{array}$ & $\begin{array}{c}0.7191^{* * * *} \\
(0.2393)\end{array}$ \\
\hline $\begin{array}{l}\text { Log own-industry } \\
\text { employment }\end{array}$ & $\begin{array}{c}-0.1689 * * * \\
(0.0649)\end{array}$ & $\begin{array}{l}-0.1399^{*} \\
(0.0752)\end{array}$ & $\begin{array}{l}-0.1422^{*} \\
(0.0759)\end{array}$ & & & \\
\hline Observations & 2,837 & 2,126 & 2,122 & 2,837 & 2,122 & 2,122 \\
\hline Estimation & ols & 2 sls & 2 sls & ols & 2 sls & 2sls \\
\hline instrumented & none & wtn & wtn-btn & none & wtn & wtn-btn \\
\hline $\mathrm{KP}$ under & & 16.59 & 17.45 & & 19.58 & 17.29 \\
\hline KP weak & & 3754.29 & 729.55 & & 32.02 & 24.02 \\
\hline \multicolumn{7}{|c|}{$\begin{array}{l}\text { Multi-level clustered standard errors by city-industry, city-year, and industry-year in parenthesis. Significance } \\
\text { levels: } * * * \mathrm{p}<0.01, * * \mathrm{p}<0.05, * \mathrm{p}<0.1 \text {. All cross-industry and within-industry connection variables have been } \\
\text { standardized for comparability. Heterogeneous regressors within are included in Columns } 4-6 \text { but not displayed. } \\
\text { City-time and industry-time effects are included in all regressions but not displayed. } 2 \text { SLS regressions use lagged } \\
\text { instruments. Note that the number of observations falls for the instrumented regressions because the instruments } \\
\text { require a lagged employment term. Thus, data from } 1851 \text { are not available for these regressions. Acronyms: wtn = } \\
\text { within, btn = between. "KP under id." denotes the test statistic for the Lagrange Multiplier underidentification } \\
\text { test based on Kleibergen \& Paap (2006). "KP weak id." denotes the test statistic for a weak instruments test based } \\
\text { on the Kleibergen-Paap Wald statistic. }\end{array}$} \\
\hline
\end{tabular}

\subsubsection{Robustness: Results before or after 1881}

This appendix presents additional results using only data before or only data after 1881, the midpoint of our study. These additional results can provide some evidence on how the agglomeration forces we identify were changing across the study period. However, because each set of results is being generated using substantially fewer data points, in general these findings will be weaker than our main results.

Table 20 presents results focusing on the 1851-1881 period only. While these results are generated using a smaller sample, so they are often less statistically significant than our main results, they are generally qualitatively similar; we find evidence of benefits from nearby supplier industries and some evidence of benefits from nearby industries using occupationally similar workforces. In both cases these effects are 
somewhat weaker than those observed in our main results. The results in Table 21, which are based on data from 1881-1911, also provide evidence that firms benefited from nearby supplier industries or industries with occupationally similar workforces. However, these results are substantially stronger, which provides some suggestive evidence that the strength of these agglomeration channels was increasing. This may indicate that these agglomeration forces became more important as development proceeded, or it may be due to the large number of new technologies, in areas such as chemicals, steel and electronics, introduced in the 1881-1911 period, which is often described as the Second Industrial Revolution.

Table 20: Regression results using only data from 1851-1881

\begin{tabular}{|c|c|c|c|c|c|c|}
\hline & $(1)$ & $(2)$ & $(3)$ & $(4)$ & $(5)$ & $(6)$ \\
\hline $\begin{array}{l}\text { Log employment in } \\
\text { local supplier } \\
\text { industries }\end{array}$ & $\begin{array}{l}0.0692^{* *} \\
(0.0299)\end{array}$ & $\begin{array}{c}0.0573^{* * *} \\
(0.0218)\end{array}$ & $\begin{array}{c}0.0183 \\
(0.0237)\end{array}$ & $\begin{array}{c}0.2117^{* * *} \\
(0.0708)\end{array}$ & $\begin{array}{c}0.1064 \\
(0.0705)\end{array}$ & $\begin{array}{c}0.0789 \\
(0.0688)\end{array}$ \\
\hline $\begin{array}{l}\text { Log employment in } \\
\text { local buyer } \\
\text { industries }\end{array}$ & $\begin{array}{l}0.0571^{*} \\
(0.0303)\end{array}$ & $\begin{array}{c}0.0141 \\
(0.0349)\end{array}$ & $\begin{array}{c}0.0439 \\
(0.0345)\end{array}$ & $\begin{array}{c}0.0675 \\
(0.0888)\end{array}$ & $\begin{array}{l}-0.0031 \\
(0.1069)\end{array}$ & $\begin{array}{c}0.0028 \\
(0.1040)\end{array}$ \\
\hline $\begin{array}{l}\text { Log employment in local } \\
\text { industries using } \\
\text { demographically } \\
\text { similar workers }\end{array}$ & $\begin{array}{c}0.0050 \\
(0.0312)\end{array}$ & $\begin{array}{l}-0.0126 \\
(0.0371)\end{array}$ & $\begin{array}{l}-0.0327 \\
(0.0369)\end{array}$ & $\begin{array}{l}-0.0601 \\
(0.0908)\end{array}$ & $\begin{array}{c}0.0730 \\
(0.0802)\end{array}$ & $\begin{array}{c}0.0155 \\
(0.0831)\end{array}$ \\
\hline $\begin{array}{l}\text { Log employment in local } \\
\text { industries using } \\
\text { similar occupations }\end{array}$ & $\begin{array}{c}0.0528 \\
(0.0390)\end{array}$ & $\begin{array}{c}0.0178 \\
(0.0360)\end{array}$ & $\begin{array}{c}0.0057 \\
(0.0338)\end{array}$ & $\begin{array}{l}0.1826^{*} \\
(0.1047)\end{array}$ & $\begin{array}{c}0.0661 \\
(0.1268)\end{array}$ & $\begin{array}{c}0.0396 \\
(0.1212)\end{array}$ \\
\hline $\begin{array}{l}\text { Log own-industry } \\
\text { employment }\end{array}$ & $\begin{array}{c}-0.0998^{* * *} \\
(0.0285)\end{array}$ & $\begin{array}{c}-0.0700^{* *} \\
(0.0285)\end{array}$ & $\begin{array}{l}-0.0616^{*} \\
(0.0316)\end{array}$ & & & \\
\hline Observations & 2,131 & 1,422 & 1,418 & 2,131 & 1,418 & 1,418 \\
\hline Estimation & ols & $2 \mathrm{sls}$ & 2 sls & ols & $2 \mathrm{sls}$ & $2 \mathrm{sls}$ \\
\hline instrumented & none & wtn & wtn-btn & none & wtn & wtn-btn \\
\hline KP under & & 11.58 & 12.16 & & 6.23 & 8.31 \\
\hline KP weak & & 1971.5 & 374.93 & & 9.71 & 8.68 \\
\hline \multicolumn{7}{|c|}{$\begin{array}{l}\text { Multi-level clustered standard errors by city-industry, city-year, and industry-year in parenthesis. Signifi- } \\
\text { cance levels: } * * * \mathrm{p}<0.01, * * \mathrm{p}<0.05, * \mathrm{p}<0.1 \text {. All cross-industry and within-industry connection variables } \\
\text { have been standardized for comparability. Heterogeneous regressors within are included in Columns } 4-6 \text { but } \\
\text { not displayed. City-time and industry-time effects are included in all regressions but not displayed. } 2 \text { SLS } \\
\text { regressions use lagged instruments. Note that the number of observations falls for the instrumented regres- } \\
\text { sions because the instruments require a lagged employment term. Thus, data from } 1851 \text { are not available } \\
\text { for these regressions. Acronyms: wtn = within, btn = between. "KP under id." denotes the test statistic } \\
\text { for the Lagrange Multiplier underidentification test based on Kleibergen \& Paap (2006). "KP weak id." } \\
\text { denotes the test statistic for a weak instruments test based on the Kleibergen-Paap Wald statistic. }\end{array}$} \\
\hline
\end{tabular}


Table 21: Regression results using only data from 1881-1911

\begin{tabular}{|c|c|c|c|c|c|c|}
\hline & $(1)$ & $(2)$ & $(3)$ & $(4)$ & $(5)$ & $(6)$ \\
\hline $\begin{array}{l}\text { Log employment in } \\
\text { local supplier } \\
\text { industries }\end{array}$ & $\begin{array}{c}0.0777 \\
(0.0475)\end{array}$ & $\begin{array}{c}0.0627 \\
(0.0598)\end{array}$ & $\begin{array}{c}0.0727 \\
(0.0512)\end{array}$ & $\begin{array}{c}0.2045^{* * *} \\
(0.0596)\end{array}$ & $\begin{array}{c}0.2225^{* * *} \\
(0.0731)\end{array}$ & $\begin{array}{c}0.2376^{* * *} \\
(0.0654)\end{array}$ \\
\hline $\begin{array}{l}\text { Log employment in } \\
\text { local buyer } \\
\text { industries }\end{array}$ & $\begin{array}{c}0.0305 \\
(0.0618)\end{array}$ & $\begin{array}{l}-0.0229 \\
(0.0487)\end{array}$ & $\begin{array}{l}-0.0648^{*} \\
(0.0351)\end{array}$ & $\begin{array}{l}-0.0926 \\
(0.0876)\end{array}$ & $\begin{array}{l}-0.1176 \\
(0.1067)\end{array}$ & $\begin{array}{l}-0.1612 \\
(0.1174)\end{array}$ \\
\hline $\begin{array}{l}\text { Log employment in local } \\
\text { industries using } \\
\text { demographically } \\
\text { similar workers }\end{array}$ & $\begin{array}{c}0.0102 \\
(0.0280)\end{array}$ & $\begin{array}{c}0.0302 \\
(0.0398)\end{array}$ & $\begin{array}{c}0.0121 \\
(0.0392)\end{array}$ & $\begin{array}{l}0.1415^{*} \\
(0.0853)\end{array}$ & $\begin{array}{c}0.1473 \\
(0.1032)\end{array}$ & $\begin{array}{c}0.0726 \\
(0.0978)\end{array}$ \\
\hline $\begin{array}{l}\text { Log employment in local } \\
\text { industries using } \\
\text { similar occupations }\end{array}$ & $\begin{array}{c}0.1000 \\
(0.0700)\end{array}$ & $\begin{array}{c}0.0524 \\
(0.0822)\end{array}$ & $\begin{array}{c}0.0415 \\
(0.0840)\end{array}$ & $\begin{array}{c}0.2604^{* *} \\
(0.1132)\end{array}$ & $\begin{array}{c}0.2696^{* *} \\
(0.1271)\end{array}$ & $\begin{array}{l}0.2298^{*} \\
(0.1372)\end{array}$ \\
\hline $\begin{array}{l}\text { Log own-industry } \\
\text { employment }\end{array}$ & $\begin{array}{l}-0.0744 \\
(0.0545)\end{array}$ & $\begin{array}{l}-0.0471 \\
(0.0507)\end{array}$ & $\begin{array}{l}-0.0501 \\
(0.0506)\end{array}$ & & & \\
\hline Observations & 2,122 & 1,410 & 1,409 & 2,122 & 1,409 & 1,409 \\
\hline Estimation & ols & 2 sls & 2 sls & ols & 2 sls & 2 sls \\
\hline instrumented & none & wtn & wtn-btn & none & wtn & wtn-btn \\
\hline KP under & & 11.31 & 12.07 & & 3.69 & 4.56 \\
\hline KP weak & & 1359.24 & 227.75 & & 5.15 & 4.34 \\
\hline \multicolumn{7}{|c|}{$\begin{array}{l}\text { Multi-level clustered standard errors by city-industry, city-year, and industry-year in parenthesis. Signifi- } \\
\text { cance levels: } * * * \mathrm{p}<0.01,{ }^{*} \mathrm{p}<0.05, * \mathrm{p}<0.1 \text {. All cross-industry and within-industry connection variables } \\
\text { have been standardized for comparability. Heterogeneous regressors within are included in Columns } 4-6 \text { but } \\
\text { not displayed. City-time and industry-time effects are included in all regressions but not displayed. 2SLS } \\
\text { regressions use lagged instruments. Note that the number of observations falls for the instrumented regres- } \\
\text { sions because the instruments require a lagged employment term. Thus, data from } 1851 \text { are not available } \\
\text { for these regressions. Acronyms: wtn = within, btn = between. "KP under id." denotes the test statistic } \\
\text { for the Lagrange Multiplier underidentification test based on Kleibergen \& Paap (2006). "KP weak id." } \\
\text { denotes the test statistic for a weak instruments test based on the Kleibergen-Paap Wald statistic. }\end{array}$} \\
\hline
\end{tabular}

\subsubsection{Robustness: Alternative connections matrices}

Next, we revisit the analysis using some alternative measures of inter-industry connections. In particular, we use an alternative matrix of input-output connections constructed by Horrell et al. (1994) for Britain in 1841. Generating results with this alternative matrix, which comes from before the study period, can help address concerns that the results we find are dependent on the specific set of matrices we consider or are due to a process of endogenous inter-industry connection formation. The cost of using this matrix is that we are forced to work with a smaller set of 12 more aggregated industry categories. ${ }^{49}$

\footnotetext{
${ }^{49}$ The industry categories are: "Mining \& quarrying," "Food, drink \& tobacco", "Metals \& Machinery," "Oils, chemicals \& drugs," "Textiles, clothing \& leather goods," "Earthenware \& bricks," "Other manufactured goods," "Construction," "Gas \& water," "Transportation," "Distribution,"
} 
Because we are now working with a smaller number of industry categories, we focus on regressions that incorporate one spillover channel at a time. Table 22 describes the results. As in the main results, we observe positive effects occurring through the local supplier channel and these results are generally statistically significant. There is also evidence that industries benefited from the presence of local buyers, but this result is clearly sensitive to the underlying set of industries used, so it should be interpreted with some caution. There is also some evidence of benefits through the presence of occupationally similar local industries.

Table 22: Alternative matrix regressions

\begin{tabular}{|c|c|c|c|c|c|c|}
\hline & (1) & $(2)$ & $(3)$ & (4) & (5) & (6) \\
\hline $\begin{array}{l}\text { Log employment in } \\
\text { local supplier } \\
\text { industries } \\
\text { (1841 IO matrix) }\end{array}$ & $\begin{array}{l}0.0681^{*} \\
(0.0355)\end{array}$ & $\begin{array}{c}0.0549 \\
(0.0379)\end{array}$ & $\begin{array}{l}0.0732^{*} \\
(0.0421)\end{array}$ & & & \\
\hline $\begin{array}{l}\text { Log employment in } \\
\text { local buyer } \\
\text { industries } \\
\text { (1841 IO matrix) }\end{array}$ & & & & $\begin{array}{c}0.2319^{* *} \\
(0.1168)\end{array}$ & $\begin{array}{c}0.2269^{* *} \\
(0.0993)\end{array}$ & $\begin{array}{c}0.2545^{* * *} \\
(0.0969)\end{array}$ \\
\hline $\begin{array}{l}\text { Observations } \\
\text { Estimation } \\
\text { Instrumented } \\
\text { KP under id. } \\
\text { KP weak id. }\end{array}$ & $\begin{array}{l}2,222 \\
\text { ols } \\
\text { none }\end{array}$ & $\begin{array}{c}1,850 \\
2 \mathrm{sls} \\
\text { wtn } \\
14.92 \\
49.14 \\
\end{array}$ & $\begin{array}{c}1,850 \\
2 \text { sls } \\
\text { wtn-btn } \\
17.16 \\
22.63\end{array}$ & $\begin{array}{c}2,222 \\
\text { ols } \\
\text { none }\end{array}$ & $\begin{array}{c}1,850 \\
2 \mathrm{sls} \\
\text { wtn } \\
12.81 \\
35.55 \\
\end{array}$ & $\begin{array}{c}1,850 \\
2 \text { sls } \\
\text { wtn-btn } \\
14.88 \\
33.17\end{array}$ \\
\hline & (7) & $(8)$ & $\overline{(9)}$ & $(10)$ & (11) & $(12)$ \\
\hline $\begin{array}{l}\text { Log employment in local } \\
\text { industries using } \\
\text { demographically } \\
\text { similar workers }\end{array}$ & $\begin{array}{c}0.1228 \\
(0.0824)\end{array}$ & $\begin{array}{c}0.1609^{*} \\
(0.0926)\end{array}$ & $\begin{array}{c}0.1098 \\
(0.0675)\end{array}$ & & & \\
\hline $\begin{array}{l}\text { Log employment in local } \\
\text { industries using } \\
\text { similar occupations }\end{array}$ & & & & $\begin{array}{c}0.0342 \\
(0.1233)\end{array}$ & $\begin{array}{c}0.1285 \\
(0.1018)\end{array}$ & $\begin{array}{c}0.1047 \\
(0.1020)\end{array}$ \\
\hline Observations & 2,222 & 1,850 & 1,850 & 2,222 & 1,850 & 1,850 \\
\hline Estimation & ols & $2 \mathrm{sls}$ & 2 sls & ols & 2 sls & 2 sls \\
\hline Instrumented & none & wtn & wtn-btn & none & wtn & wtn-btn \\
\hline KP under id. & & 12.86 & 13.96 & & 6.43 & 16.71 \\
\hline KP weak id. & & 42.89 & 39.48 & & 19.94 & 61.55 \\
\hline
\end{tabular}

Multi-level clustered standard errors by city-industry, city-year, and industry-year in parenthesis. $* * *$ $\mathrm{p}<0.01, * * \mathrm{p}<0.05, * \mathrm{p}<0.1$. All cross-industry and within-industry connection variables have been standardized for comparability. A full set of within regressors, city-time and industry-time effects are included in all regressions but not displayed. 2SLS regressions use lagged instruments. Note that the number of observations falls for the instrumented regressions because the instruments require a lagged employment term. Thus, data from 1851 are not available for these regressions. Acronyms: wtn $=$ within, btn $=$ between . "KP under id." denotes the test statistic for the Lagrange Multiplier underidentification test based on Kleibergen \& Paap (2006). "KP weak id." denotes the test statistic for a weak instruments test based on the Kleibergen-Paap Wald statistic.

and "All other services." 


\subsubsection{Robustness: Cross-city effects}

There is substantial variation in the proximity of cities in our database to other nearby cities. Some cities, particularly those in Lancashire, West Yorkshire, and the North Midlands, are located in close proximity to a number of other nearby cities. Others, such as Norwich, Hull, and Portsmouth are relatively more isolated. In this section, we extend our analysis to consider the possibility that city-industry growth may also be affected by forces due to other nearby cities.

We consider two potential channels for cross-city effects. First, industries may benefit from proximity to consumers in nearby cities. This market potential effect has been suggested by Hanson (2005), who finds that regional demand linkages play an important role in generating spatial agglomeration using modern U.S. data. Second, industries may benefit from spillovers from other industries in nearby towns, through any of the channels that we have identified. We analyze these effects using the more detailed industry categories from Section 7.

We begin our analysis by collecting data on the distance (as the crow flies) between each of the cities in our database, which we call distance $e_{i j}$. Using these, we construct a measure for the remoteness of one city from another $d_{i j}=\exp \left(-\right.$ distance $\left._{i j}\right) .{ }^{50}$ Our measures of market potential for each city is then,

$$
M P_{c t}=\ln \left(\sum_{j \neq c} P O P_{j t} * d_{c j}\right),
$$

where $P O P_{j t}$ is the population of city $j$. This differs slightly from Hanson's approach, which uses income in a city instead of population, due to the fact that income at the city level is not available for the period we study.

We also want to measure the potential for cross-industry spillovers occurring across cities. We measure proximity to an industry $i$ in other cities as the distance-weighted sum of log employment in that industry across all other cities. Our full regression specification, including both cross-city market potential and spillover effects, is then,

$$
\triangle \ln \left(L_{i c t+1}\right) \quad=\quad \tilde{\tau}_{i i} \ln \left(L_{i c t}\right)
$$

\footnotetext{
${ }^{50}$ This distance weighting measure is motivated by Hanson (2005). We have also explored using $d_{i j}=1 /$ distance $_{i j}$ as the distance weighting measure and this delivers similar results.
} 


$$
\begin{aligned}
& +\beta_{1} \sum_{k \neq i} \operatorname{IOin}_{k i} \ln \left(L_{k c t}\right)+\beta_{2} \sum_{k \neq i} \text { IOout }_{k i} \ln \left(L_{k c t}\right) \\
& +\beta_{3} \sum_{k \neq i} E M P_{k i} \ln \left(L_{k c t}\right)+\beta_{4} \sum_{k \neq i} \text { OCC }_{k i} \ln \left(L_{k c t}\right) \\
& +\beta_{5}\left[\sum_{k \neq i} \operatorname{IOin}_{k i} \sum_{j \neq c} d_{j c} * \ln \left(L_{k j t}\right)\right]+\beta_{6}\left[\sum_{k \neq i} \text { IOout }_{k i} \sum_{j \neq c} d_{j c} * \ln \left(L_{k j t}\right)\right] \\
& +\beta_{7}\left[\sum_{k \neq i} E M P_{k i} \sum_{j \neq c} d_{j c} * \ln \left(L_{k j t}\right)\right]+\beta_{8}\left[\sum_{k \neq i} \text { OCC } C_{k i} \sum_{j \neq c} d_{j c} * \ln \left(L_{k j t}\right)\right] \\
& +\beta_{9} M P_{c t}+\log \left(\text { WORKpop }_{c t}\right)+\theta_{c}+\chi_{i t}+\epsilon_{i c t} .
\end{aligned}
$$

One difference between this and our baseline specification is that we now include city fixed effects $\left(\theta_{c}\right)$ in place of city-year effects because city-year effects would be perfectly correlated with the market potential measure. To help deal with city-size effects, we also include the $\log$ of $W O R K p o p_{c t}$, the working population of city $c$ in period $t$.

The results generated using this specification are shown in Table 23. The first thing to take away from this table is that our baseline results are essentially unchanged when we include the additional cross-city terms. The city employment term in the fifth column reflects the negative growth impact of city size. The coefficients on the market potential measure is always positive but not statistically significant. The results do not provide statistically significant evidence that cross-city spillovers matter through any of the channels that we measure. However, these results are imprecisely measured so we would not rule out a role for cross-city spillovers based only on these estimates.

As a simpler alternative to the approach shown in Table 23, where we assume that the effect of distance falls off in a continuous way, in Table 24 we consider cross-city effects using a sharp cutoff at $50 \mathrm{~km}$. This reflects the possibility that it may be that only nearby areas affect city growth. The cutoff of $50 \mathrm{~km}$ is chosen because it results in reasonable groupings of cities into regional economies. For example, nearly all of the cotton towns of the Northwest region are within $50 \mathrm{~km}$ of each other. Overall these results look similar to those shown in Table 23 except that we now observe that employment in other nearby cities is negatively related to city-industry growth. This may be due in part to the heavily export-oriented nature of the British economy 
during this period. Also, there is evidence that nearby cities generated substantial negative externalities on public health through channels such as pollution (see, e.g., Beach \& Hanlon (2016)).

Table 23: Regression results with cross-city variables and continuous distance effects

\begin{tabular}{|c|c|c|c|}
\hline & $(1)$ & $(2)$ & $(3)$ \\
\hline $\begin{array}{l}\text { Log employment in } \\
\text { local supplier industries }\end{array}$ & $\begin{array}{c}0.1245^{* * *} \\
(0.0433)\end{array}$ & $\begin{array}{c}0.1280^{* * *} \\
(0.0460)\end{array}$ & $\begin{array}{c}0.1241^{* * *} \\
(0.0477)\end{array}$ \\
\hline $\begin{array}{l}\text { Log employment in } \\
\text { local buyer industries }\end{array}$ & $\begin{array}{c}-0.1473^{* *} \\
(0.0727)\end{array}$ & $\begin{array}{c}-0.1527^{* *} \\
(0.0725)\end{array}$ & $\begin{array}{c}-0.1561^{* *} \\
(0.0725)\end{array}$ \\
\hline $\begin{array}{l}\text { Log employment in local industries } \\
\text { using demographically similar workers }\end{array}$ & $\begin{array}{l}-0.1071 \\
(0.0797)\end{array}$ & $\begin{array}{l}-0.1193 \\
(0.0827)\end{array}$ & $\begin{array}{l}-0.1225 \\
(0.0834)\end{array}$ \\
\hline $\begin{array}{l}\text { Log employment in local industries } \\
\text { using similar occupations }\end{array}$ & $\begin{array}{l}0.1484^{*} \\
(0.0885)\end{array}$ & $\begin{array}{c}0.1261 \\
(0.0890)\end{array}$ & $\begin{array}{c}0.1247 \\
(0.0888)\end{array}$ \\
\hline Log city employment & $\begin{array}{c}-0.3193 * * * \\
(0.0783)\end{array}$ & $\begin{array}{c}-0.2984^{* * *} \\
(0.0759)\end{array}$ & $\begin{array}{c}-0.3028^{* * *} \\
(0.0782)\end{array}$ \\
\hline $\begin{array}{l}\text { Market Potential: Employment in } \\
\text { nearby cities weighted by distance }\end{array}$ & $\begin{array}{c}0.0513 \\
(0.0519)\end{array}$ & & $\begin{array}{c}0.0388 \\
(0.0752)\end{array}$ \\
\hline $\begin{array}{l}\text { Log employment in supplier } \\
\text { industries in nearby cities } \\
\text { weighted by distance }\end{array}$ & & $\begin{array}{l}-0.0093 \\
(0.1174)\end{array}$ & $\begin{array}{l}-0.0608 \\
(0.1403)\end{array}$ \\
\hline $\begin{array}{l}\text { Log employment in buyer } \\
\text { industries in nearby cities } \\
\text { weighted by distance }\end{array}$ & & $\begin{array}{l}-0.1599 \\
(0.1624)\end{array}$ & $\begin{array}{l}-0.1429 \\
(0.1649)\end{array}$ \\
\hline $\begin{array}{l}\text { Log employment in industries using } \\
\text { demographically similar workers in nearby } \\
\text { cities weighted by distance }\end{array}$ & & $\begin{array}{c}0.1764 \\
(0.1206)\end{array}$ & $\begin{array}{c}0.1392 \\
(0.1370)\end{array}$ \\
\hline $\begin{array}{l}\text { Log employment in industries using } \\
\text { similar occupations in nearby } \\
\text { cities weighted by distance }\end{array}$ & & $\begin{array}{c}0.0687 \\
(0.1239)\end{array}$ & $\begin{array}{c}0.0572 \\
(0.1303)\end{array}$ \\
\hline Observations & 3,549 & 3,549 & 3,549 \\
\hline KP under & 19.04 & 20.66 & 19.07 \\
\hline KP weak & 2.02 & 2.3 & 2.02 \\
\hline
\end{tabular}

Multi-level clustered standard errors by city-industry, city-year, and industry-year in parenthesis. Significance levels: ${ }^{* * *} \mathrm{p}<0.01,{ }^{* *} \mathrm{p}<0.05,{ }^{*} \mathrm{p}<0.1$. All cross-industry and withinindustry connection variables, including those for nearby cities, have been standardized for comparability. A full set of within regressors, city-time and industry-time effects are included in all regressions but not displayed. All regressions instrument the within and between regressors with lagged instruments. Acronyms: $\mathrm{wtn}=$ within, $\mathrm{btn}=$ between . "KP under" denotes the test statistic for the Lagrange Multiplier underidentification test based on Kleibergen \& Paap (2006). "KP weak" denotes the test statistic for a weak instruments test based on the Kleibergen-Paap Wald statistic. 
Table 24: Regression results with cross-city variables reflecting employment within $50 \mathrm{~km}$

\begin{tabular}{|c|c|c|c|}
\hline & $(1)$ & $(2)$ & $(3)$ \\
\hline $\begin{array}{l}\text { Log employment in } \\
\text { local supplier industries }\end{array}$ & $\begin{array}{c}0.1227^{* * *} \\
(0.0428)\end{array}$ & $\begin{array}{c}0.1397^{* * *} \\
(0.0444)\end{array}$ & $\begin{array}{c}0.1340^{* * *} \\
(0.0441)\end{array}$ \\
\hline $\begin{array}{l}\text { Log employment in } \\
\text { local buyer industries }\end{array}$ & $\begin{array}{r}-0.1290^{*} \\
(0.0718)\end{array}$ & $\begin{array}{c}-0.1597^{* *} \\
(0.0702)\end{array}$ & $\begin{array}{r}-0.1388^{*} \\
(0.0719)\end{array}$ \\
\hline $\begin{array}{l}\text { Log employment in local industries } \\
\text { using demographically similar workers }\end{array}$ & $\begin{array}{l}-0.0241 \\
(0.0681)\end{array}$ & $\begin{array}{l}-0.0983 \\
(0.0773)\end{array}$ & $\begin{array}{l}-0.0392 \\
(0.0719)\end{array}$ \\
\hline $\begin{array}{l}\text { Log employment in local industries } \\
\text { using similar occupations }\end{array}$ & $\begin{array}{r}0.1802^{* *} \\
(0.0837)\end{array}$ & $\begin{array}{l}0.1556^{*} \\
(0.0853)\end{array}$ & $\begin{array}{c}0.1772^{* *} \\
(0.0822)\end{array}$ \\
\hline Log city employment & $\begin{array}{c}-0.2819^{* * *} \\
(0.0719)\end{array}$ & $\begin{array}{c}-0.2879 * * * \\
(0.0723)\end{array}$ & $\begin{array}{c}-0.2714^{* * *} \\
(0.0711)\end{array}$ \\
\hline $\begin{array}{l}\text { Market potential: employment } \\
\text { in cities within } 50 \mathrm{~km} \text { (millions) }\end{array}$ & $\begin{array}{c}-0.1783^{* *} \\
(0.0755)\end{array}$ & & $\begin{array}{c}-0.1699^{* *} \\
(0.0786)\end{array}$ \\
\hline $\begin{array}{l}\text { Log employment in supplier } \\
\text { industries in nearby cities } \\
\text { weighted by distance }\end{array}$ & & $\begin{array}{c}-0.0735^{* *} \\
(0.0345)\end{array}$ & $\begin{array}{l}-0.0433 \\
(0.0362)\end{array}$ \\
\hline $\begin{array}{l}\text { Log employment in buyer } \\
\text { industries in nearby cities } \\
\text { weighted by distance }\end{array}$ & & $\begin{array}{l}0.0244^{*} \\
(0.0131)\end{array}$ & $\begin{array}{c}0.0196 \\
(0.0133)\end{array}$ \\
\hline $\begin{array}{l}\text { Log employment in industries using } \\
\text { demographically similar workers in nearby } \\
\text { cities weighted by distance }\end{array}$ & & $\begin{array}{l}-0.0049 \\
(0.0294)\end{array}$ & $\begin{array}{c}0.0069 \\
(0.0266)\end{array}$ \\
\hline $\begin{array}{l}\text { Log employment in industries using } \\
\text { similar occupations in nearby } \\
\text { cities weighted by distance }\end{array}$ & & $\begin{array}{c}0.0006 \\
(0.0219)\end{array}$ & $\begin{array}{c}0.0010 \\
(0.0214)\end{array}$ \\
\hline Observations & 3,549 & 3,549 & 3,549 \\
\hline KP under & 19.57 & 19.14 & 19.55 \\
\hline KP weak & 2.78 & 2.56 & 2.75 \\
\hline
\end{tabular}

Multi-level clustered standard errors by city-industry, city-year, and industry-year in parenthesis. Significance levels: ${ }^{* * *} \mathrm{p}<0.01,{ }^{* *} \mathrm{p}<0.05,{ }^{*} \mathrm{p}<0.1$. All cross-industry and withinindustry connection variables, including those for nearby cities, have been standardized for comparability. A full set of within regressors, city-time and industry-time effects are included in all regressions but not displayed. All regressions instrument the within and between regressors with lagged instruments. Acronyms: $\mathrm{wtn}=$ within, $\mathrm{btn}=$ between . "KP under" denotes the test statistic for the Lagrange Multiplier underidentification test based on Kleibergen \& Paap (2006). "KP weak" denotes the test statistic for a weak instruments test based on the Kleibergen-Paap Wald statistic. 